\title{
A Recent Study on the Relationship between Global Radiative Forcing and Global Annual Climatic Variability
}

\author{
Yehia Yehia Hafez*, Mansour Almazroui \\ Department of Meteorology, Center of Excellence for Climate Change Research, King Abdulaziz University, \\ Jeddah, Saudi Arabia \\ Email: “ysalam@kau.edu.sa, mansour@kau.edu.sa
}

Received 7 December 2014; revised 1 January 2015; accepted 6 January 2015

Copyright $@ 2015$ by authors and Scientific Research Publishing Inc.

This work is licensed under the Creative Commons Attribution International License (CC BY). http://creativecommons.org/licenses/by/4.0/

(c) $\underset{\mathrm{EY}}{\mathrm{B}}$ Open Access

\begin{abstract}
The present paper investigates the relationship between the global radiative forcing (GRF) and global annual climatic variability. The relation between the GRF and global annual changes in the operational weather and climatic parameters is uncovered. There are several datasets which have been used to challenge this goal. The NCEP/NCAR Reanalysis dataset of several meteorological elements, such as air temperature, wind, surface pressure, outgoing long wave radiation, precipitation rate and geopotential height at level $500 \mathrm{hPa}$, etc. for the globe for the period (1948-2012), has been used. Furthermore, the GRF data for greenhouse gases through the period (1979-2010) has been used. Also, datasets of climatic indices NAO, SOI, El Nino 3.4 and SST during the period (1948-2012) have been used through this study. Time series analysis, anomaly and correlation coefficient technique methods have been used to analyze the datasets. The results reveal that there is an outstanding positive correlation coefficient (more than +0.80 ) between GRF and the global annual weather elements of surface air temperature, temperature and geopotential height at level $500 \mathrm{hPa}$, precipitation rate and sea surface temperature. $\mathrm{CO}_{2}$ has a significant correlation coefficient $(+0.89)$ with the outcomes longwave radiation and sea surface temperature. There is a significant relationship between the global annual variability of weather and climatic elements and GHGs, global warming and climatic indices, NAO, SOI, El Nino 3.4 and SST.
\end{abstract}

\section{Keywords}

Global Radiative Forcing, Global Annual Climatic Variability, Weather Elements, Climatic Indices

\footnotetext{
${ }^{*}$ Corresponding author.
}

How to cite this paper: Hafez, Y.Y. and Almazroui, M. (2015) A Recent Study on the Relationship between Global Radiative Forcing and Global Annual Climatic Variability. Atmospheric and Climate Sciences, 5, 23-55. 


\section{Introduction}

Worldwide, increasing attention is given to the present and the potential future impacts of climate change. Intergovernmental Panel on Climate Change predicts that it is very likely that extreme weather events will occur more frequently in the future [1]. Climate change is therefore defined as "long-term weather patterns and trends becoming different over an extended period of time" [2]. Global warming is commonly referred to as an increase in the temperature of the lowest layers of Earth's atmosphere [3]. However, global warming has occurred in the distant past as the result of the natural influences, but the term is most often used to refer to the warming predicted to occur as a result of increased emissions of greenhouse gases. Primary greenhouse gases include water vapor, carbon dioxide $\left(\mathrm{CO}_{2}\right)$, methane $\left(\mathrm{CH}_{4}\right)$, nitrous oxide $(\mathrm{NO})$ and ozone $\left(\mathrm{O}_{3}\right)$ [4]. Carbon dioxide, as well as other greenhouse gases, is a very important factor in the vital cycles which sustain life on this planet. The greenhouse effect is a natural process which makes life on Earth feasible. The greenhouse gases in atmosphere let the energy in and prevent it from escaping, directing it back to Earth's surface [5]. In fact, there are notably increases in greenhouse gases over the globe of the Earth (e.g. [6]-[12]). Weather patterns are and will be modified: number of radically hot days will augment; frequency and severity of storms, hurricanes, floods, droughts and forest fires will increase; more intense rainfall will bother some areas, and at the same time water supplies in some regions, particularly in already affected areas arid with deserted climate (e.g. [13]-[24]). However, there are several scenarios of models for global warming in the future. Unfortunately, it has an uncertainty factor [25] [26].

The NOAA Annual Greenhouse Gas Index (AGGI) measures the commitment society has already made to living in a changing climate. It is based on the highest quality atmospheric observations from sites around the world. Its uncertainty is very low. The AGGI is a measure of the warming influence supplied by long-lived trace gases and how that influence is changing each year. The AGGI provides a way for the warming influence to be presented as a simple index. However, the Earth's climate depends on the functioning of a natural "greenhouse effect". This effect is the result of heat-trapping gases (also known as greenhouse gases), like water vapor, carbon dioxide, ozone, methane and nitrous oxide, which absorb heat radiated from the Earth's surface and lower atmosphere and then radiate much of the energy back toward the surface. However, human activities have been releasing additional heat-trapping gases, intensifying the natural greenhouse effect, and thereby changing the Earth's climate. The climate is influenced by a variety of factors, both human-induced and natural. The increase in the carbon dioxide concentration has been the principal factor causing warming over the past 60 years. Its concentration has built up in the Earth's atmosphere since the beginning of the industrial era in the mid-1700s, primarily due to the burning of the fossil fuels (coal, oil and natural gas) and the clearing of forests. Human activities have also increased the emissions of other greenhouse gases, such as methane and nitrous oxide. Increases in the abundance of atmospheric greenhouse gases since the industrial revolution are largely the result of human activity and are largely responsible for the observed increases in global temperature [1]. However, climate projections have modeled uncertainties that overwhelm the uncertainties in greenhouse gas measurements. We present here an index that is directly proportional to the direct warming influence (also known as global radiative forcing) supplied from these gases. Because it is based on the amounts of long-lived greenhouse gases in the atmosphere, this index contains relatively little uncertainty.

The climate forcing is a "change" in the status quo. IPCC takes the pre-industrial era (arbitrarily chosen as the year 1750) as the baseline. The perturbation to direct climate forcing (also termed "radiative forcing") that has the largest magnitude and the least scientific uncertainty is the forcing related to changes in long-lived and well mixed greenhouse gases, carbon dioxide $\left(\mathrm{CO}_{2}\right)$, methane $\left(\mathrm{CH}_{4}\right)$, nitrous oxide $\left(\mathrm{N}_{2} \mathrm{O}\right)$ and halogenated compounds (mainly $\mathrm{CFCs}$ ) in particular. Atmospheric global greenhouse gas abundances are used to calculate changes in radiative forcing for the period beginning in 1979 when NOAA's global air sampling network expanded significantly. The change in annual average total radiative forcing by all the long-lived greenhouse gases since the pre-industrial era (1750) is used to define the NOAA Annual Greenhouse Gas Index (AGGI), which was introduced in 2004 [8] and has been updated annually.

El Nino/Southern Oscillation (ENSO) teleconnection patterns can be thought of as resulting from the interannual warming and cooling of equatorial Pacific sea surface temperatures (SSTs) and associated atmospheric circulation changes. The opposing phases of ENSO, the warm El Nino and the cold La Nina, though occurring quasi-periodically with roughly a cycle of 3 - 7 years, have not proved to be highly predictable [27] despite considerable effort. El Nino also tends to cause warmer than average conditions over parts of the tropics and into 
the extra-tropics [28]. Suggest mechanisms further illustrate the interconnectivity of the atmosphere-ocean system and include higher latitude warming strong enough to enhance the monsoon and overcome the rain suppressing effects of El Nino (e.g. [29]-[35]).

North Atlantic Oscillation (NAO) whether the major mode of mid or high northern hemisphere variability is better characterized as a regional oscillation. A measure of the NAO is an index generally defined as a pressure difference between a high latitude station representative of the Icelandic low (Reykjavik or Stykkisholmur, Iceland) and a subtropical station (Lisbon or Gibraltar) which represents other centers of action in the Azores surface high pressure system. The phase of the NAO modulates climate in eastern North America and North Atlantic, particularly in winter months. The NAO, like ENSO, is an inter-annual oscillation with an irregular pattern of several years [36]-[40]. Many studies have examined the factors involved in forcing variability in the NAO and have found a variety of potential mechanisms within the Earth system: SST [41]-[43]. The variability of climate due to these teleconnection patterns is therefore variable over longer time scales. The present work aims to study the relationship between the GRF and global annual climatic variability of the weather elements and climatic indices over the globe.

\section{Data and Methodology}

\subsection{Data}

The NCEP/NCAR Reanalysis project is using a state-of-the-art analysis/forecast system to perform data assimilation, within resolution of $2.5 \times 2.5$ degree lat/lon grid, using past data from 1948 to 2011. Data used in the present study is annual mean and annual time series of several meteorological elements (air temperature, wind, surface pressure, outgoing long wave radiation, precipitation rate and geopotential height at level $500 \mathrm{hPa}$, etc.) over the globe of Earth for the period (1948-2011). The data are obtained from the Web site

http://www.cdc.noaa.gov/. The data have been provided by the NOAA/OAR/ESRL PSD, Boulder, Colorado, USA [44]. Furthermore, the corresponding annual mean values of NAO index, SOI, El Nino 3.4 and SST have been obtained from the Climate Prediction Centre Web site http://www.cpc.ncep.noaa.gov. However, NCEP data set domain considered in the present work are extended to $90^{\circ} \mathrm{N}-90^{\circ} \mathrm{S}, 180^{\circ} \mathrm{W}-180^{\circ} \mathrm{E}$ for whole the globe. The global radiatve forcing data of GHG for the period (1979-2011) has been used. However, the annual average total radiative forcing by all the long-lived greenhouse gases since the pre-industrial era (1750) is used to define the NOAA Annual Greenhouse Gas Index (AGGI), which was introduced in 2004 [8] and has been updated annually since.

\subsection{Methodology}

\section{A. Calculation of Annual Averages}

For each grid point in the domain [resolution of $144 \times 73$ grid points] of the globe of the Earth annual averages for meteorological elements (surface temperature, wind, surface pressure, geopotential height, etc.) have been calculated. Using the NCEP/NCAR reanalysis monthly data sets for the year using of statistical mean average (i.e. (12 months/12) along the period from 1948 to 2011). The annual composite mean comes from the statistical mean for twelve months from January to December for the period of study. However, the interactive plotting and analysis NCEP/NCAR software program has been used for this analysis. The annual values of NAO index, SOI, and El Nino 3.4 have been calculated in the same manner. The global radiative forcing for GHG's has been calculated according to [45]. The anomaly method has been used.

\section{B. Local Significance and Calculation of Correlation Patterns}

For a given year, means of meteorological elements, e.g. geopotential height at level $500 \mathrm{hPa}$ at each grid point correlates with the (Global surface air temperature, Solar index, NAO, SOI and El Nino 3.4). Each grid point correlation is a t-tested for local significance using [46] allowing for temporal autocorrelation according to [47] method. For field significance, the areal extent of locally significant correlations in a correlation map must exceed the areal extent that can be expected by chance. To estimate the correlation, we use the Monte Carlo methodology. The field-significance statistic is the area-weighted average absolute correlation of a given correlation map (considering only the locally significant correlations). The field-significance threshold is the 95th percentile of a 1000-member Monte-Carlo population.

\section{Radiative Forcing Calculations}


To determine the total radiative forcing of the greenhouse gases, we have used IPCC recommended expressions to convert greenhouse gas changes, relative to 1750 , to instantaneous radiative forcing (see Table 1). These empirical expressions are derived from atmospheric radiative transfer models and generally have an uncertainty of about $10 \%$. The uncertainties in the global average abundances of the long-lived greenhouse gases are much smaller $(<1 \%$, [45]).

\section{Linear Correlation Method}

For a linear correlation analysis of the previous global weather elements, climatic indices NAO, SOI, El Nino 3.4 and SST and global radiative forcing datasets during the study period (1948-2011), the methodology of Monte Carlo has been used [47]. Based on this methodology a correlation of $+/-0.3$ would be significant. These significance levels are local for a resolution of $144 \times 73$ grid points. One would assume at least $0.05 \times(144 \times 73)=$ 526 grids would be significant by chance at the one-sided $95 \%$ level (at Web site http://www.ersl.noaa.gov/psd/data/correlation/significance.html). In addition to that linear correlation coefficient according to [48] has been used.

\section{Results}

\subsection{Study the Variability of Global Annual Geopotential Height at Level $500 \mathrm{hPa}$ through the Period (1948-2012)}

In fact, the geopotential height at level $500 \mathrm{hPa}$ played a greater role in climate and abnormal weather over the globe. The NCEP/NCAR Reanalysis data assimilation, within resolution of $2.5 \times 2.5$ degree lat/lon grid, for the globe from 1948 to 2012 has been used. Data used in the present section are annual mean of geopotential height at $500 \mathrm{hPa}$, global temperature, and solar index, NAO, SOI and El Nino 3.4. Analysis of this data revealed that:

1) Global annual geopotential height anomaly at level $500 \mathrm{hPa}$ time series analysis observed that, it varies from year to year with time and becomes continues above its normal value from year 2000 up to 2012. The trend of variation is a positive trend as shown in Figure 1.

2) An outstanding correlation coefficient between global annual geopotential height and global temperature composites mean reached to $(+1)$ in the tropics meanwhile the correlation decrease towards the north and South Pole. However, there is a positive correlation in the northern polar region; meanwhile there is a negative sign of correlation towards the South Pole through the study period (1948-2012). It is clear from Figure 2(a).

3) Non significant appears between annual geopotential height and solar index in general, see Figure 2(b).

4) Annual geopotential height has a significant negative correlation of $(-0.9)$ with NAO over Iceland. Meanwhile, there is a positive correlation $(+0.7)$ over the north Atlantic region. The tropics have not any significant correlations as clear in Figure 2(c).

5) Annual geopotential height has significant correlations of (0.7) with SOI over the tropics. It has outstanding correlations over all the Atlantic Ocean through the study period (1948-2010) as shown in Figure 2(d).

6) Annual geopotential height has a significant positive correlation reached to (0.7) with El Nino 3.4 over the tropics. Meanwhile, there are significant correlations reached at $(+0.7)$ over the central of the Atlantic Ocean as clear in Figure 2(e). It is noticed that over the Atlantic Ocean the signs of correlation contradicting to the signs of correlations with SOI. See Figure 2(d) and Figure 2(e).

Table 1. Expressions for calculating radiative forcing.

\begin{tabular}{ccc}
\hline Trace Gase & Simplified Expression Radiative Forcing, $\Delta \mathbf{F}\left(\mathbf{W} / \mathbf{M}^{-2}\right)$ & Constant \\
\hline $\mathrm{CO}_{2}$ & $\Delta \mathrm{F}=\alpha \ln \left(C / C_{o}\right)$ & $\alpha=5.35$ \\
$\mathrm{CH}_{4}$ & $\Delta F=\beta\left(M^{1 / 2}-M_{o}^{1 / 2}\right)-\left[f\left(M, N_{o}\right)-f\left(M_{o}, N_{o}\right)\right]$ & $\beta=0.036$ \\
$\mathrm{~N}_{2} \mathrm{O}$ & $\Delta F=\varepsilon\left(N^{1 / 2}-N_{o}^{1 / 2}\right)-\left[f\left(M_{o}, N\right)-f\left(M_{o}, N_{o}\right)\right]$ & $\varepsilon=0.12$ \\
$\mathrm{CFC} 11$ & $\Delta \mathrm{F}=\lambda\left(X-X_{o}\right)$ & $\lambda=0.25$ \\
$\mathrm{CFC} 12$ & $\Delta \mathrm{F}=\omega\left(X-X_{o}\right)$ & $\omega=0.32$ \\
\hline
\end{tabular}

[Source IPCC (2001)]. The subscript " $o$ " denotes the unperturbed (1750) abundance; $f(M, N)=0.47 \ln \left[1+2.01 \times 10^{-5}(\mathrm{MN}) 0.75+5.31 \times 10-15\right.$ $\mathrm{M}(\mathrm{MN}) 1.52] ; \mathrm{C}$ is $\mathrm{CO}_{2}$ in ppm; $\mathrm{M}$ is $\mathrm{CH}_{4}$ in ppb; $\mathrm{N}$ is $\mathrm{N}_{2} \mathrm{O}$ in ppb; $X$ is $\mathrm{CFC}$ in ppb; $C_{o}=278 \mathrm{ppm} ; M_{o}=700 \mathrm{ppb} ; N_{o}=270 \mathrm{ppb} ; X_{o}=0$. 


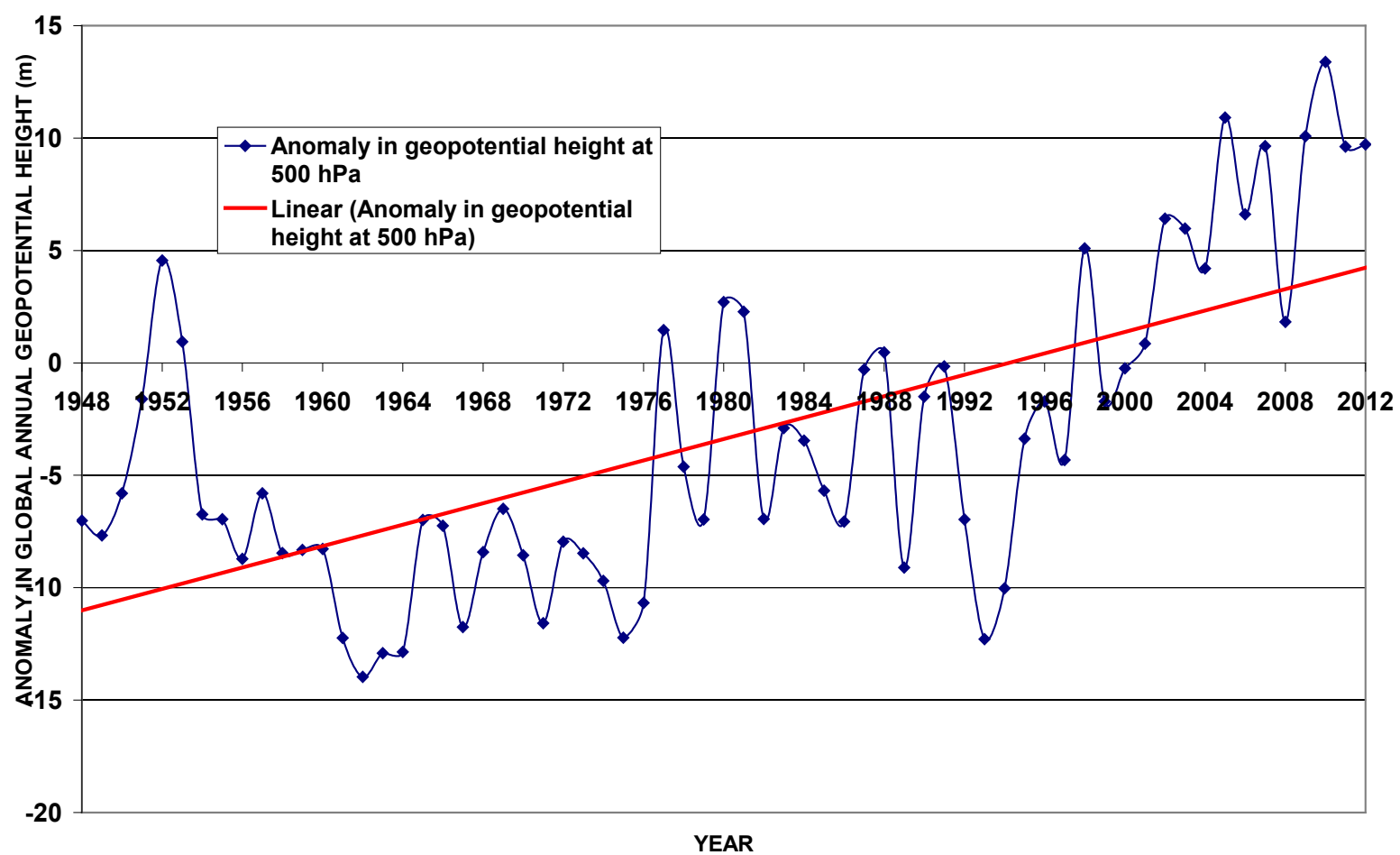

Figure 1. The time series of global annual anomaly in geopotential height $500 \mathrm{hPa}$ and the trend through the period (19482012).

\subsection{Study the Relationship between the GRF and Global Annual Weather Elements Varia- bility through the Period (1979-2011)}

Through this section, the variability of weather meteorological elements (surface air temperature, $500 \mathrm{hPa}$ air temperature, sea level pressure, geopotential height at level $500 \mathrm{hPa}$, surface wind, precipitation rate, OLR and SST over the globe has been analyzed through the period of (1948-2012). In addition to that, the greenhouse gases and global radiative forcing has been analyzed. Time series analysis has been used to study the variability between all of these datasets. The results revealed that:

1) For $\mathrm{CO}_{2}$ and surface air temperature and $500 \mathrm{hPa}$ level of temperature anomaly, it is clear that, all of these three parameters have a sharp increase with time through the period (1950-2012) and all of it becomes above its normal value after year 2000 up to 2012 as appears in the Figure 3(a). With the continuing increase of $\mathrm{CO}_{2}$ the geopotential height increases too. Meanwhile, surface air pressure gradually decreases in contradicting to the variability of geopotential height. See Figure 3(a) and Figure 3(b). Precipitation rate increase to become more its normal values on year 1985 up to the year 2012 over the globe likely the variability of $\mathrm{CO}_{2}$ during the same period. Meanwhile the surface wind varies like a wave and not related to $\mathrm{CO}_{2}$ variation through the period of study (1950-2012) as shown in Figure 3(c). Outgoing longwave radiation (OLR) and sea surface temperature (SST) varies and increases with time, typically with the $\mathrm{CO}_{2}$ variability for all the period (1950-2012) over the globe as shown in Figure 3(d).

2) For $\mathrm{CH}_{4}$ and surface air temperature and $500 \mathrm{hPa}$ level of temperature anomaly, it is clear that, $\mathrm{CH}_{4}$ increase sharply through the period of study (1979-2011) and becomes above its normal value since 1992 and do not return to its normal value until 2011. The increasing after year 2000 matches with the increase of temperature as shown in Figure 4(a). $\mathrm{CH}_{4}$ variability after year 2000 coincide with the variability of geopotential height at level $500 \mathrm{hPa}$ and contradicting with variation of sea level pressure in general, see Figure 4(b). It is noticed that, for the period of (1995-2011) the increase in precipitation rate matches with the increase in $\mathrm{CH}_{4}$. In fact the wind variability does not follow the $\mathrm{CH}_{4}$ variability as clear from Figure 4(c). For OLR and SST it is observed that after 1997 they has amounted over its normal values and continues increase to the year 2011. There is a positive increase through the study period for all of these three parameters as shown in Figure 4(d). 


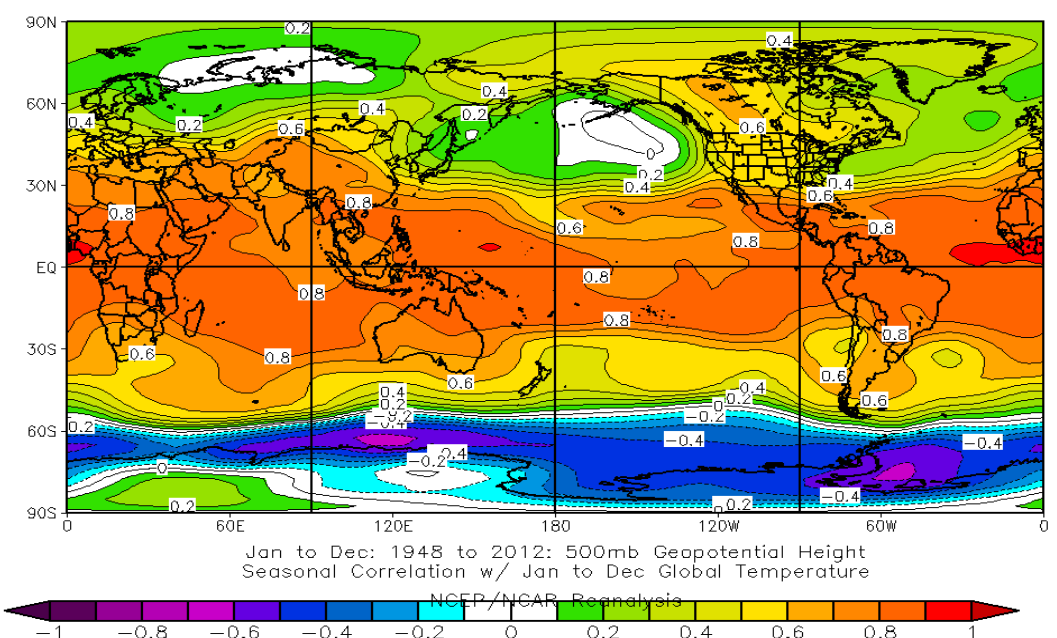

(a)
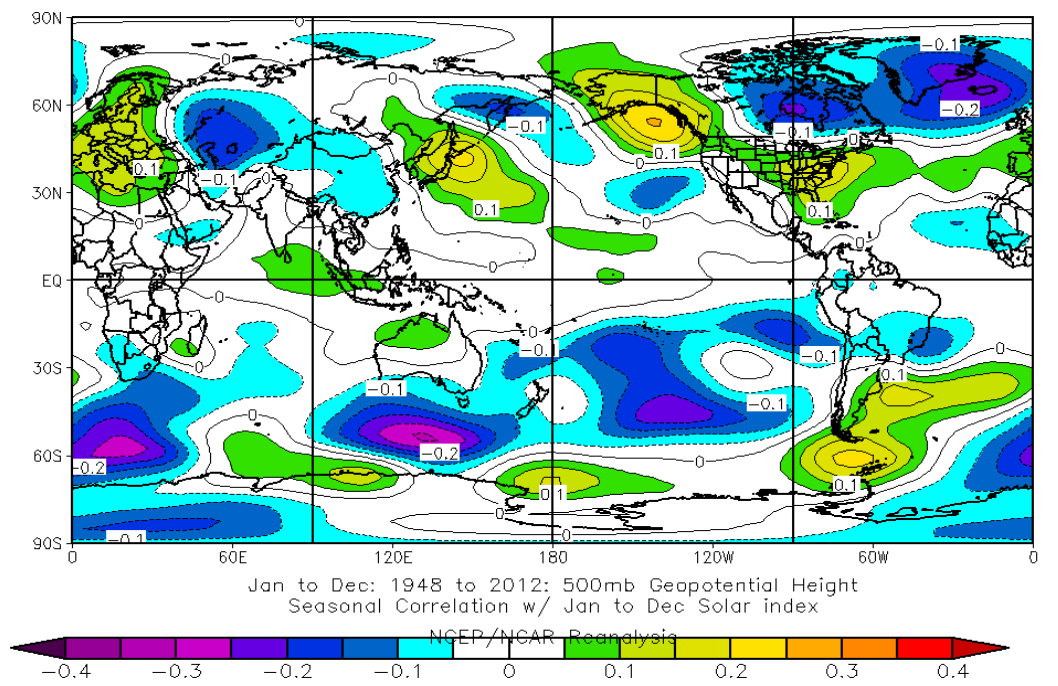

(b)
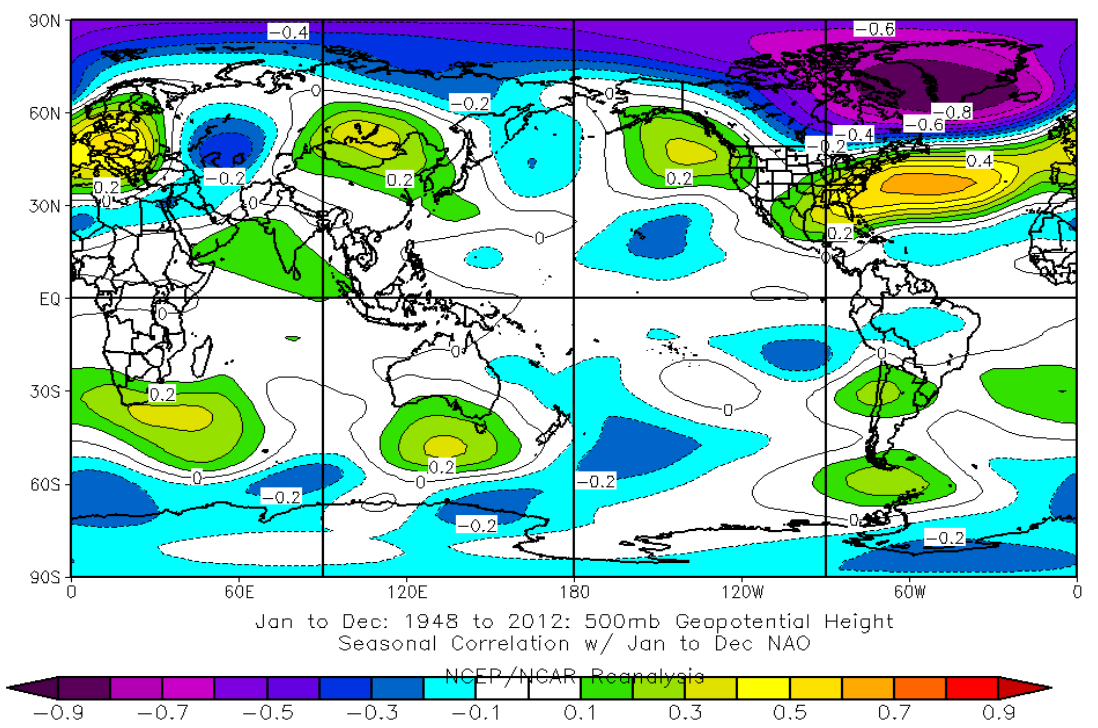

(c) 


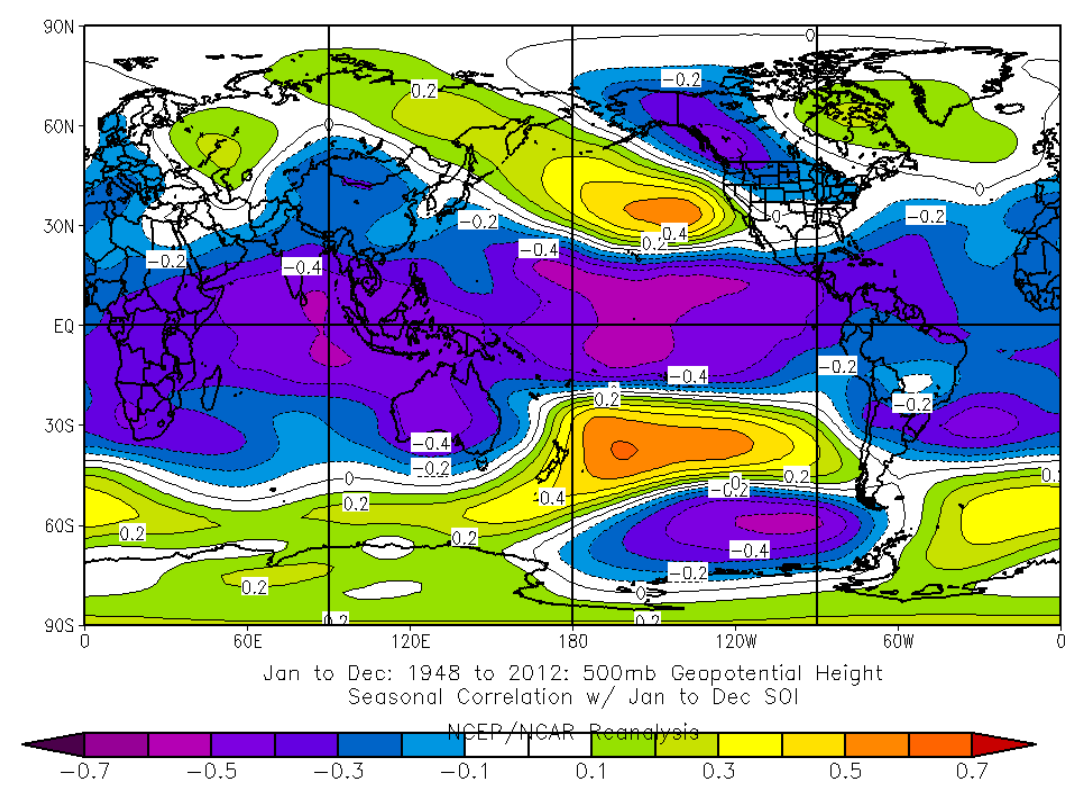

(d)

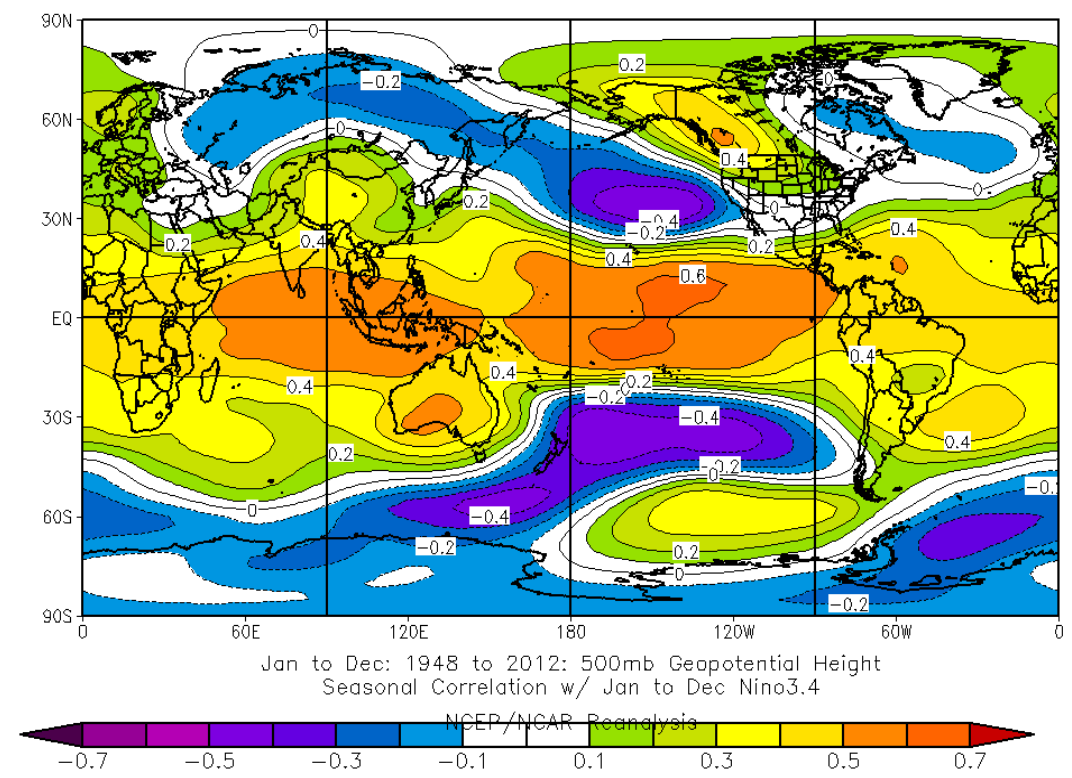

(e)

Figure 2. (a) The correlation coefficient distribution of composite of global annual geopotential height at level $500 \mathrm{hPa}$ and global surface air temperature through the period (1948-2012); (b) The correlation coefficient distribution of composite of global annual geopotential height at level $500 \mathrm{hPa}$ and Solar index through the period (1948-2012); (c) The correlation coefficient distribution of composite of global annual geopotential height at level $500 \mathrm{hPa}$ and NAO through the period (19482012); (d) The correlation coefficient distribution of composite of global annual geopotential height at level $500 \mathrm{hPa}$ and SOI through the period (1948-2012); (e) The correlation coefficient distribution of composite of global annual geopotential height at level $500 \mathrm{hPa}$ and El Nino 3.4 through the period (1948-2012).

3) For $\mathrm{N}_{2} \mathrm{O}$ and surface air temperature and $500 \mathrm{hPa}$ level of temperature anomaly, it is clear that, all of these three parameters have a sharp increase with time through the period (1979-2011) and all of it becomes above its normal value after year 1999 up to 2011 as appears in the Figure 5(a). It is clear that with the continual increase of $\mathrm{N}_{2} \mathrm{O}$ the geopotential height increase too. Mean while surface air pressure gradually decreases in contradicting to the variability of geopotential height. See Figure 5(a) and Figure 5(b). Precipitation rate increase to become more its normal values on year 1995 up to the year 2011 over the globe likely the variability of $\mathrm{N}_{2} \mathrm{O}$. 
Meanwhile the surface wind varies like a wave and not related to $\mathrm{N}_{2} \mathrm{O}$ variation through the period of study (1979-2011) as shown in Figure 5(c). Outgoing longwave radiation (OLR) and sea surface temperature (SST) varies and increases with time, typically with the $\mathrm{N}_{2} \mathrm{O}$ variability for all the period (1979-2011) over the globe as shown in Figure 5(d).

4) For CFC 12 and surface air temperature and $500 \mathrm{hPa}$ level of temperature anomaly, it is clear that the CFC 12 has become more its normal values since 1991. It decreases with time from the year 2004 up to 2011 as

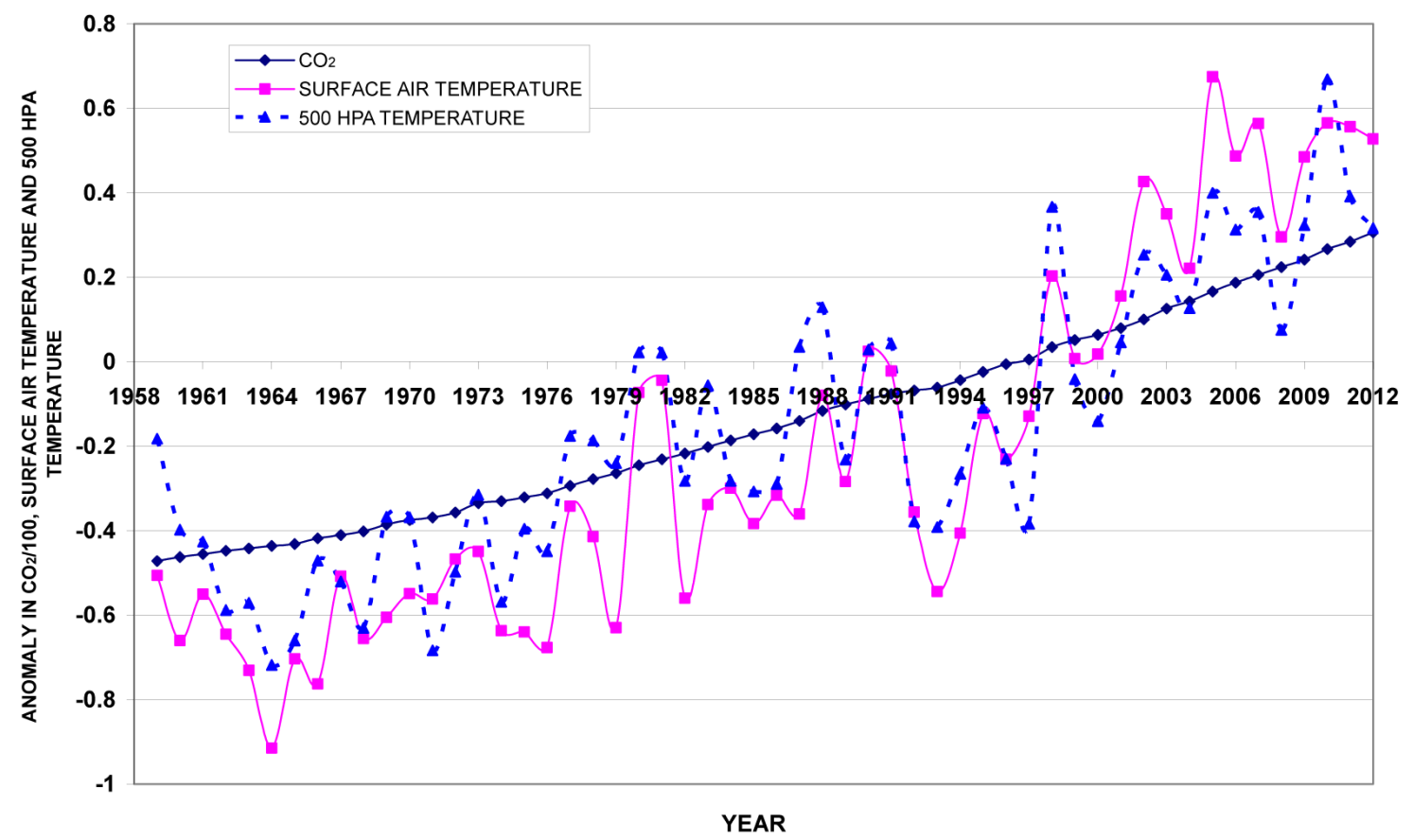

(a)

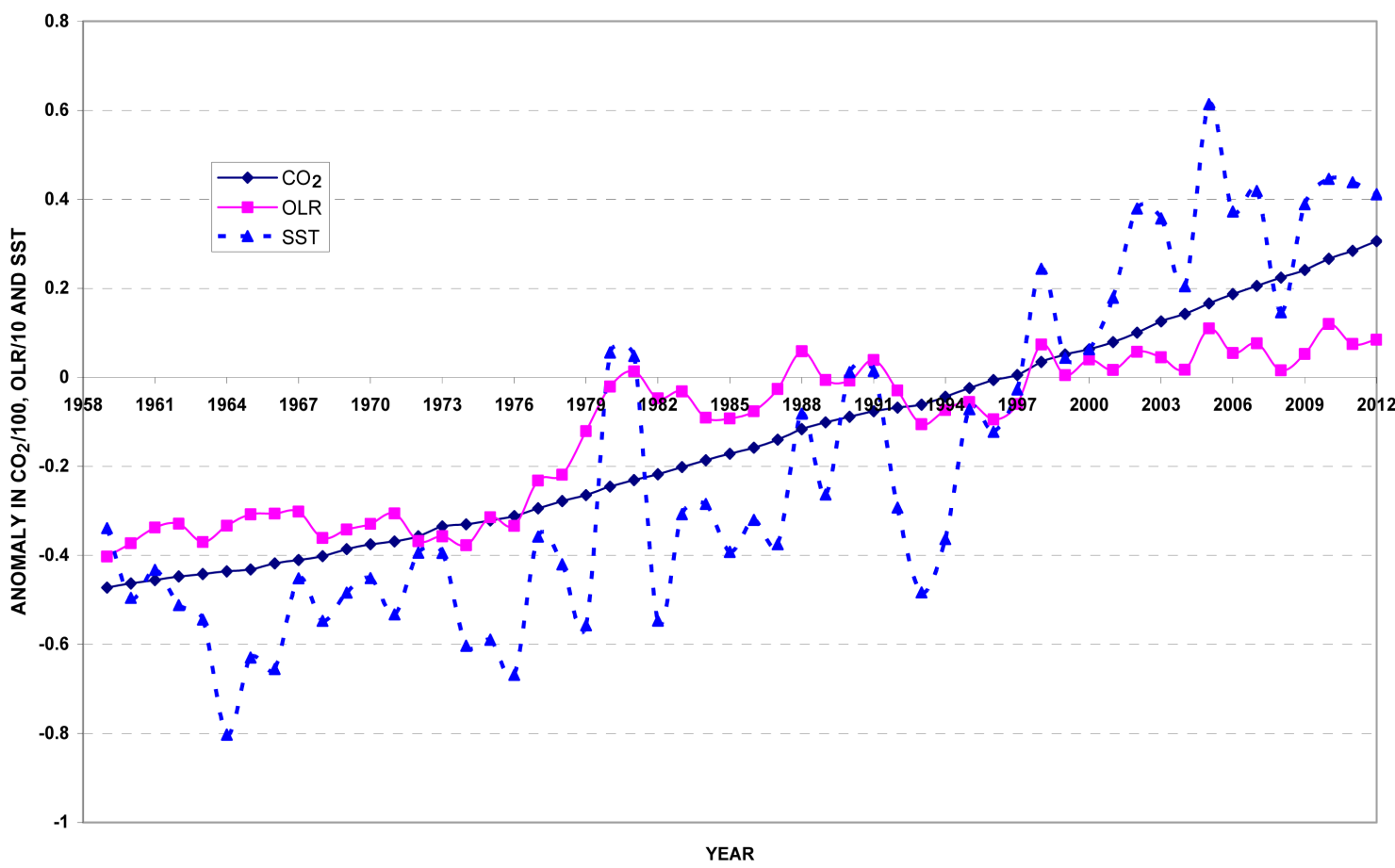

(b) 


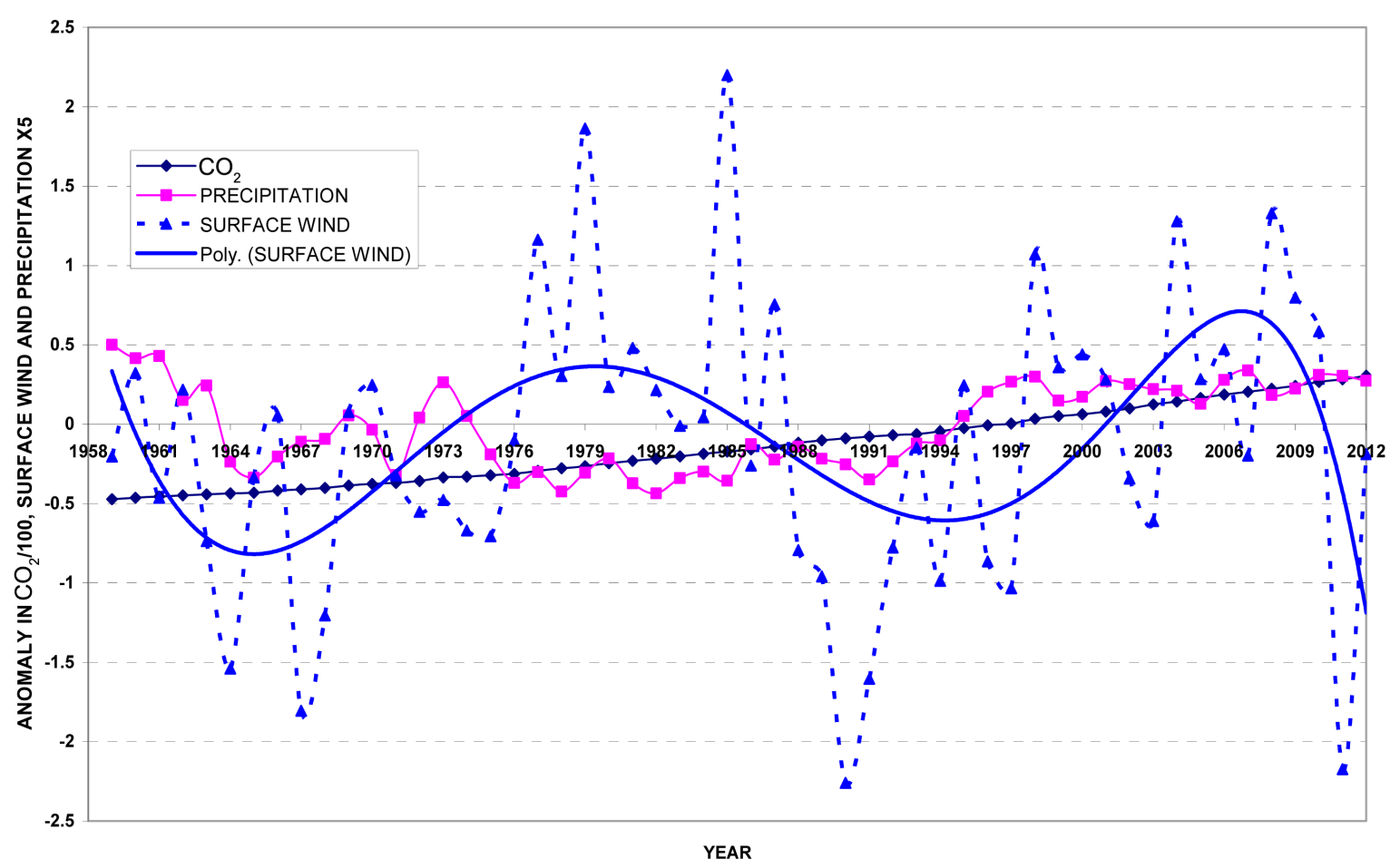

(c)

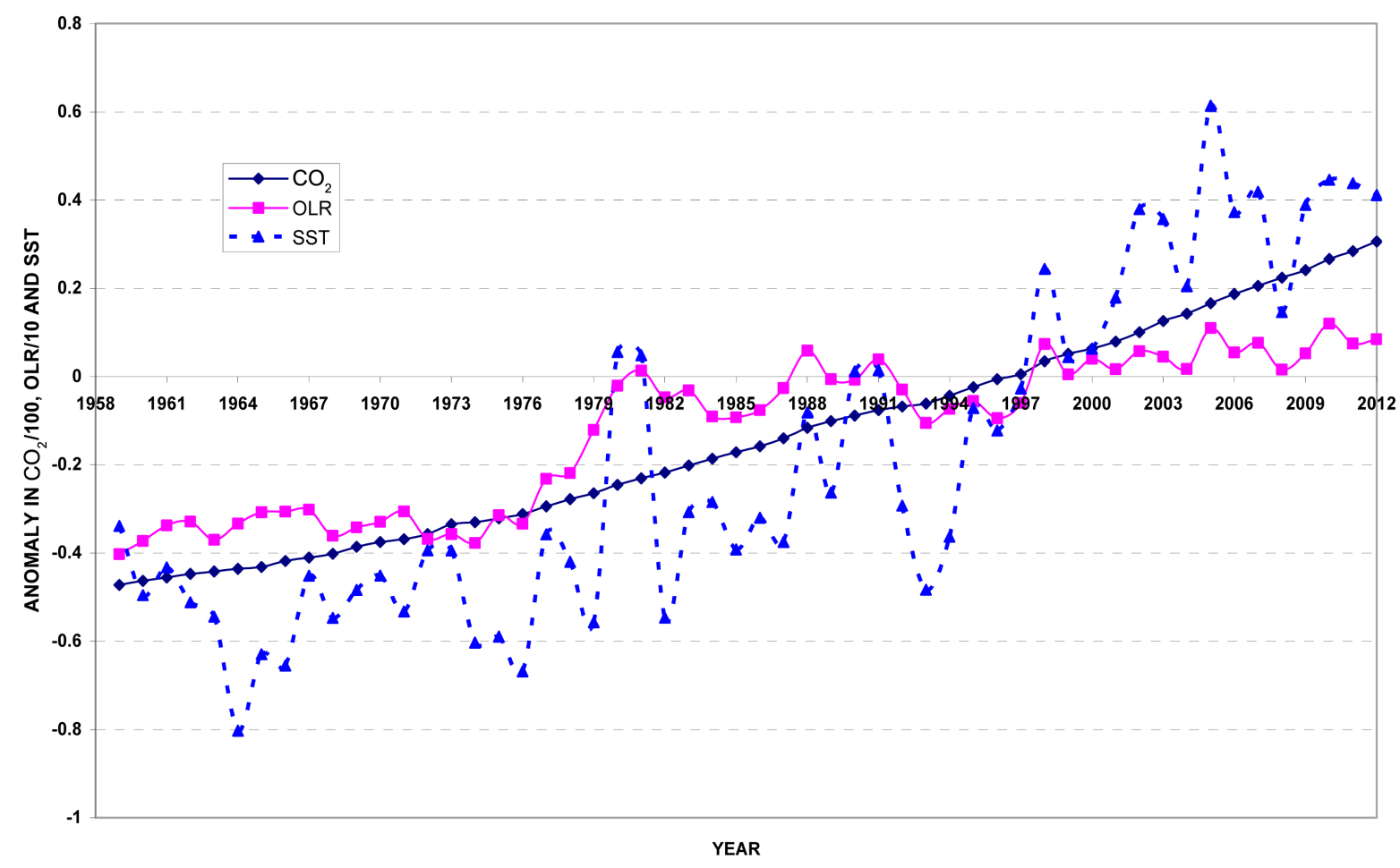

(d)

Figure 3. (a) Time series of $\mathrm{CO}_{2}$, surface air temperature and $500 \mathrm{hPa}$ temperature anomalies for the globe through the period (1950-2012); (b) Time series of $\mathrm{CO}_{2}$, sea level pressure and $500 \mathrm{hPa}$ level of geopotential height anomaly for the globe through the period (1950-2012); (c) Time series of $\mathrm{CO}_{2}$, surface wind and precipitation rate anomaly for the globe through the period (1950-2012); (d) Time series of $\mathrm{CO}_{2}$, OLR and SST anomaly for the globe through the period (1950-2012). 
appears in Figure 6(a). Variably connection of CFC 12 with the geopotential height, surface air pressure, Precipitation rate, surface wind, OLR and SST are not clear through the study period (1979-2011). See Figures 6(b)-(d).

5) For CFC 11 variability, like as CFC 12 no connection appears with weather elements variably over the globe through the period of study (1979-2011). Meanwhile, CFC 11 returned to its normal values from the year 2006 as shown in Figures 7(a)-(d).

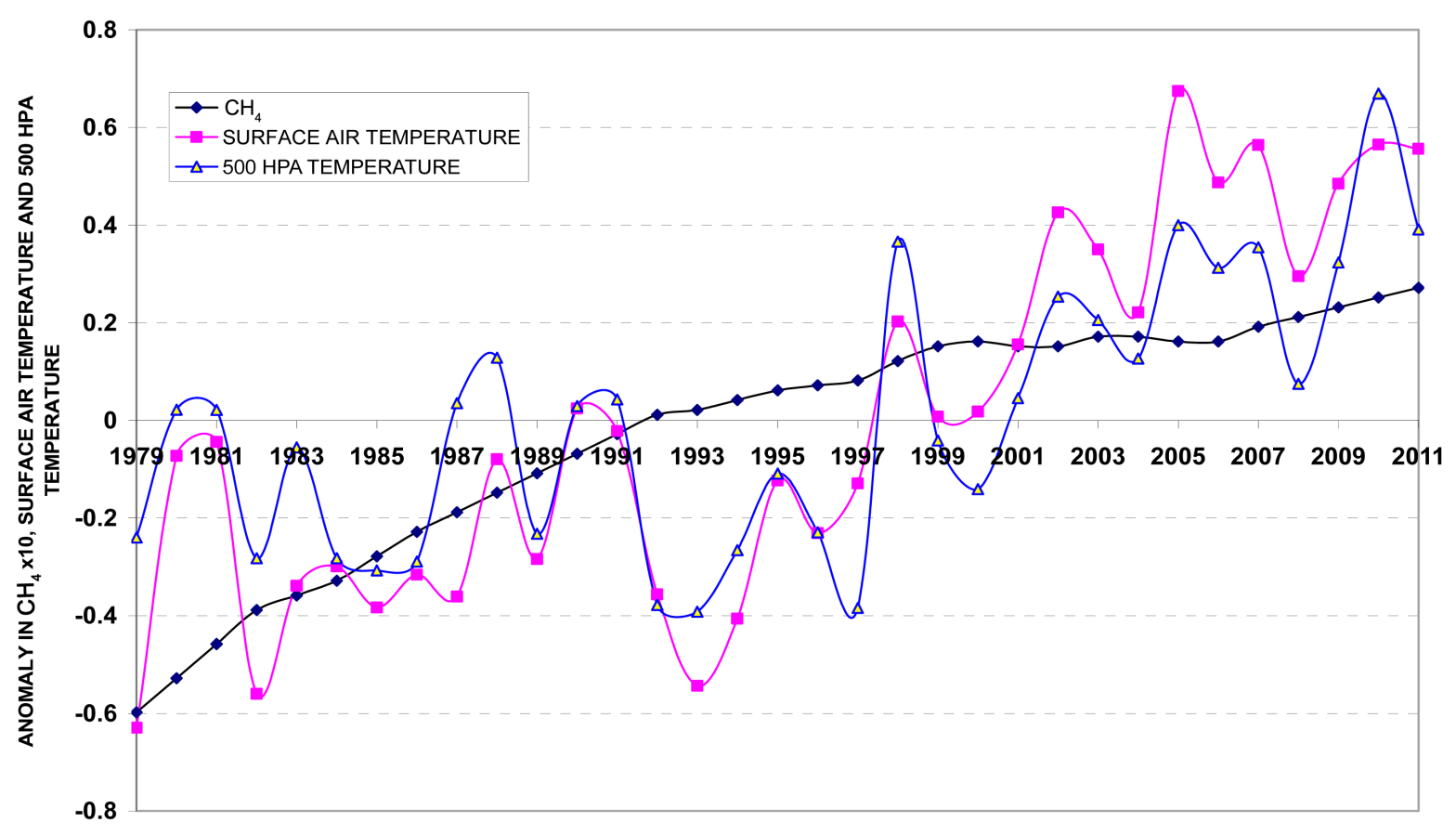

(a)

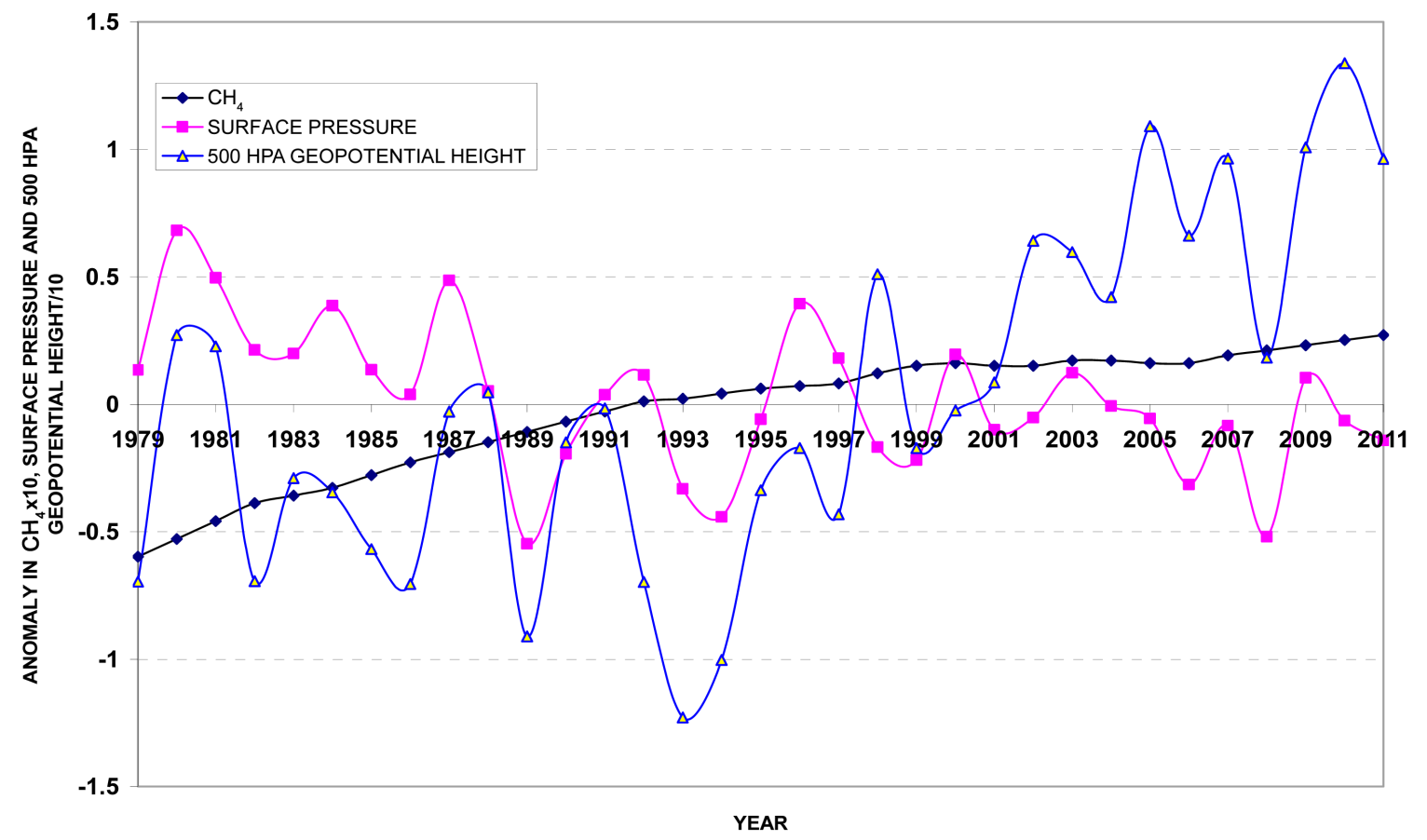

(b) 


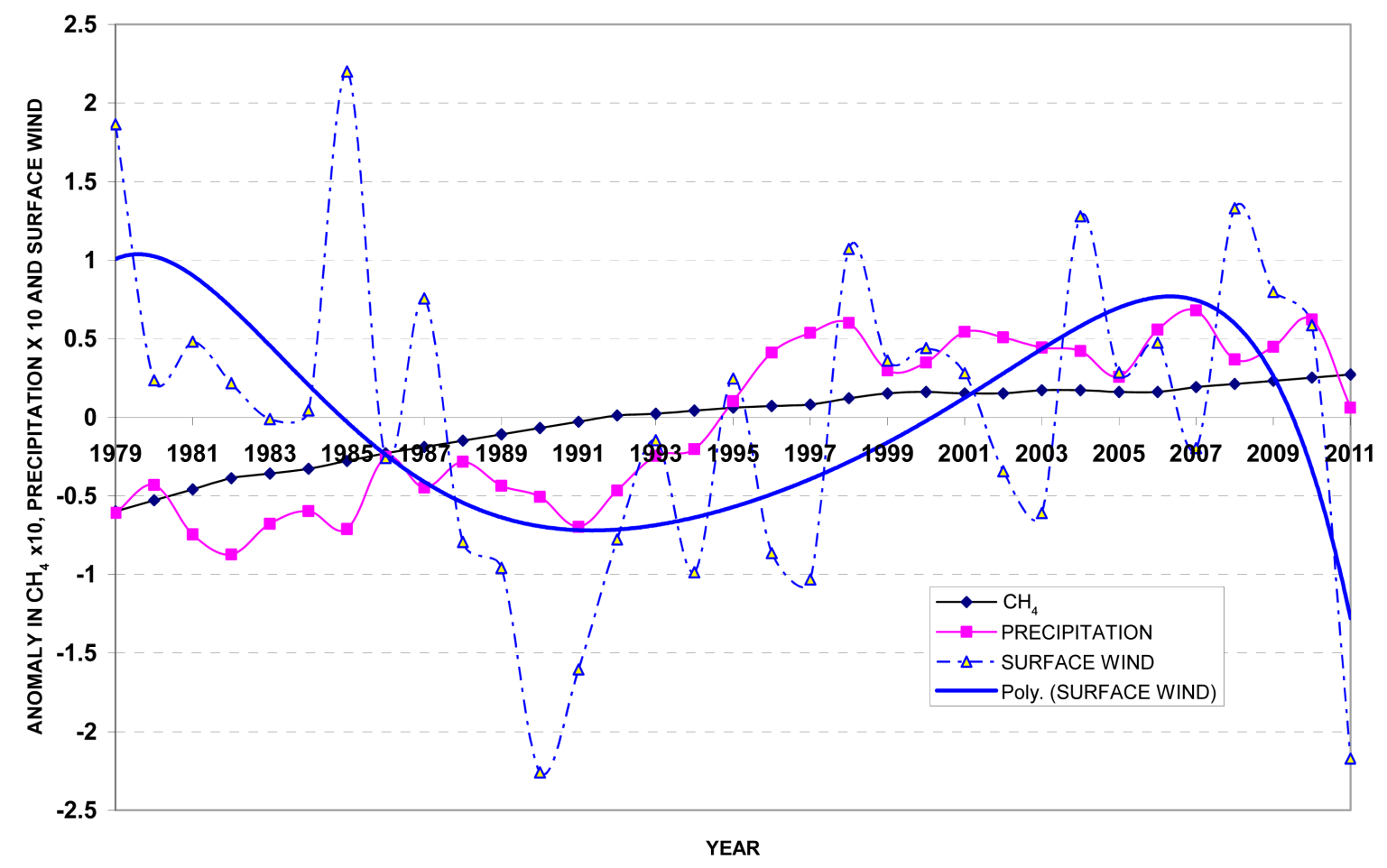

(c)

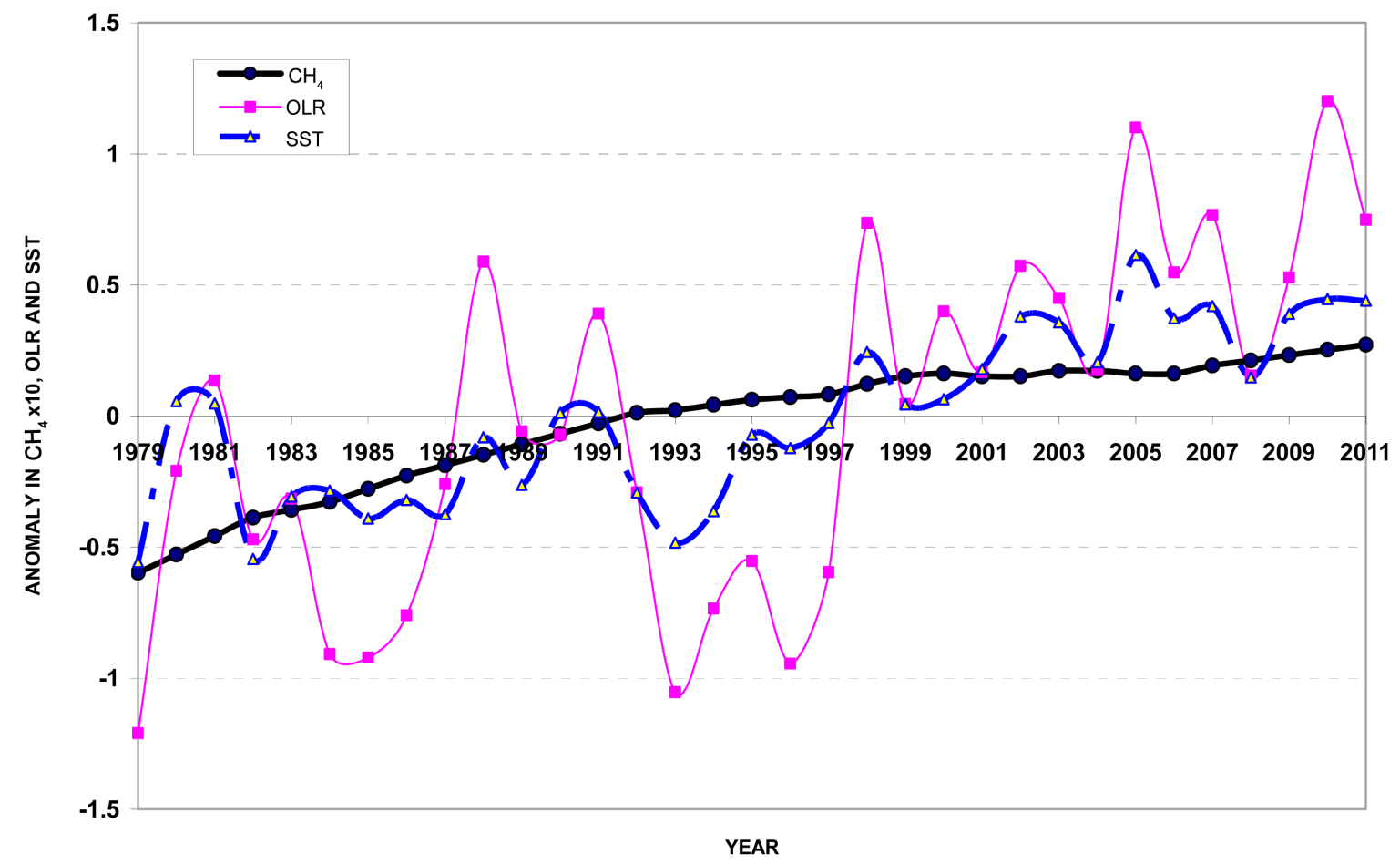

(d)

Figure 4. (a) Time series of $\mathrm{CH}_{4}$, surface air temperature and $500 \mathrm{hPa}$ temperature anomalies for the globe through the period (1979-2011); (b) Time series of $\mathrm{CH}_{4}$, sea level pressure and $500 \mathrm{hPa}$ level of geopotential height anomaly for the globe through the period (1979-2011); (c) Time series of $\mathrm{CH}_{4}$, surface wind and precipitation rate anomaly for the globe through the period (1979-2011); (d) Time series of $\mathrm{CH}_{4}$, OLR and SST anomaly for the globe through the period (1979-2011). 
6) For $15-\mathrm{MINOR}$, and surface air temperature and $500 \mathrm{hPa}$ level of temperature anomaly, it is clear that, 15MINOR became more than its normal values after 1993. All of these three parameters have a sharp increase with time through the period (2001-2011) as appears in Figure 8(a). With the continual increase of 15-MINOR, the geopotential height increase contradicted to surface air pressure almost time of the study period. See Figure 5(b). Precipitation rate increase to became more its normal values from the year 1995 to the year 2011 over the globe

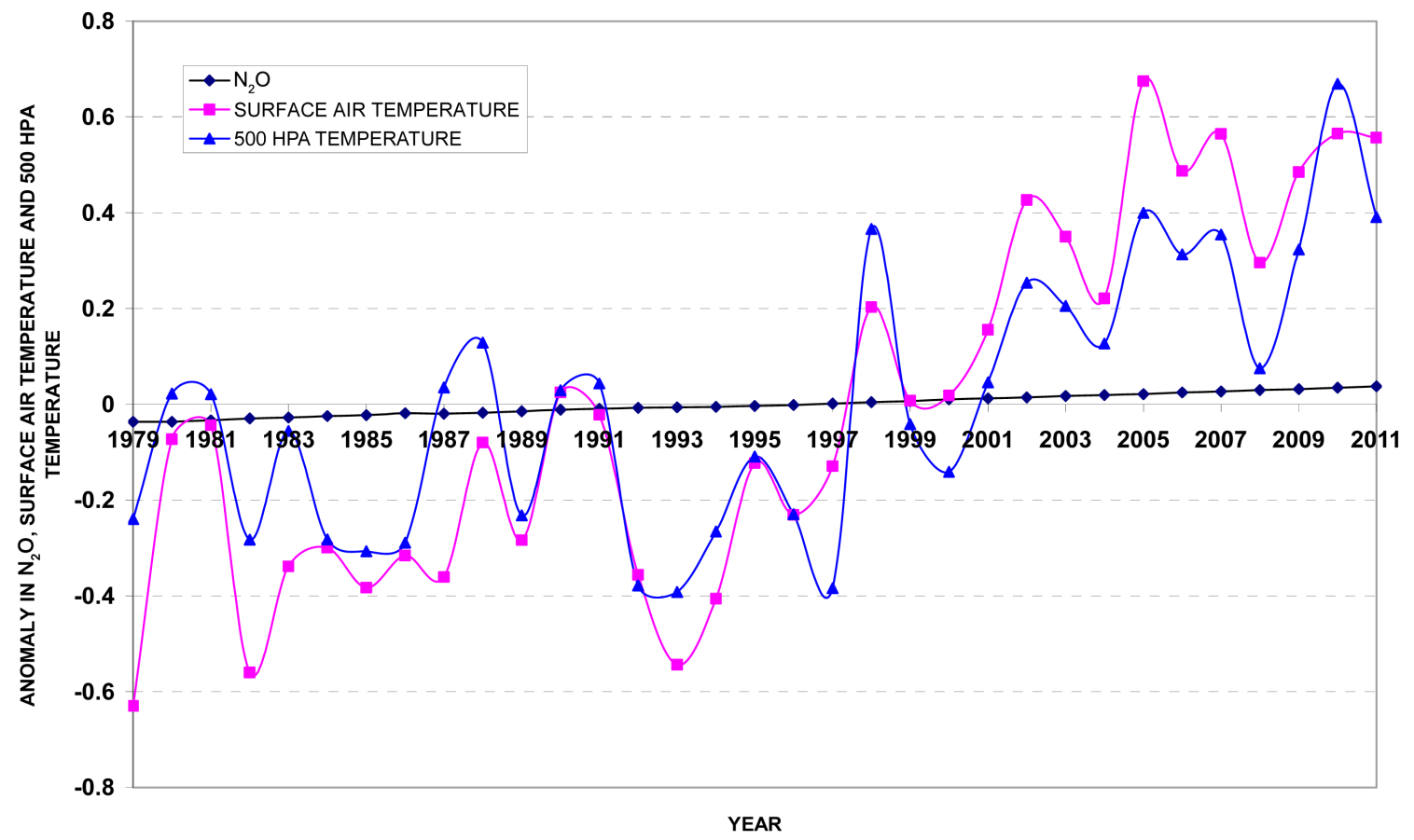

(a)

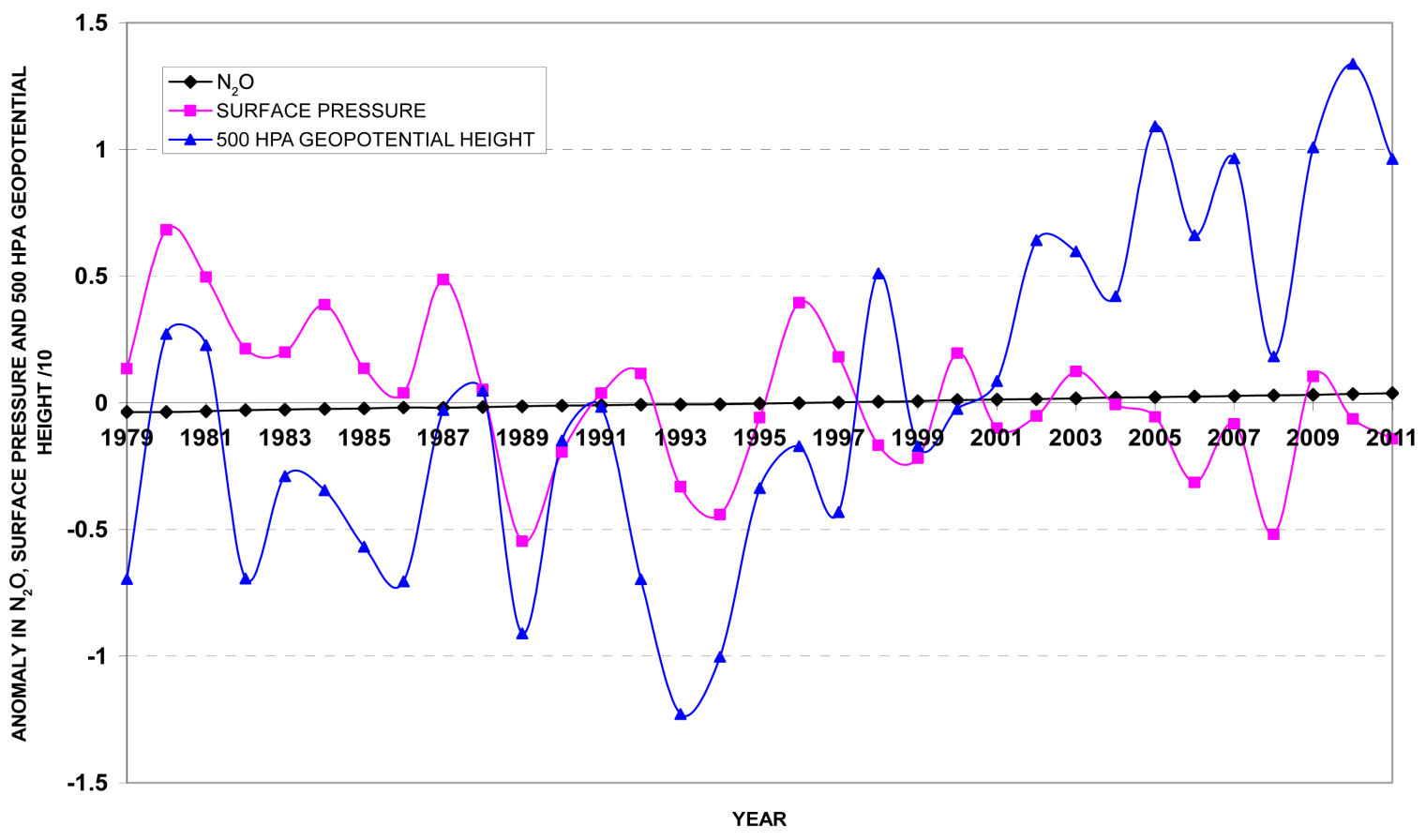

(b) 


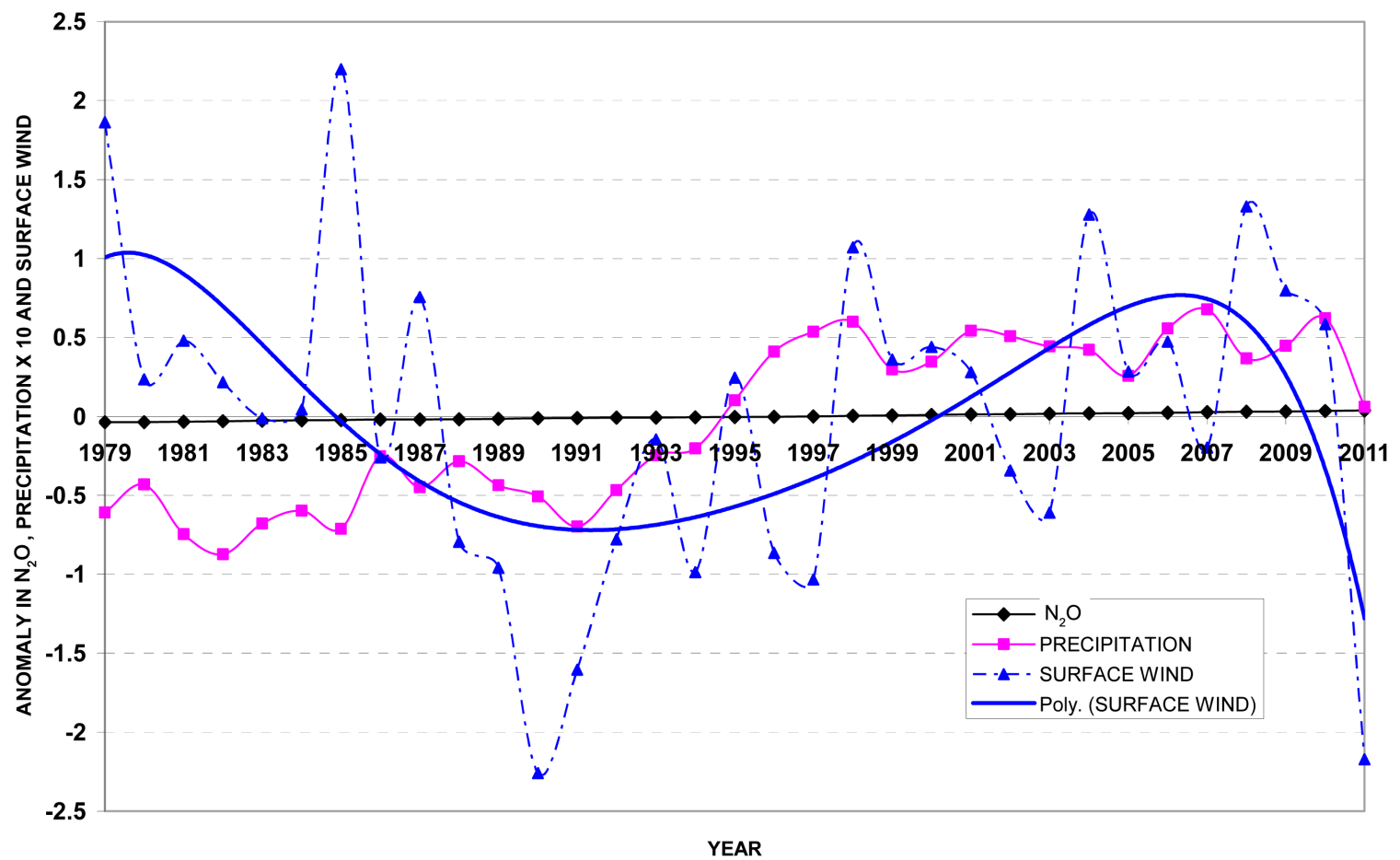

(c)

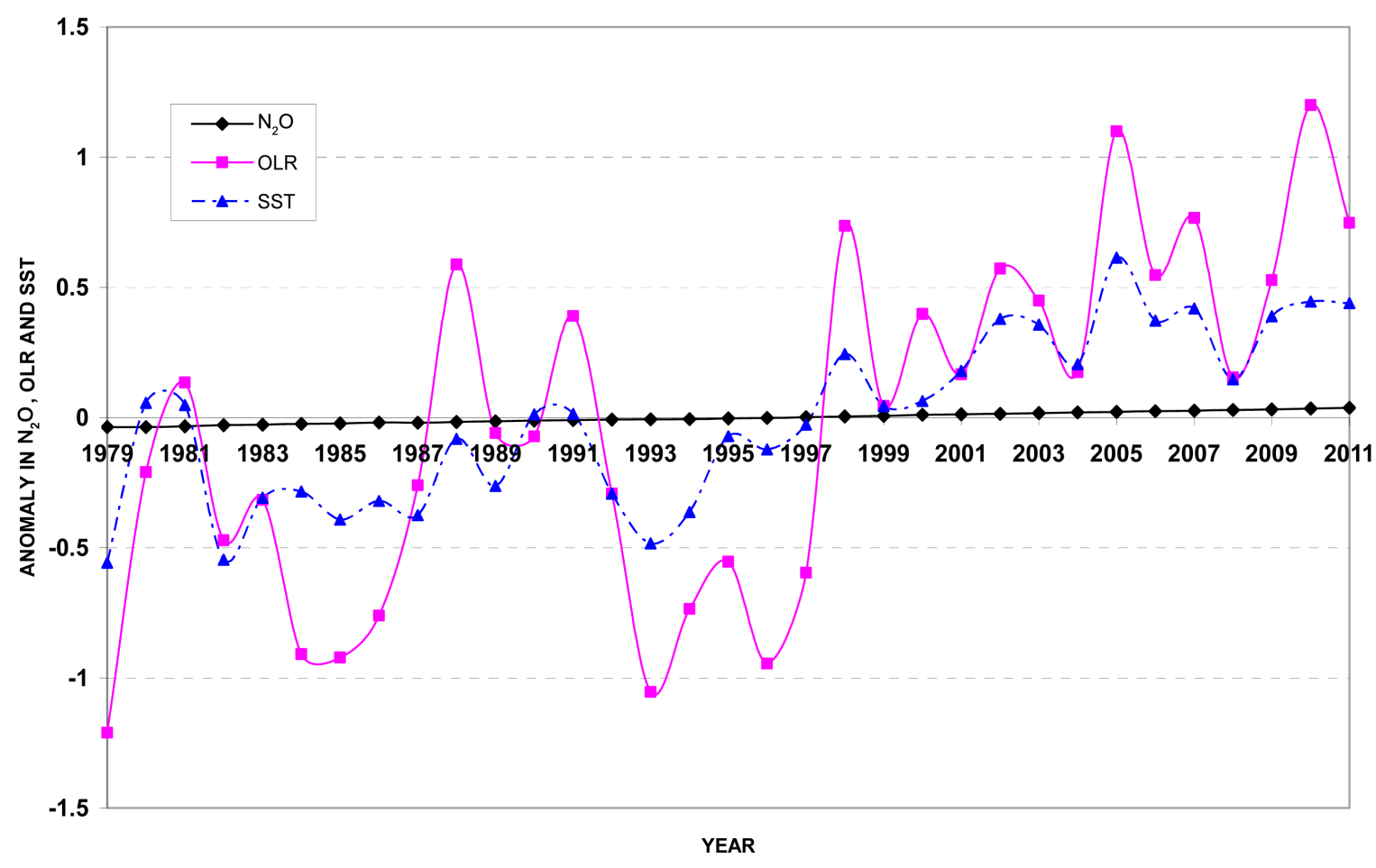

(d)

Figure 5. (a) Time series of $\mathrm{N}_{2} \mathrm{O}$, surface air temperature and $500 \mathrm{hPa}$ temperature anomalies for the globe through the period (1979-2011); (b) Time series of $\mathrm{N}_{2} \mathrm{O}$, sea level pressure and $500 \mathrm{hPa}$ level of geopotential height anomaly for the globe through the period (1979-2011); (c) Time series of $\mathrm{N}_{2} \mathrm{O}$, surface wind and precipitation rate anomaly for the globe through the period (1979-2011); (d) Time series of $\mathrm{N}_{2} \mathrm{O}$, OLR and SST anomaly for the globe through the period (1979-2011). 


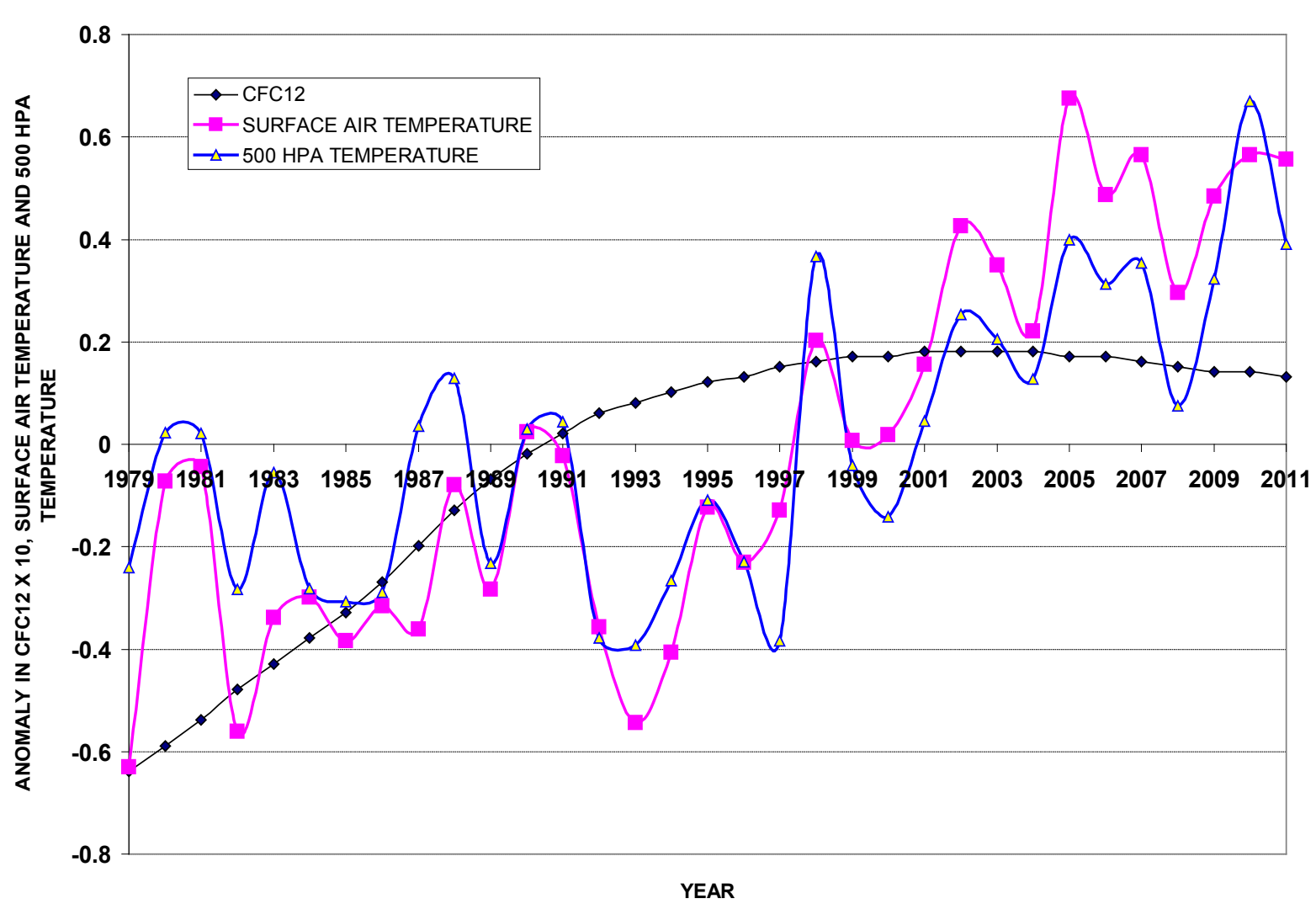

(a)

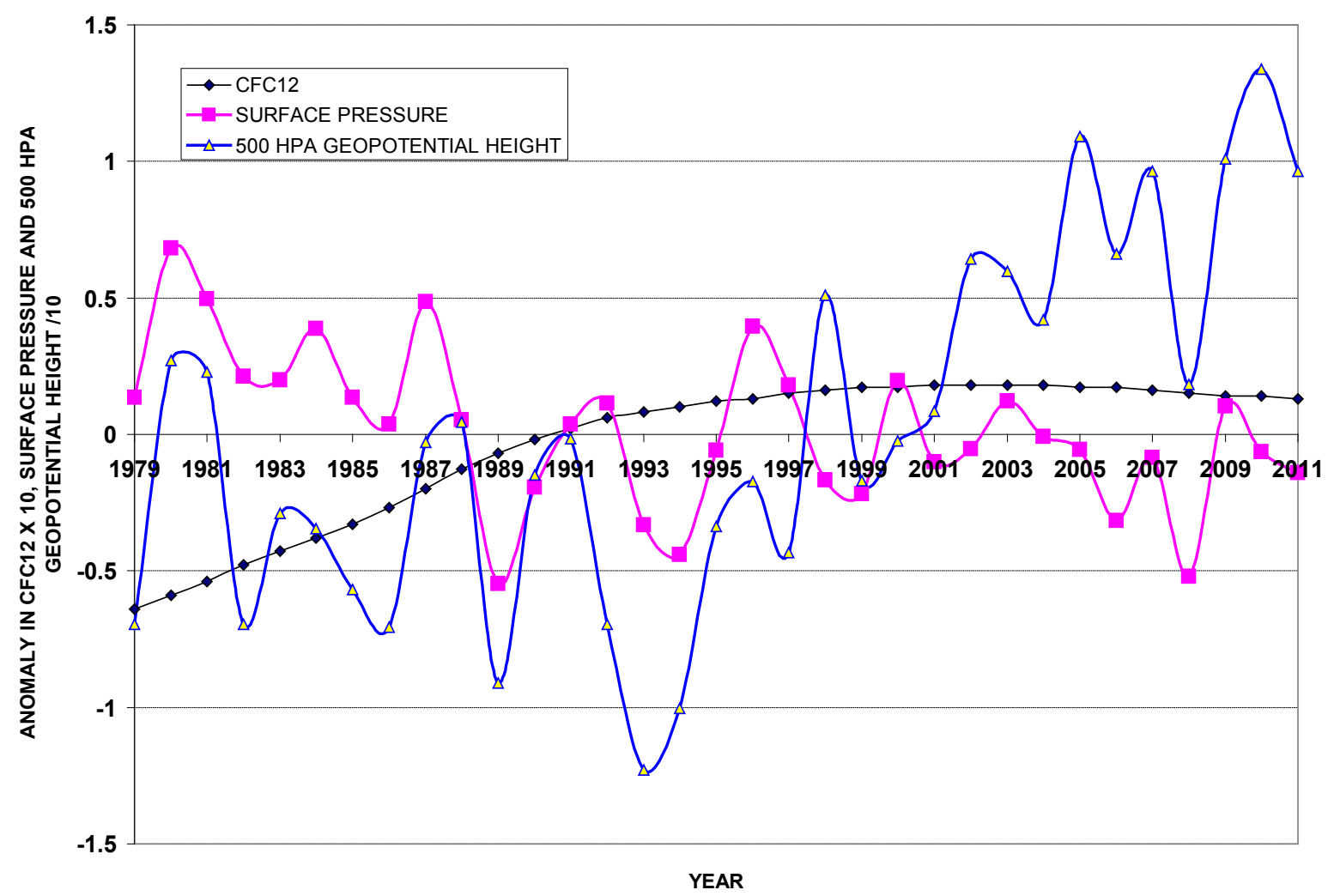

(b) 


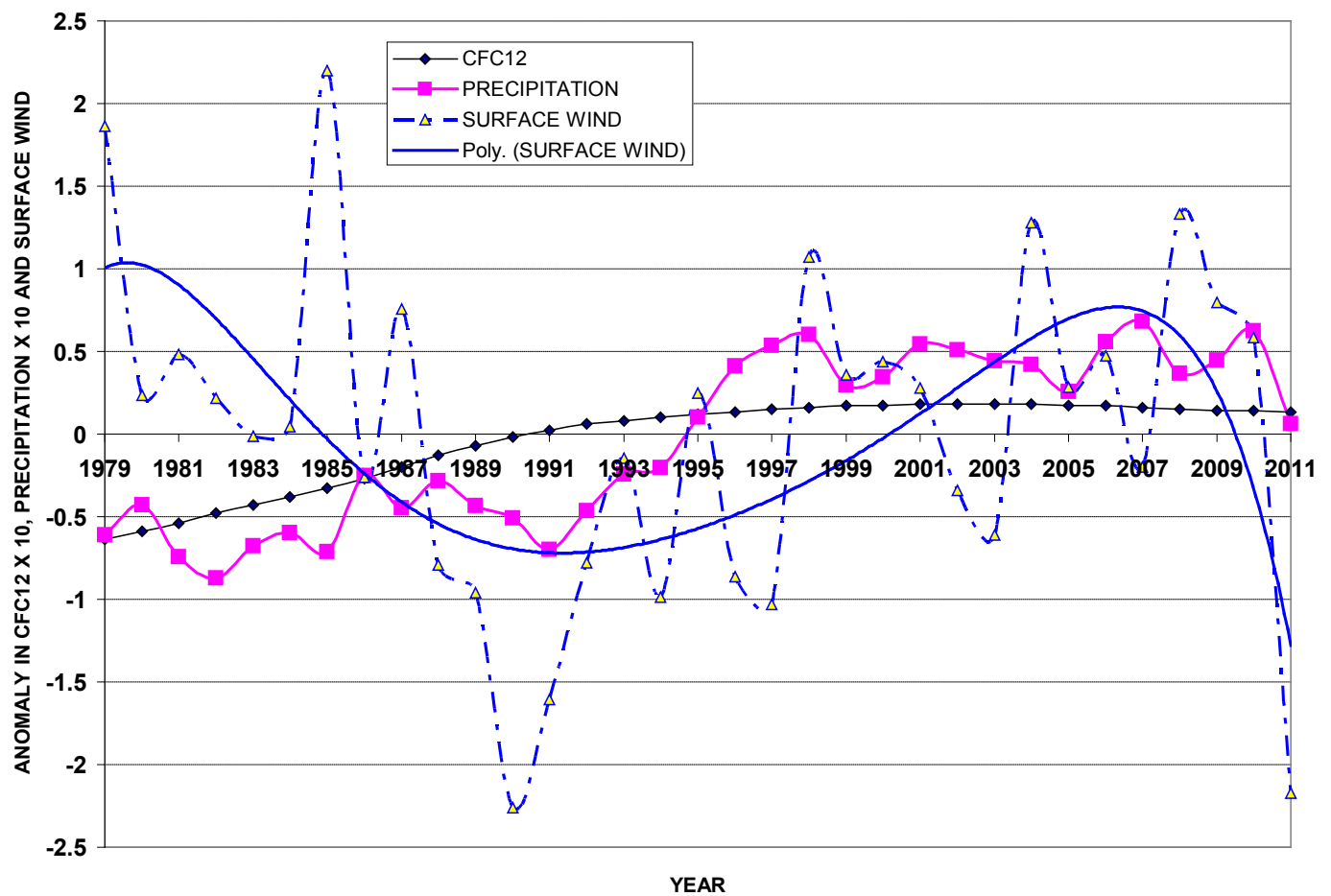

(c)

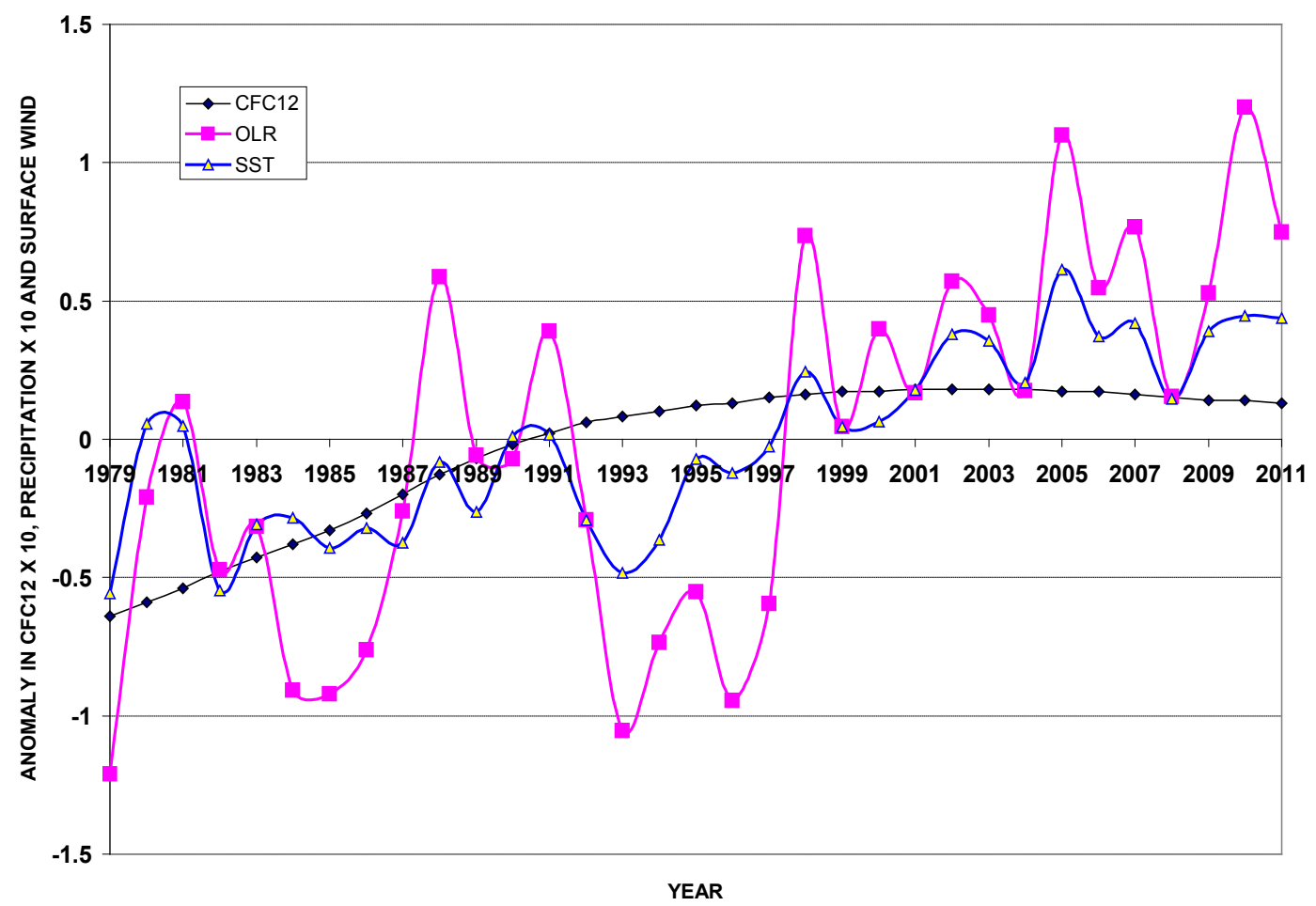

(d)

Figure 6. (a) Time series of CFC 12, surface air temperature and $500 \mathrm{hPa}$ temperature anomalies for the globe through the period (1979-2011); (b) Time series of CFC 12, sea level pressure and $500 \mathrm{hPa}$ level of geopotential height anomaly for the globe through the period (1979-2011); (c) Time series of CFC 12, surface wind and precipitation rate anomaly for the globe through the period (1979-2011); (d) Time series of CFC 12, OLR and SST anomaly for the globe through the period (1979-2011). 
likely the variability of $15-\mathrm{MINOR}$. Meanwhile the surface wind varies like a wave and not related to 15 MINOR variation through the period of study (1979-2011) as shown in Figure 8(c). Generally, OLR and SST vary and increase with time, typically with the 15-MINOR variability for all the period (1979-2011) over the globe as shown in Figure 8(d).

7) It is noticed that the variability of total GRF and AGGI values is the same with the variability of the

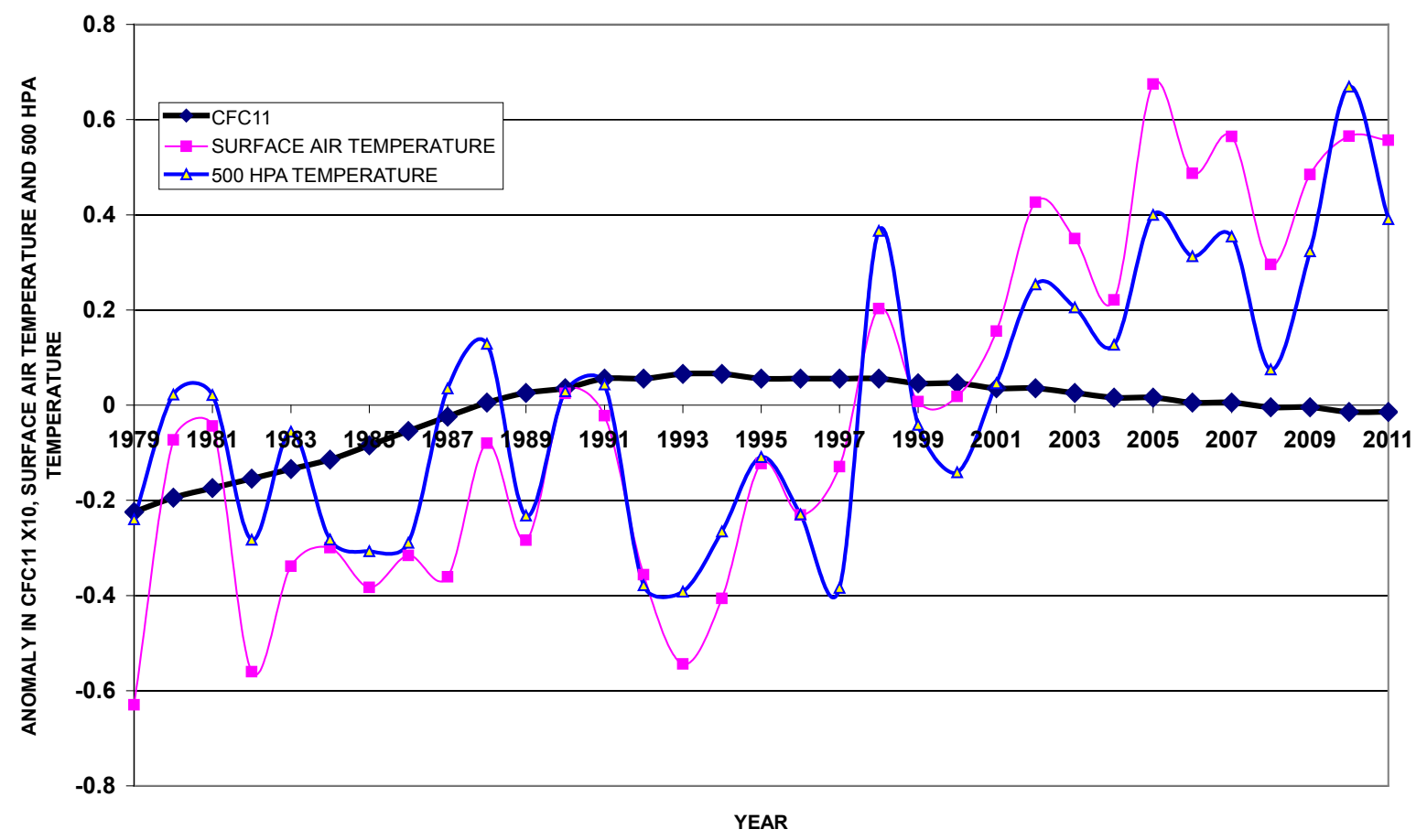

(a)

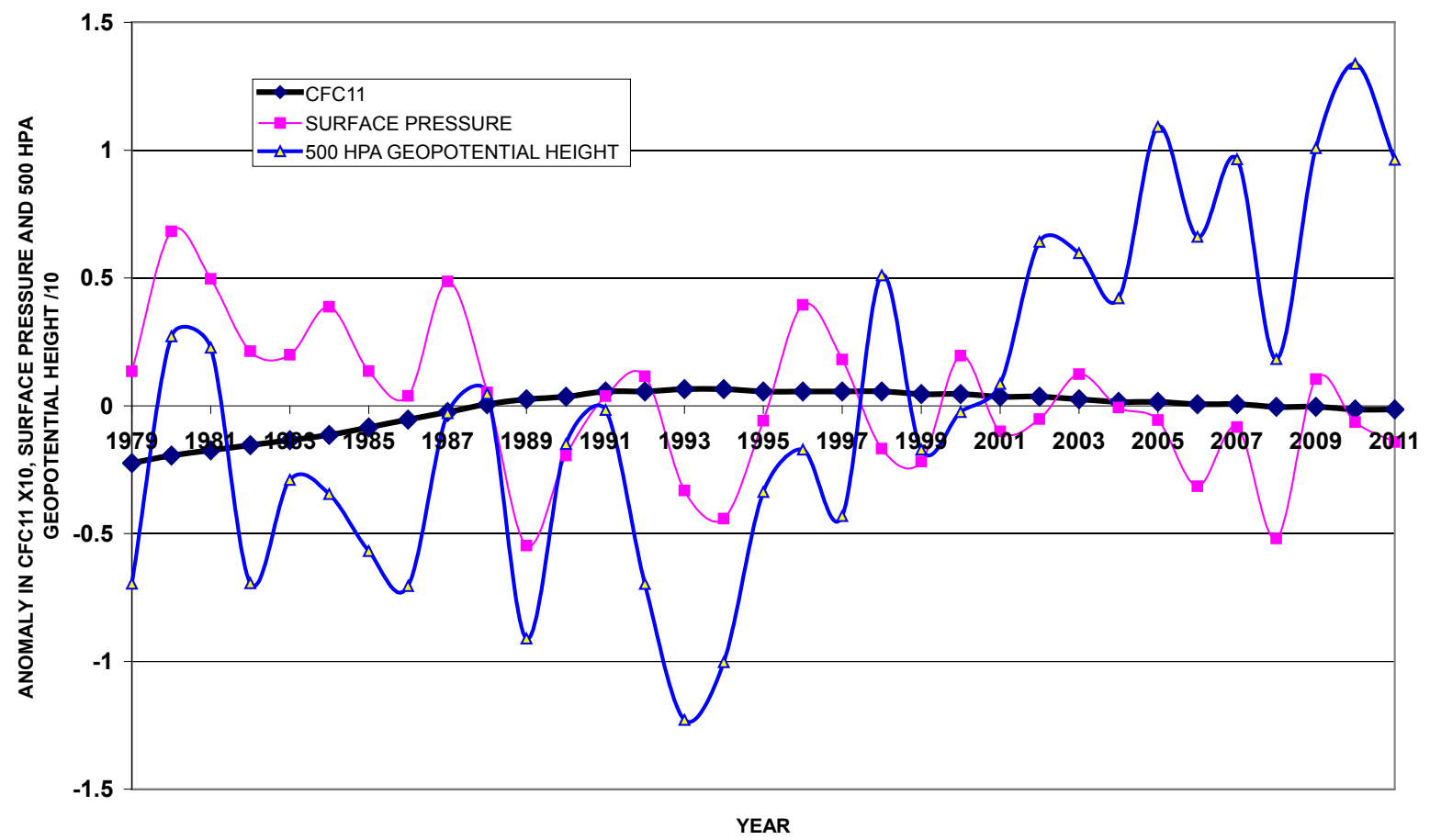

(b) 


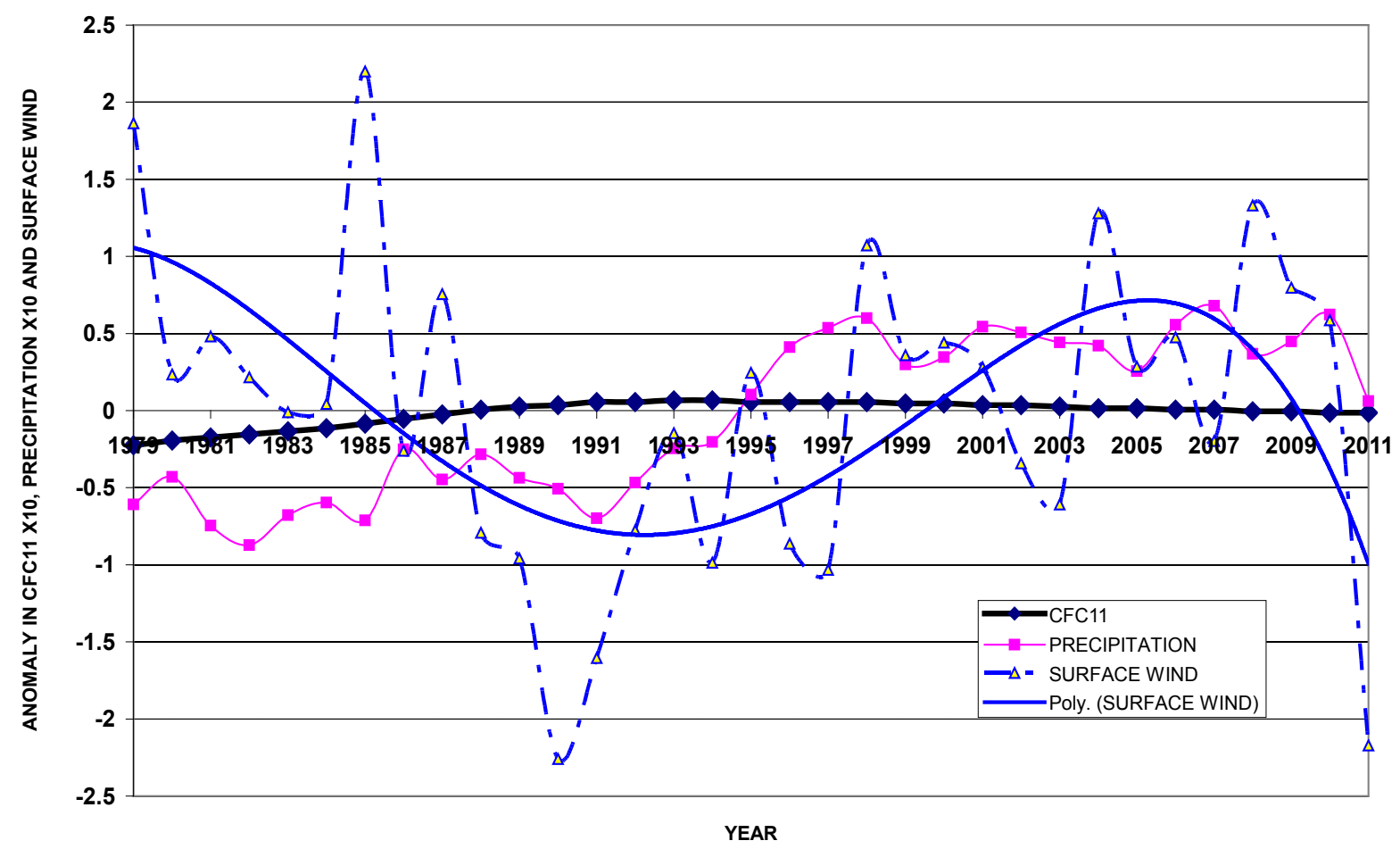

(c)

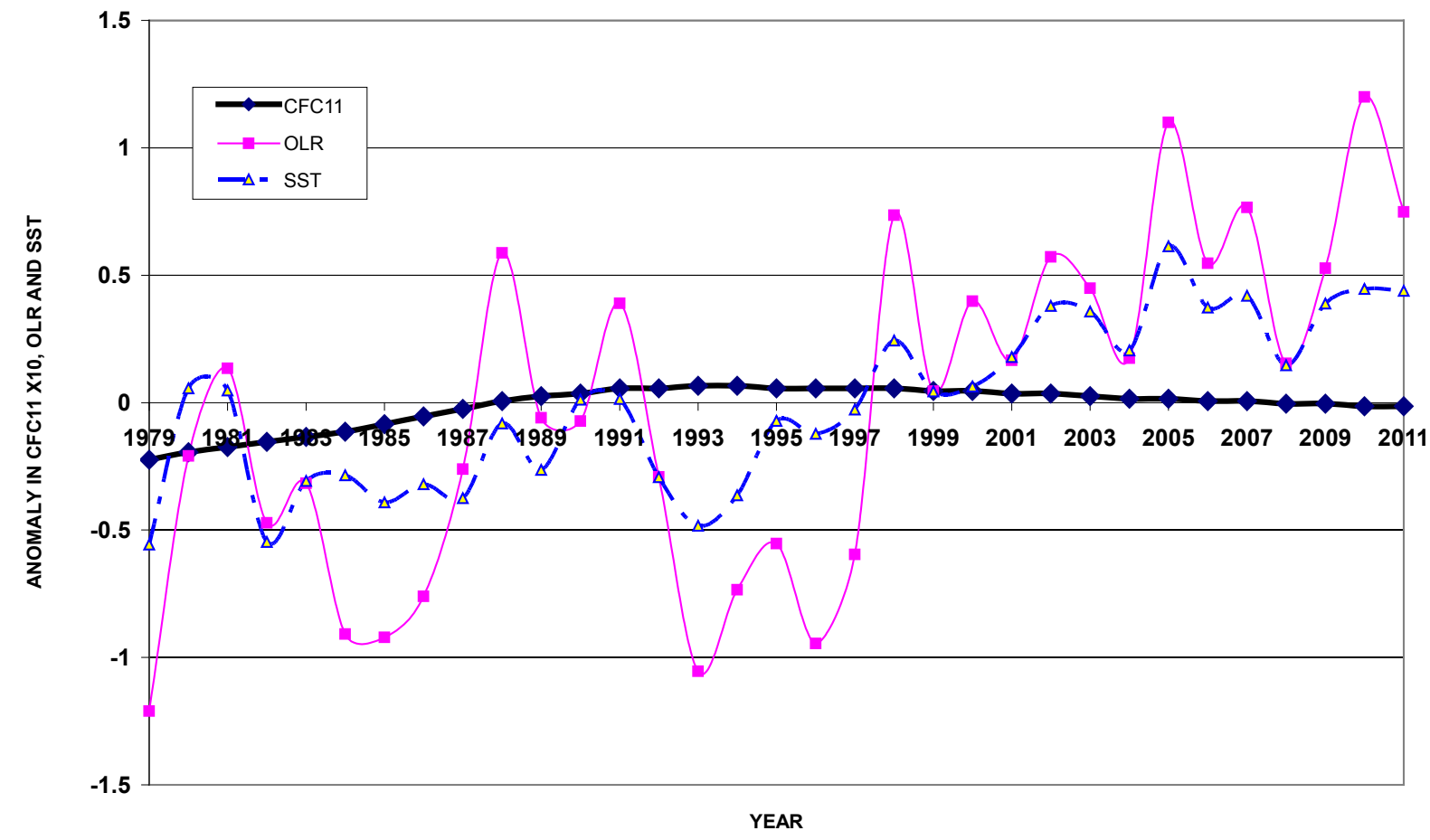

(d)

Figure 7. (a) Time series of CFC 11, surface air temperature and $500 \mathrm{hPa}$ temperature anomalies for the globe through the period (1979-2011); (b) Time series of CFC 11, sea level pressure and $500 \mathrm{hPa}$ level of geopotential height anomaly for the globe through the period (1979-2011); (c) Time series of CFC 11, surface wind and precipitation rate anomaly for the globe through the period (1979-2011); (d) Time series of CFC 11, OLR and SST anomaly for the globe through the period (19792011). 


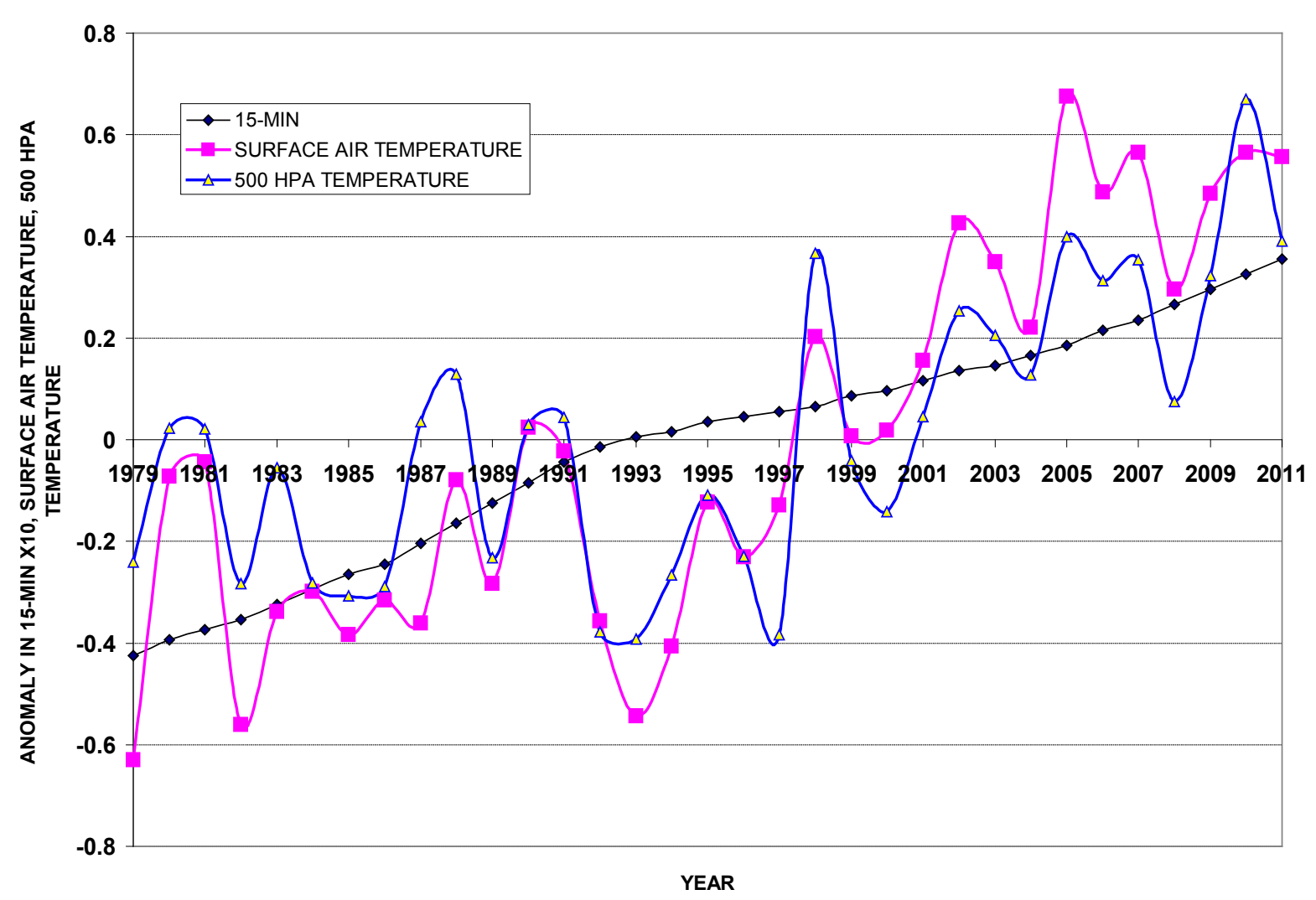

(a)

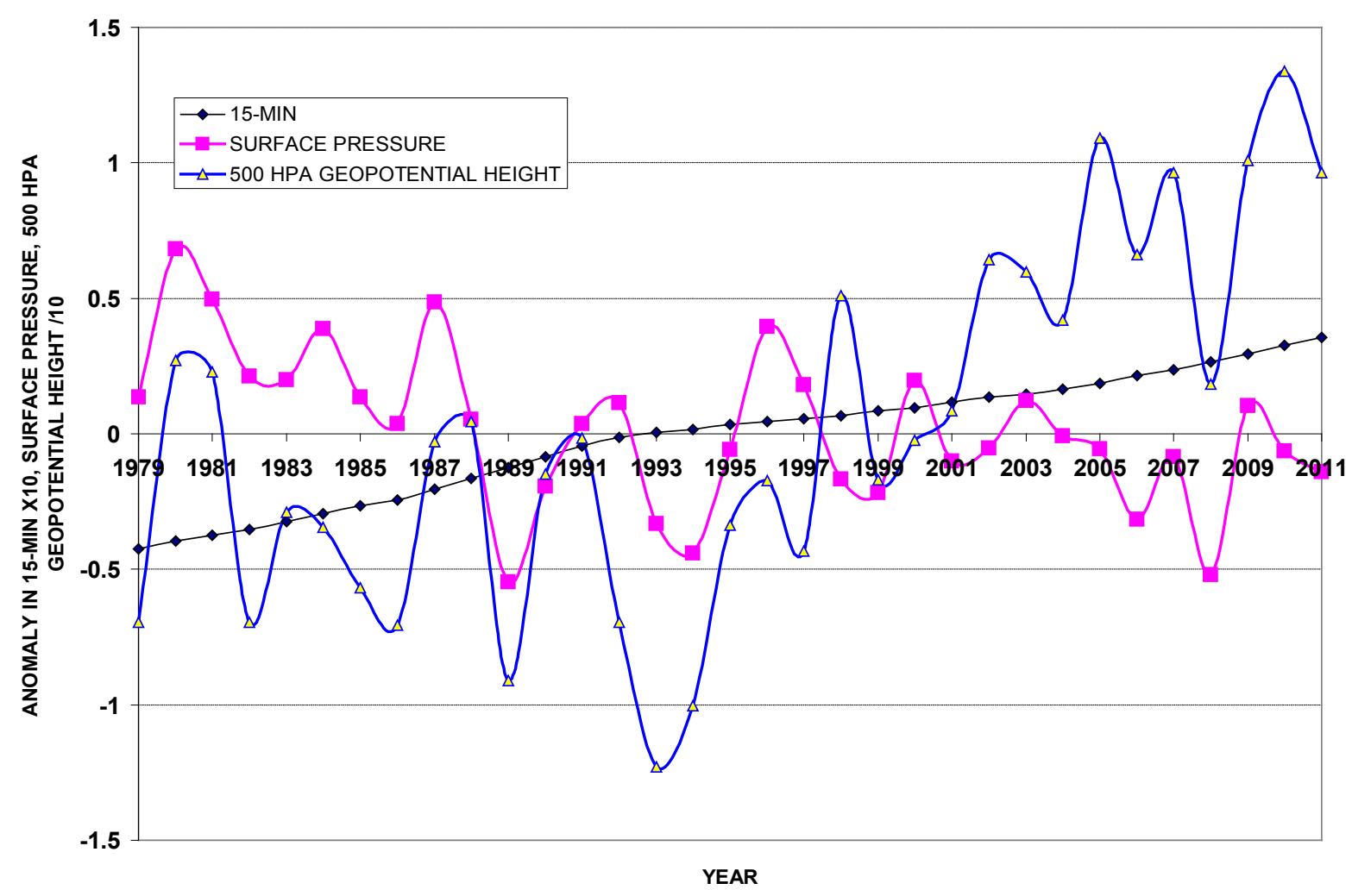

(b) 


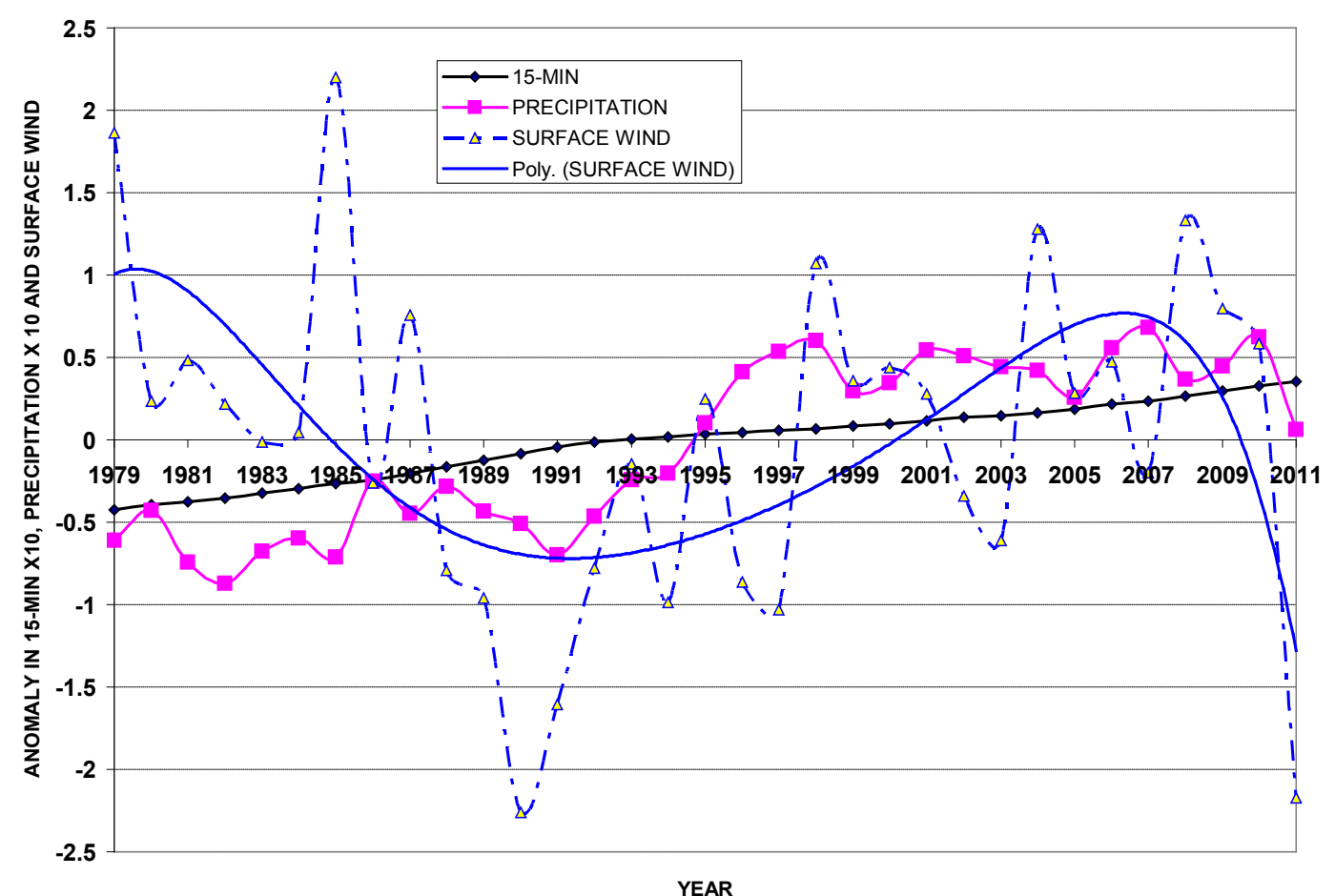

(c)

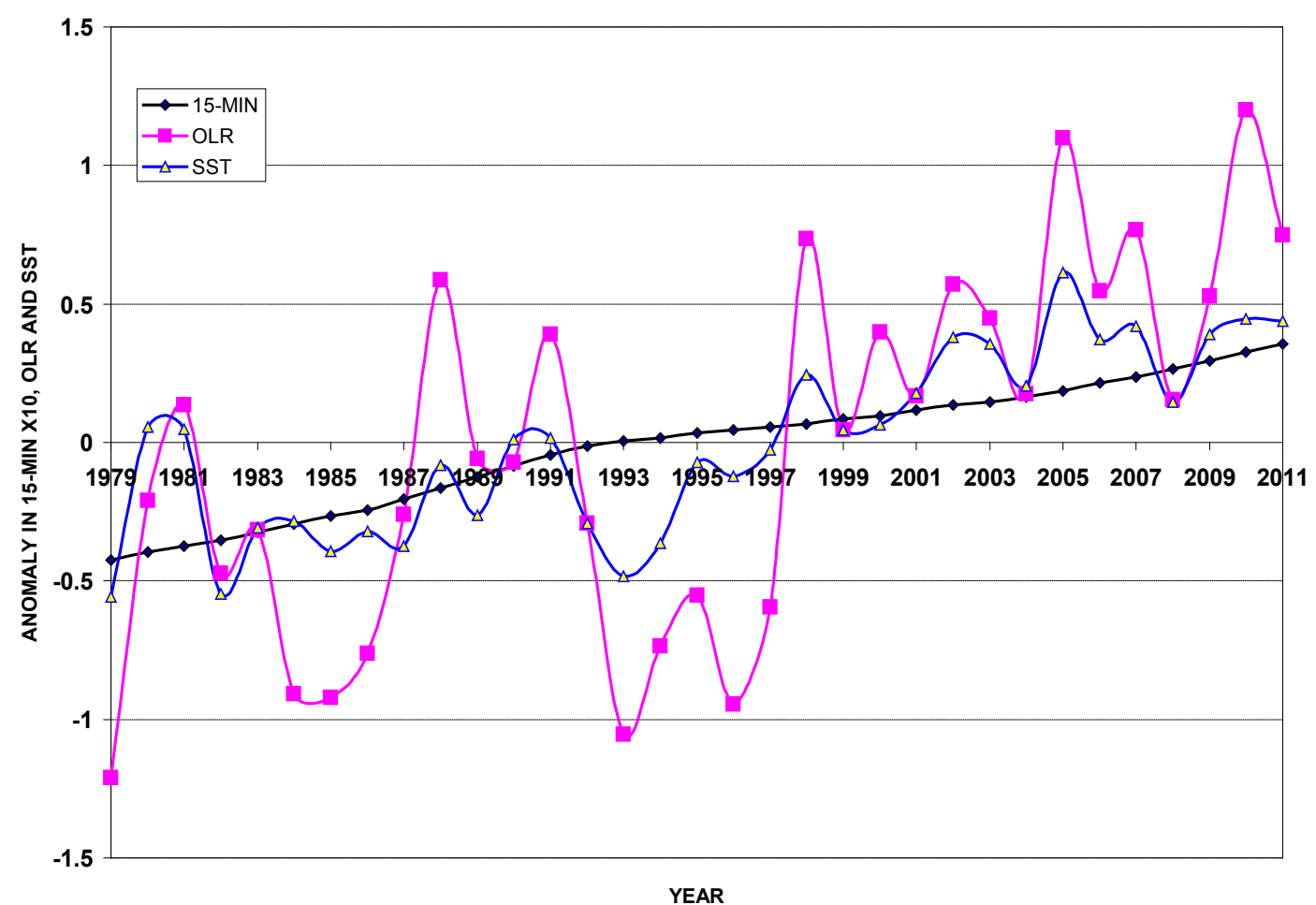

(d)

Figure 8. (a) Time series of 15-MINOR, surface air temperature and $500 \mathrm{hPa}$ temperature anomaly for the globe through the period (1979-2011); (b) Time series of 15-MINOR, sea level pressure and $500 \mathrm{hPa}$ level of geopotential height anomaly for the globe through the period (1979-2011); (c) Time series of 15-MINOR, surface wind and precipitation rate anomaly for the globe through the period (1979-2011); (d) Time series of 15-MINOR, OLR and SST anomaly for the globe through the period (1979-2011). 
global annual weather elements through the period of study except with surface air pressure and wind. Whereas, the total GRF and AGGI values have become above normal since 1995 with the same manner of the meteorological elements in general. See Figure 9 and Figure 10.

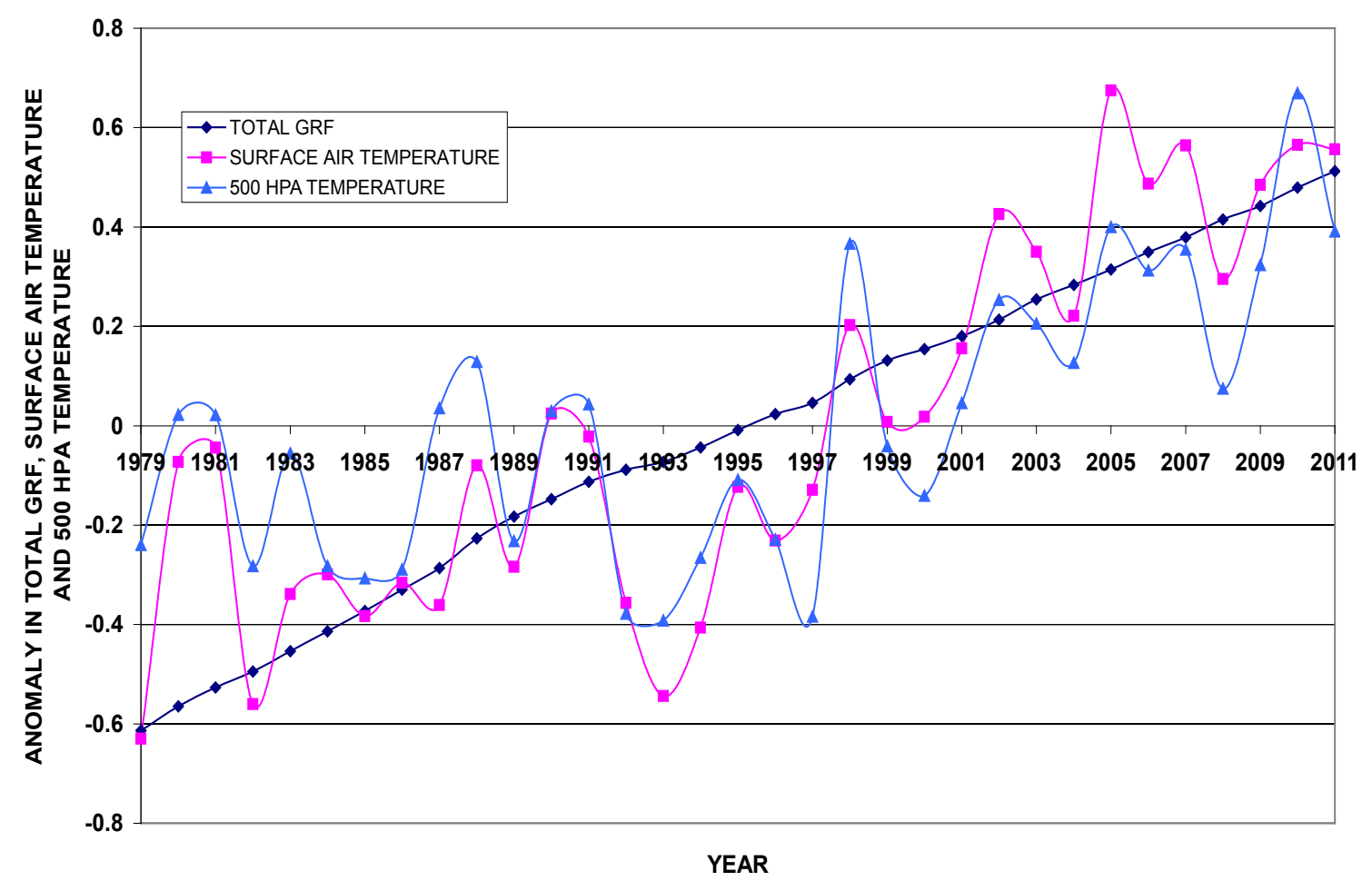

(a)

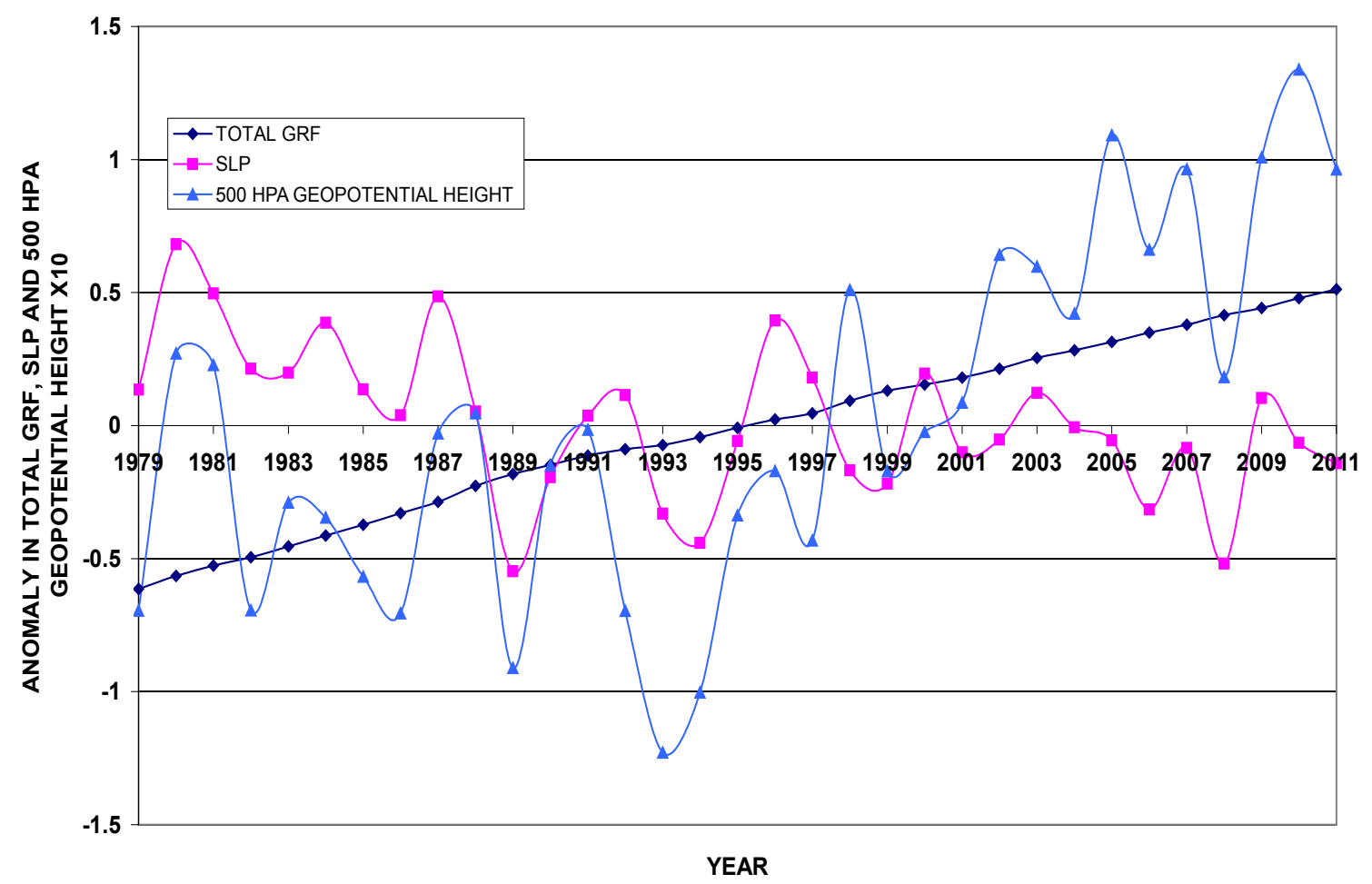

(b) 


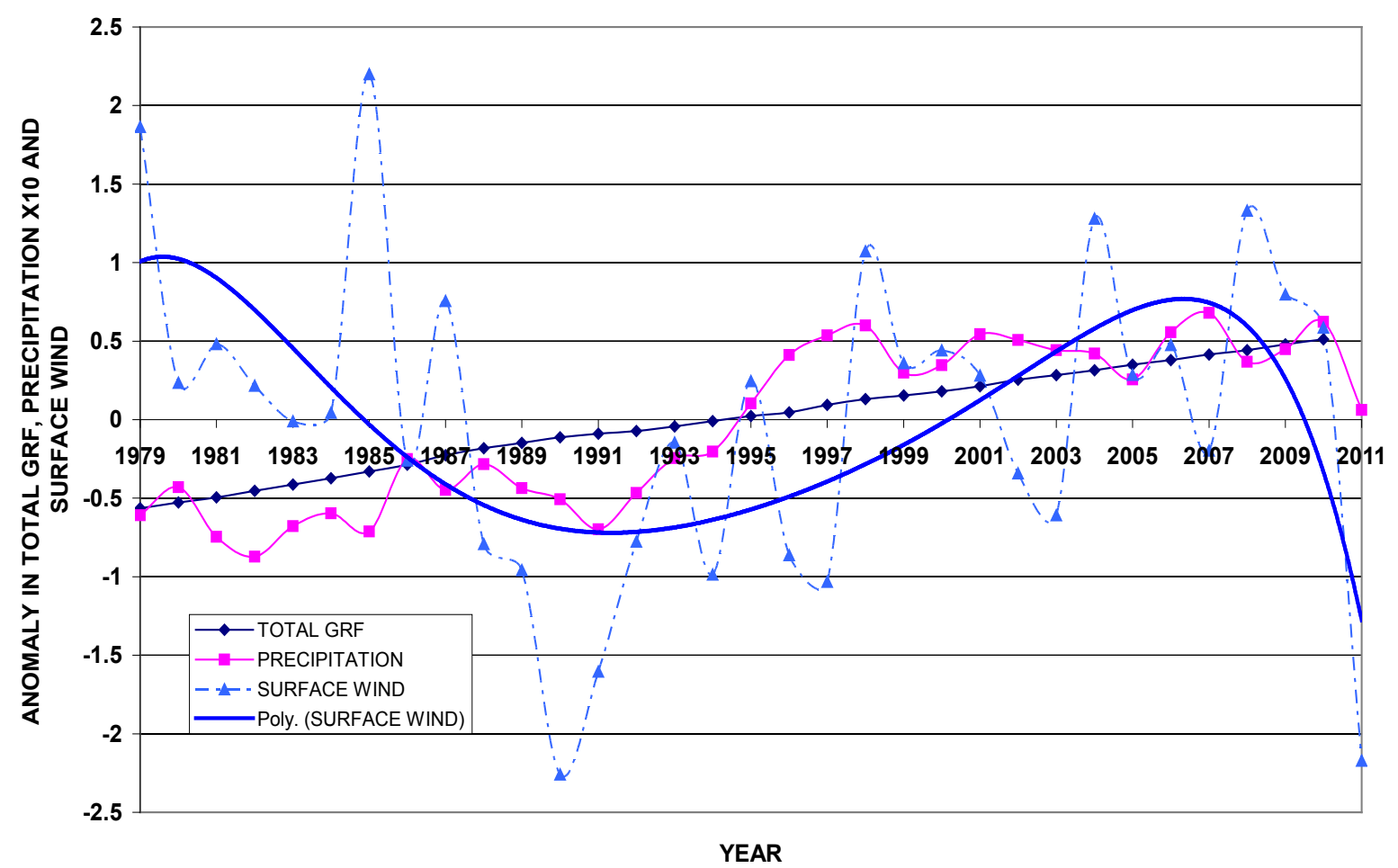

(c)

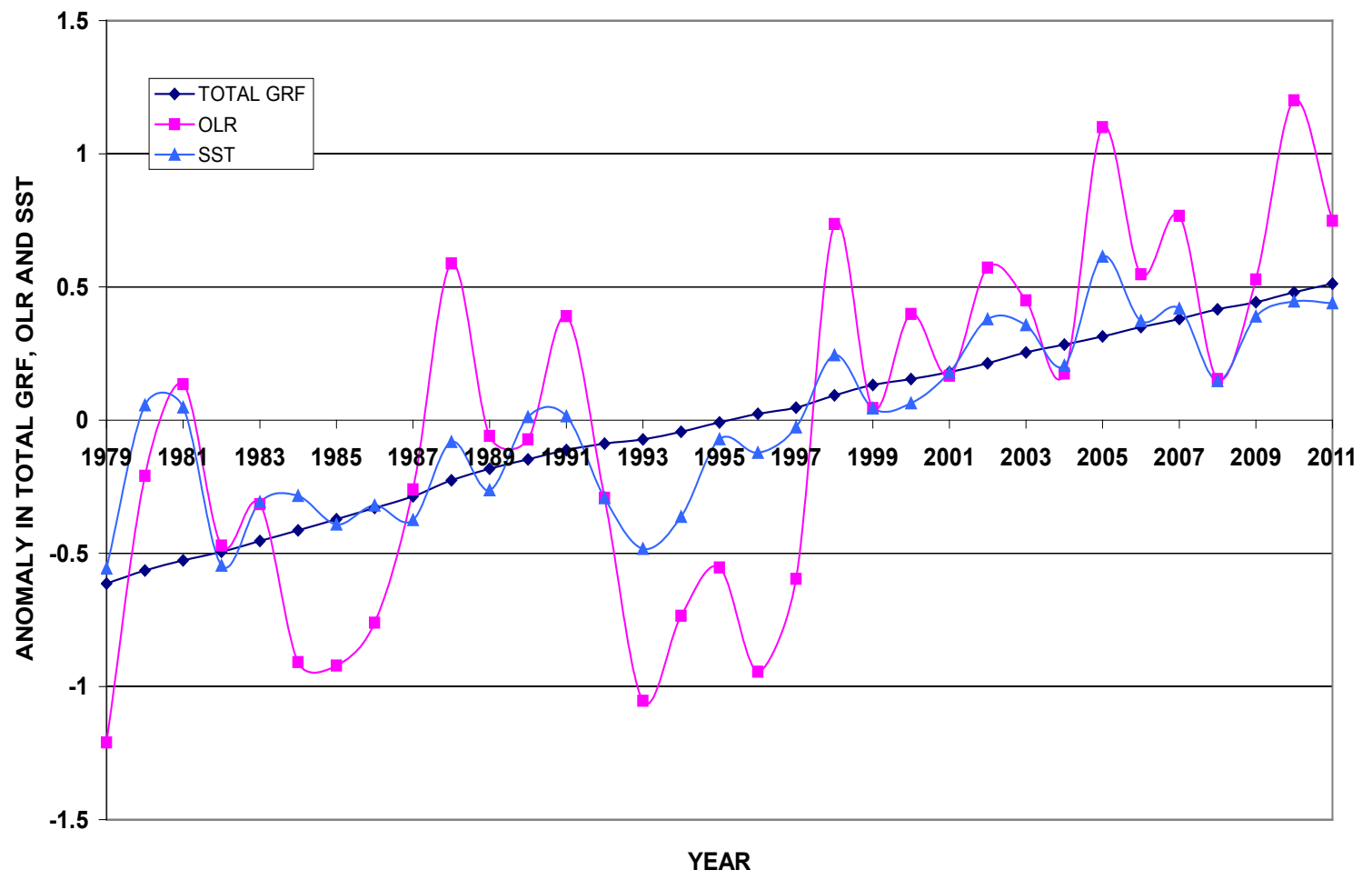

(d)

Figure 9. (a) Time series of GRF, surface air temperature and $500 \mathrm{hPa}$ temperature anomalies for the globe through the period (1979-2011); (b) Time series of GRF, sea level pressure and $500 \mathrm{hPa}$ level of geopotential height anomaly for the globe through the period (1979-2011); (c) Time series of GRF, surface wind and precipitation rate anomaly for the globe through the period (1979-2011); (d) Time series of GRF, OLR and SST anomaly for the globe through the period (1979-2011). 


\subsection{The Relation between GRF and Climatic Indices NAO, SOI, El Nino 3.4 and SST Variability during the Period (1979-2011)}

From the above results it has become clear that the effect of global radiative forcing for greenhouse gases varies from greenhouse gas to another in the annual weather and climatic conditions for the globe. Through this sub-

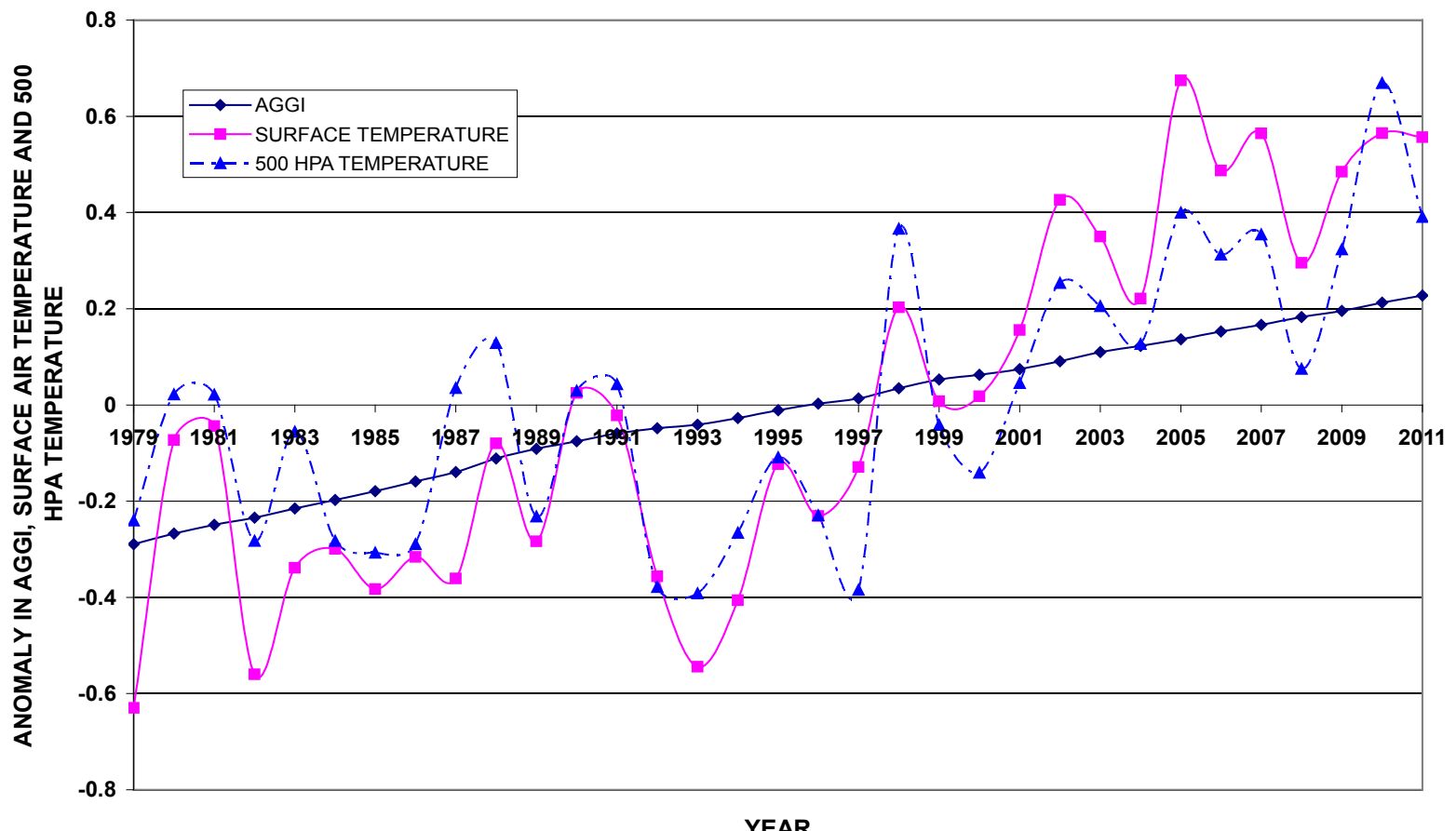

(a)

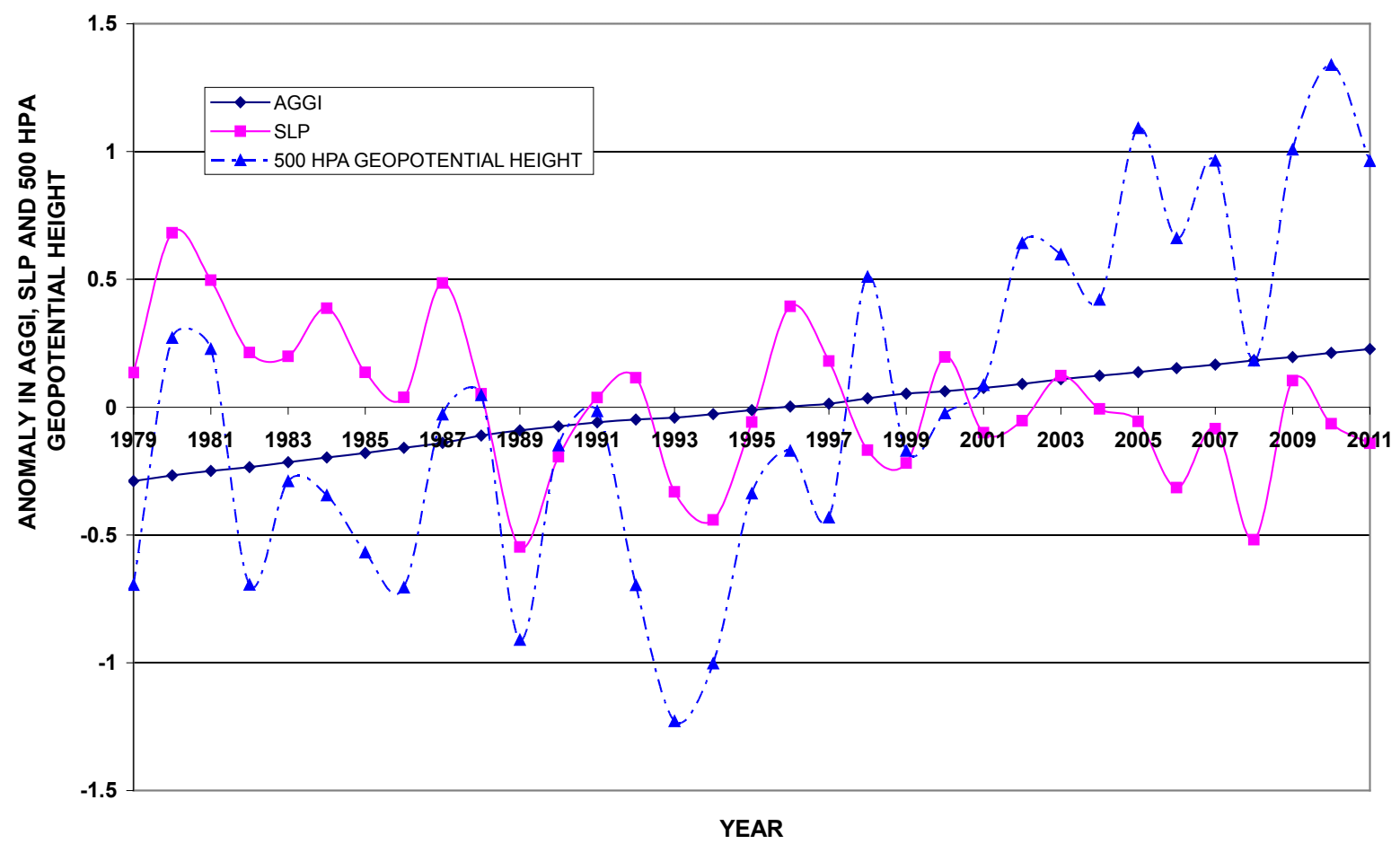

(b) 


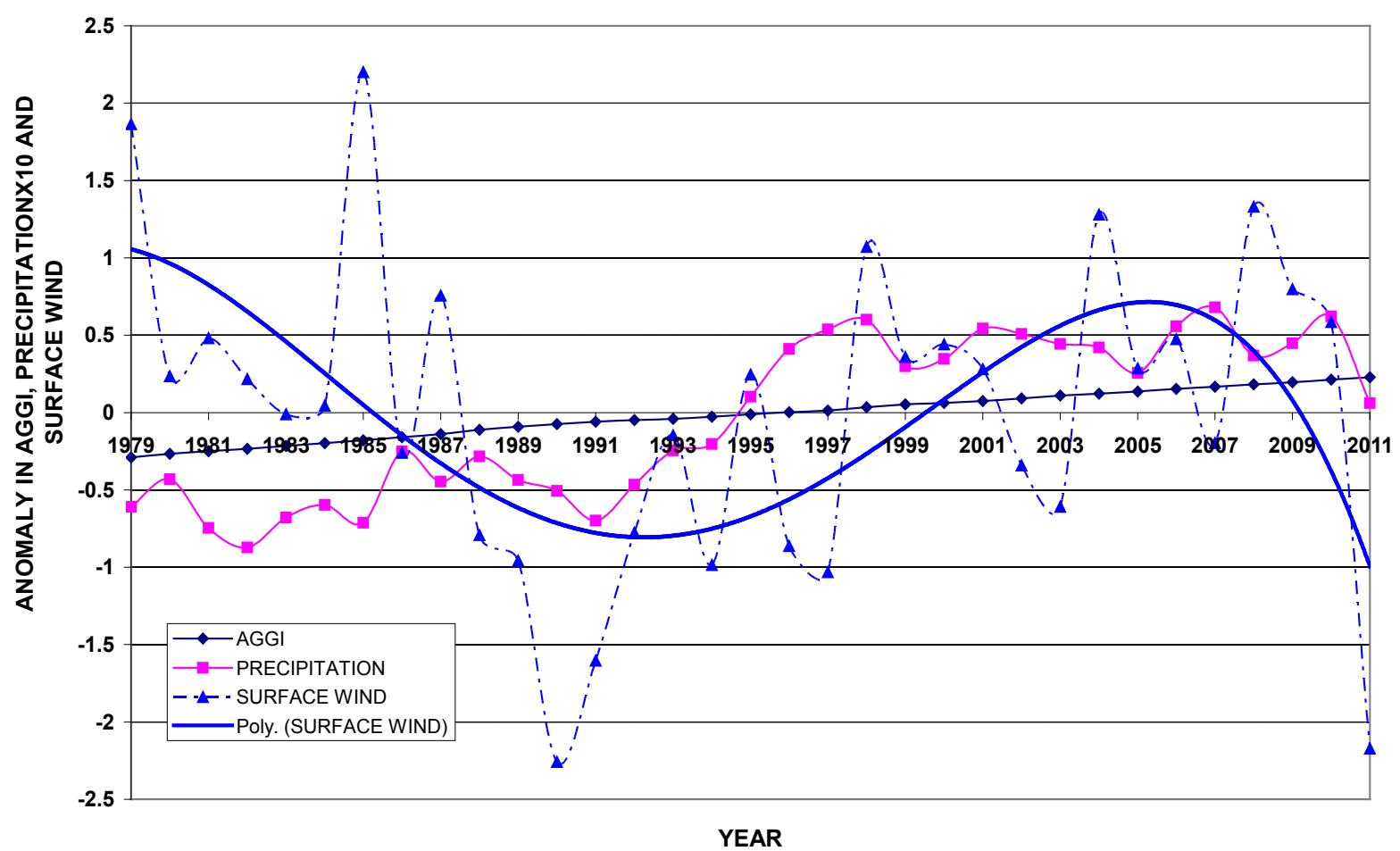

(c)

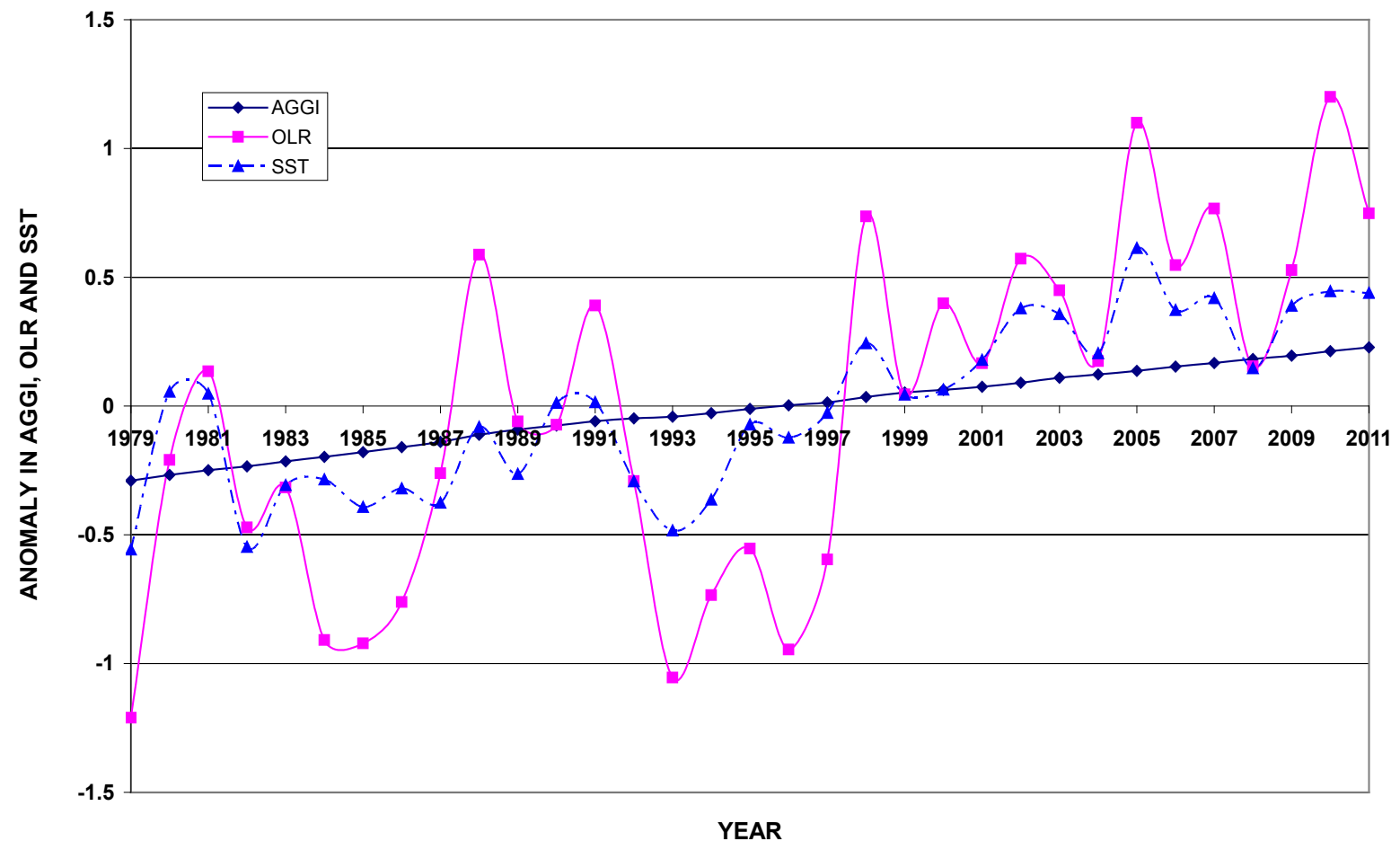

(d)

Figure 10. (a) Time series of AGGI, surface air temperature and $500 \mathrm{hPa}$ temperature anomalies for the globe through the period (1979-2011); (b) Time series of AGGI, sea level pressure and $500 \mathrm{hPa}$ level of geopotential height anomaly for the globe through the period (1979-2011); (c) Time series of AGGI, surface wind and precipitation rate anomaly for the globe through the period (1979-2011); (d) Time series of AGGI, OLR and SST anomaly for the globe through the period (19792011). 
section the time series trend analysis has been sued to study the relation between GRF, AGGI and for each of greenhouse gases and annual climatic indices NAO, SOI and El Nino 3.4 through the study period. The results revealed that there is a positive trend of the NAO, El Nino 3.4 and total GRF, AGGI and for each of greenhouse gases in general. Meanwhile, the connection between CFC 12 and CFC 11 and climatic indices variability are not clear through the study period, as clear from Figures 11(a)-(h).

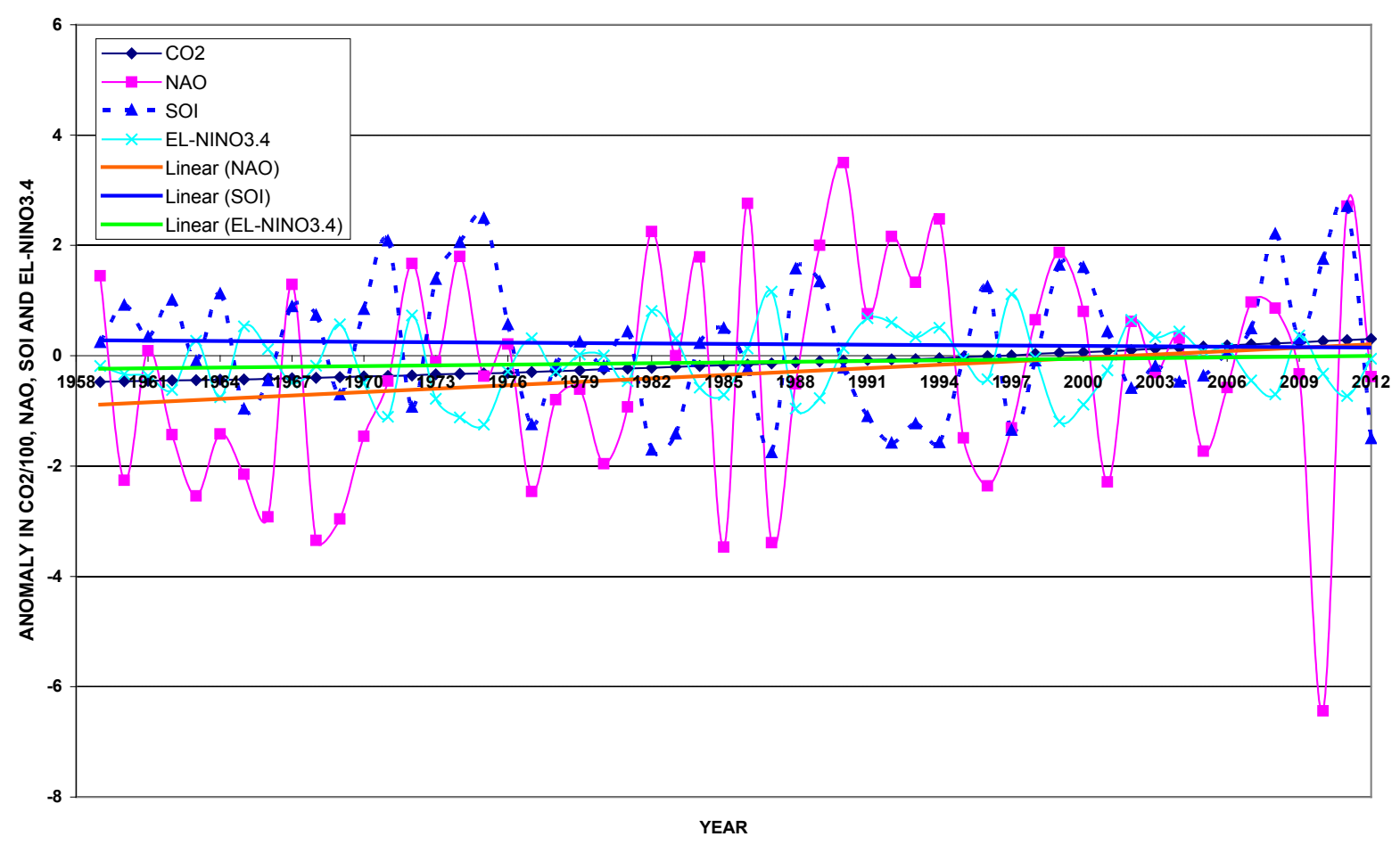

(a)

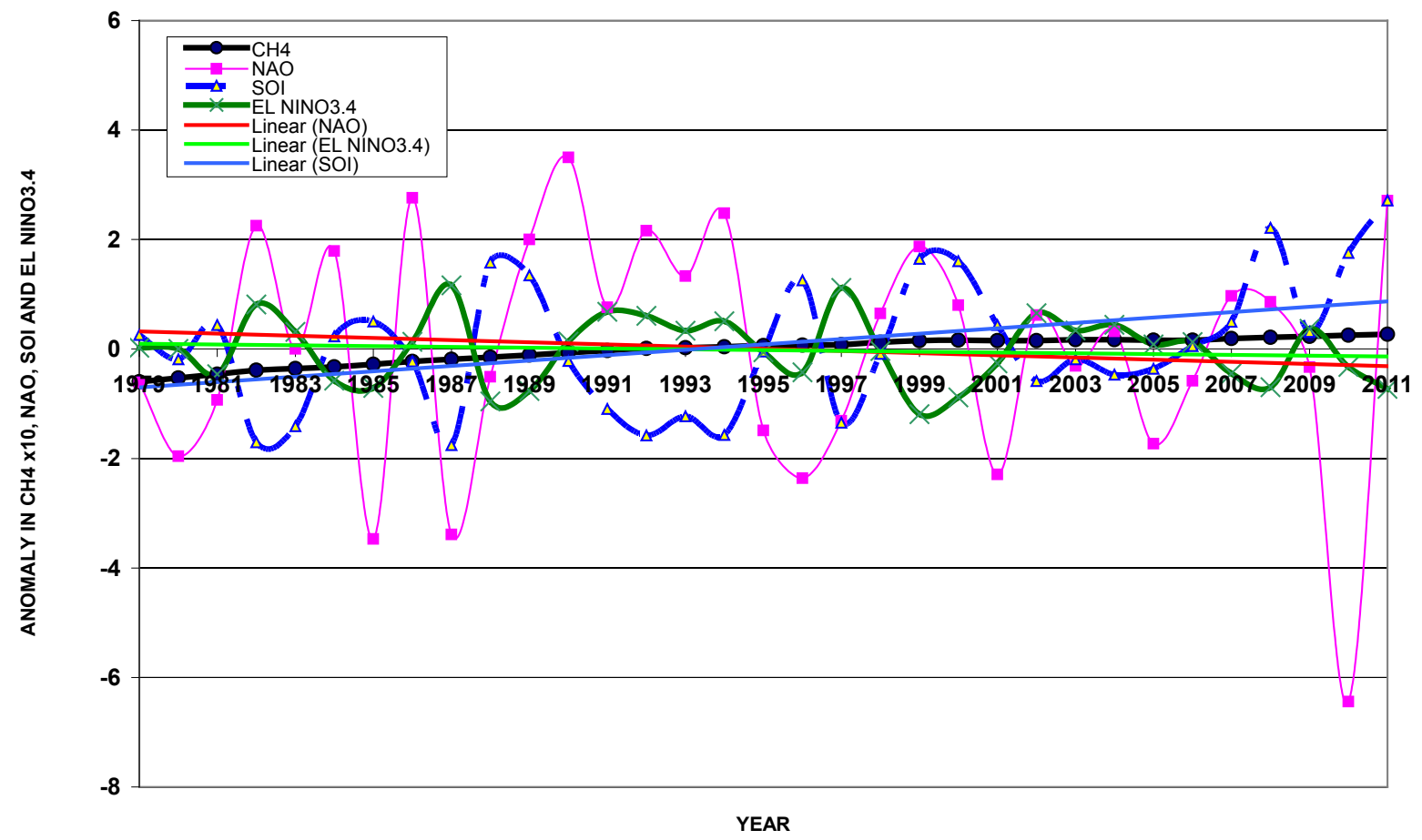

(b) 


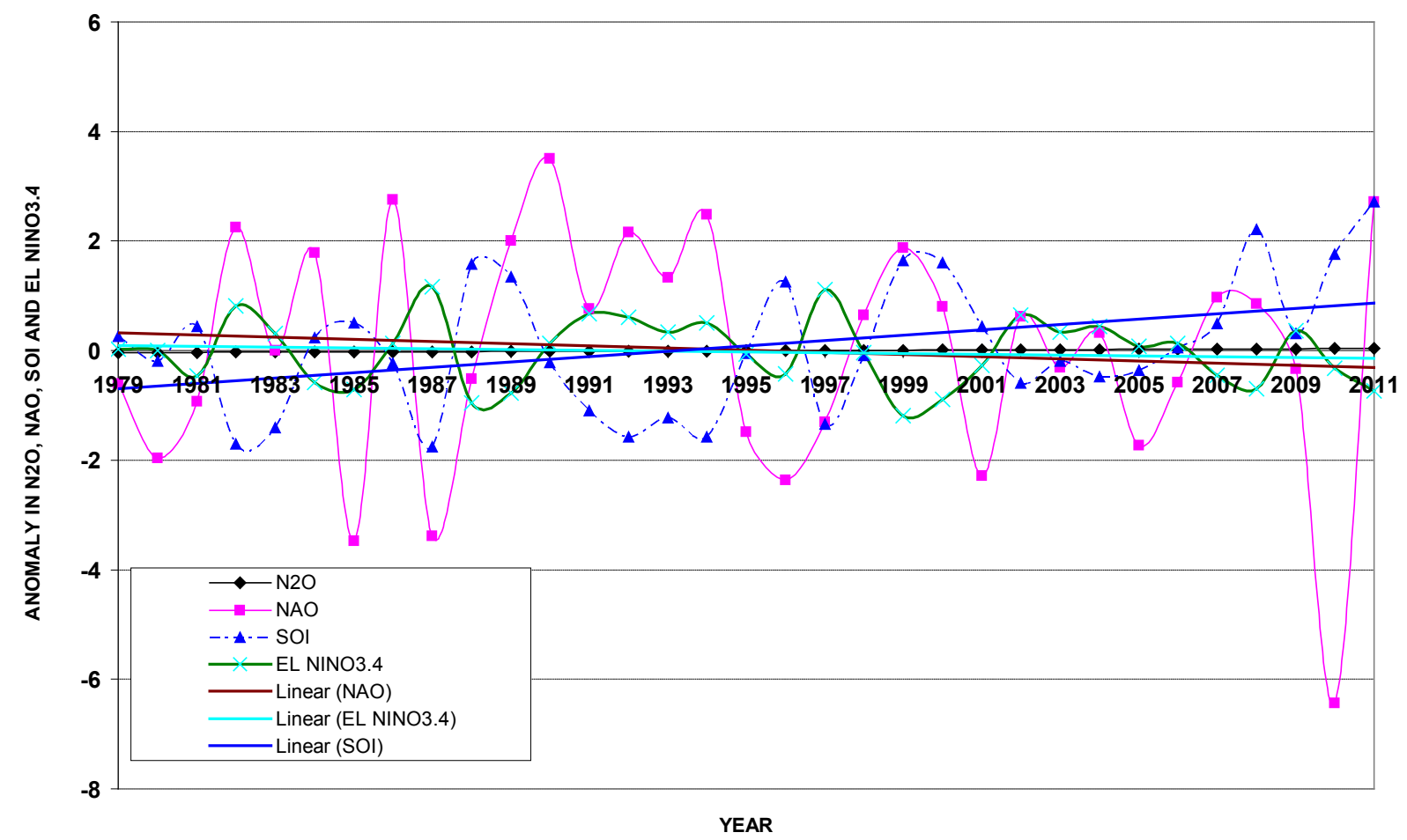

(c)

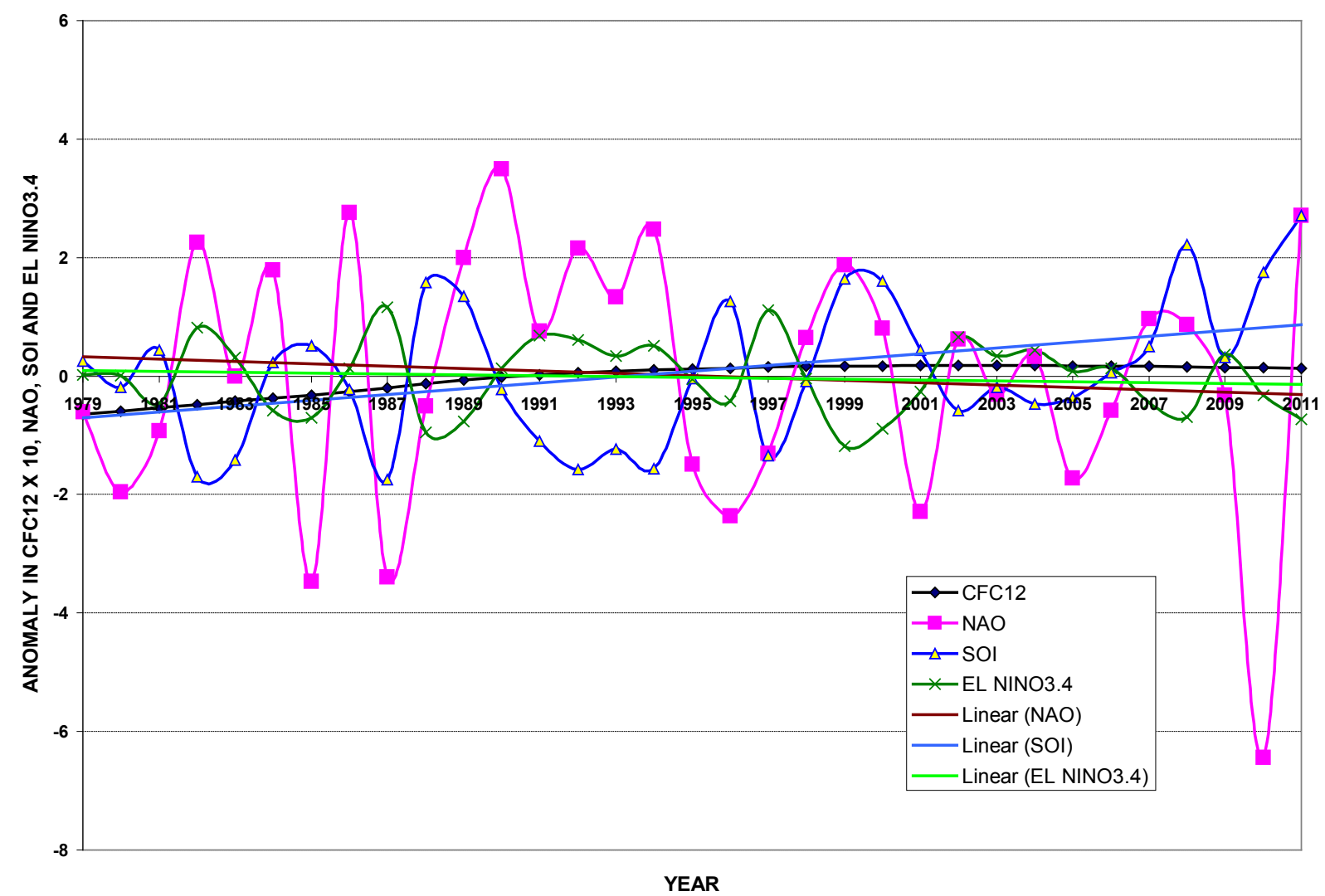

(d) 


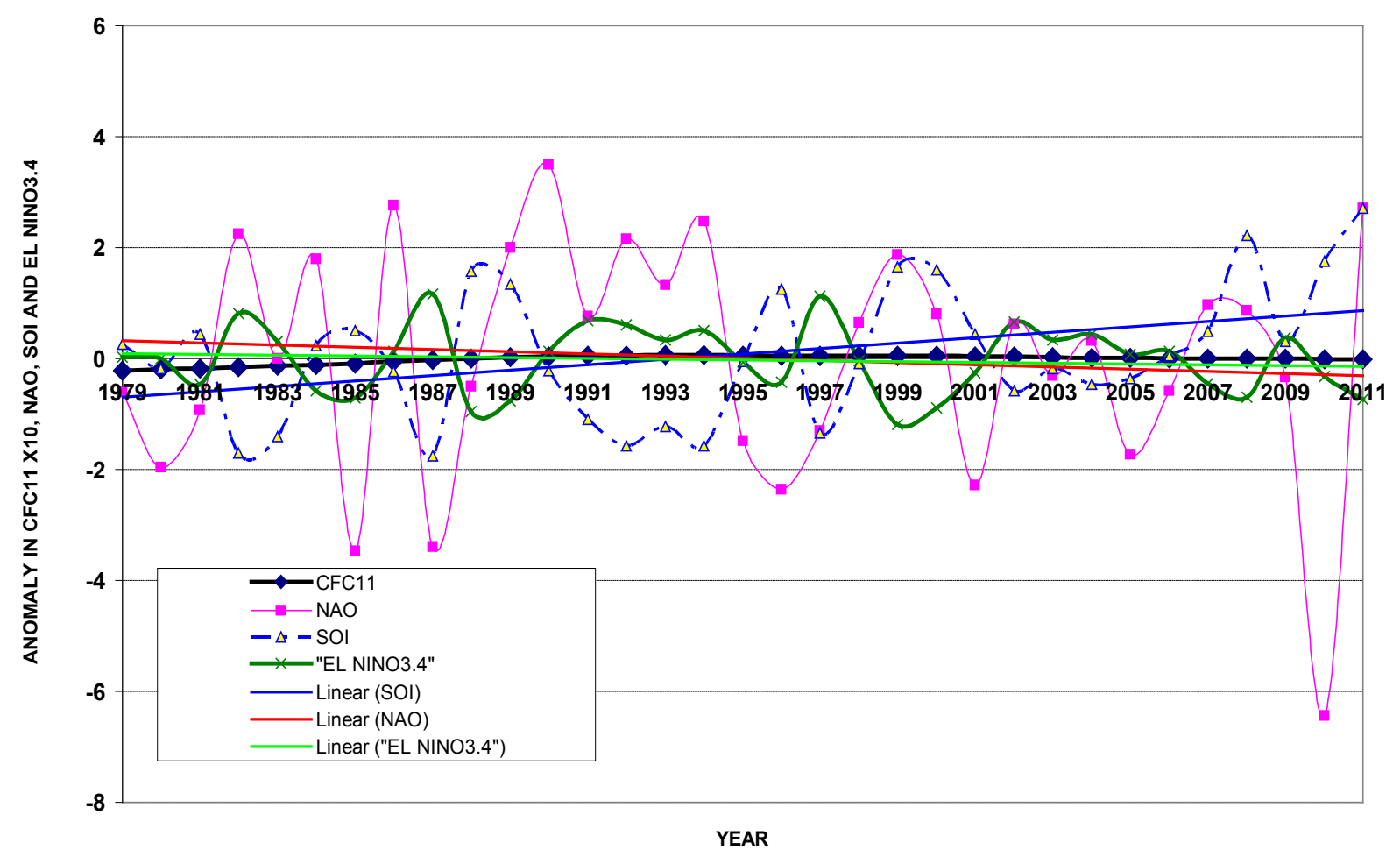

(e)

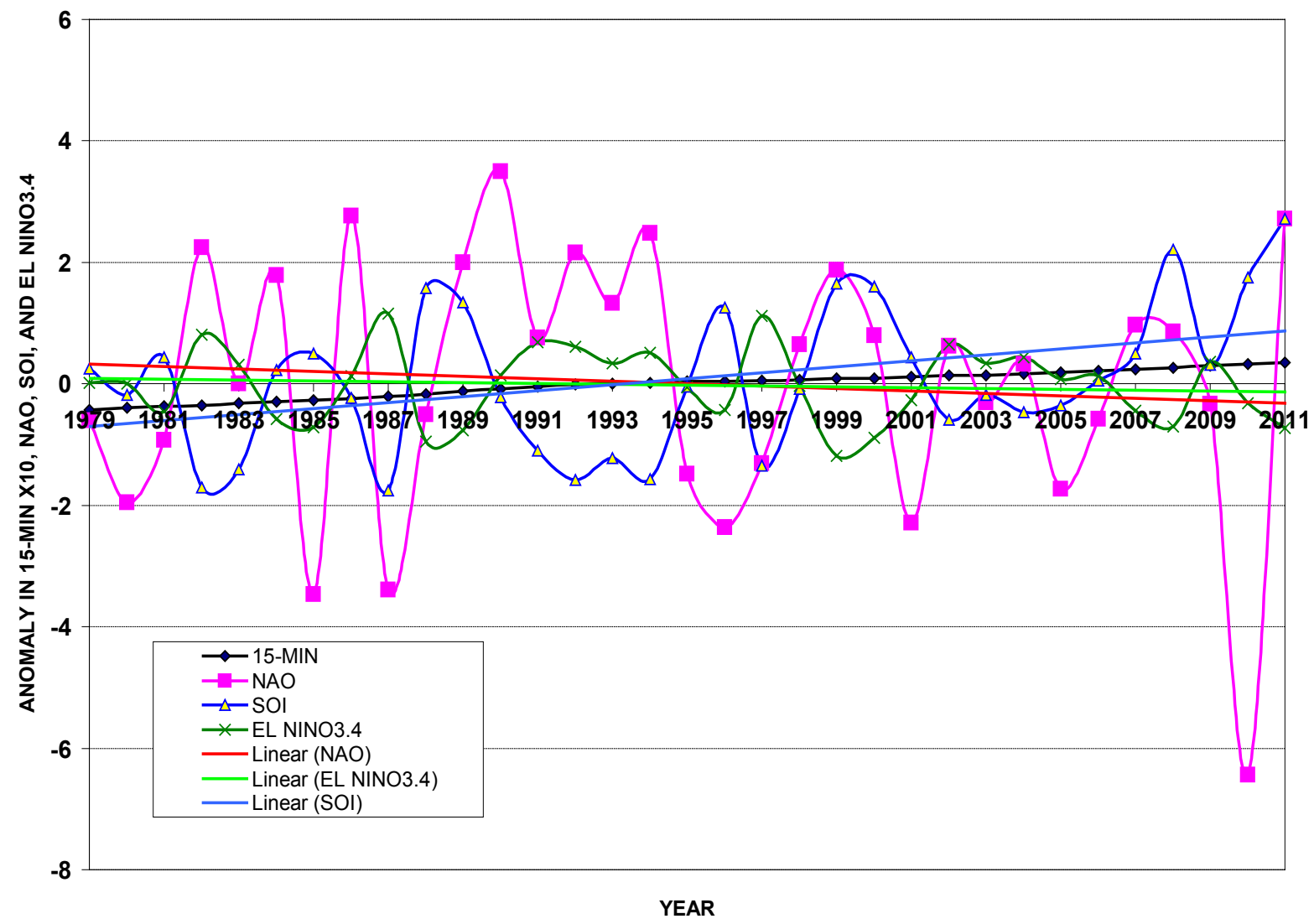

(f) 


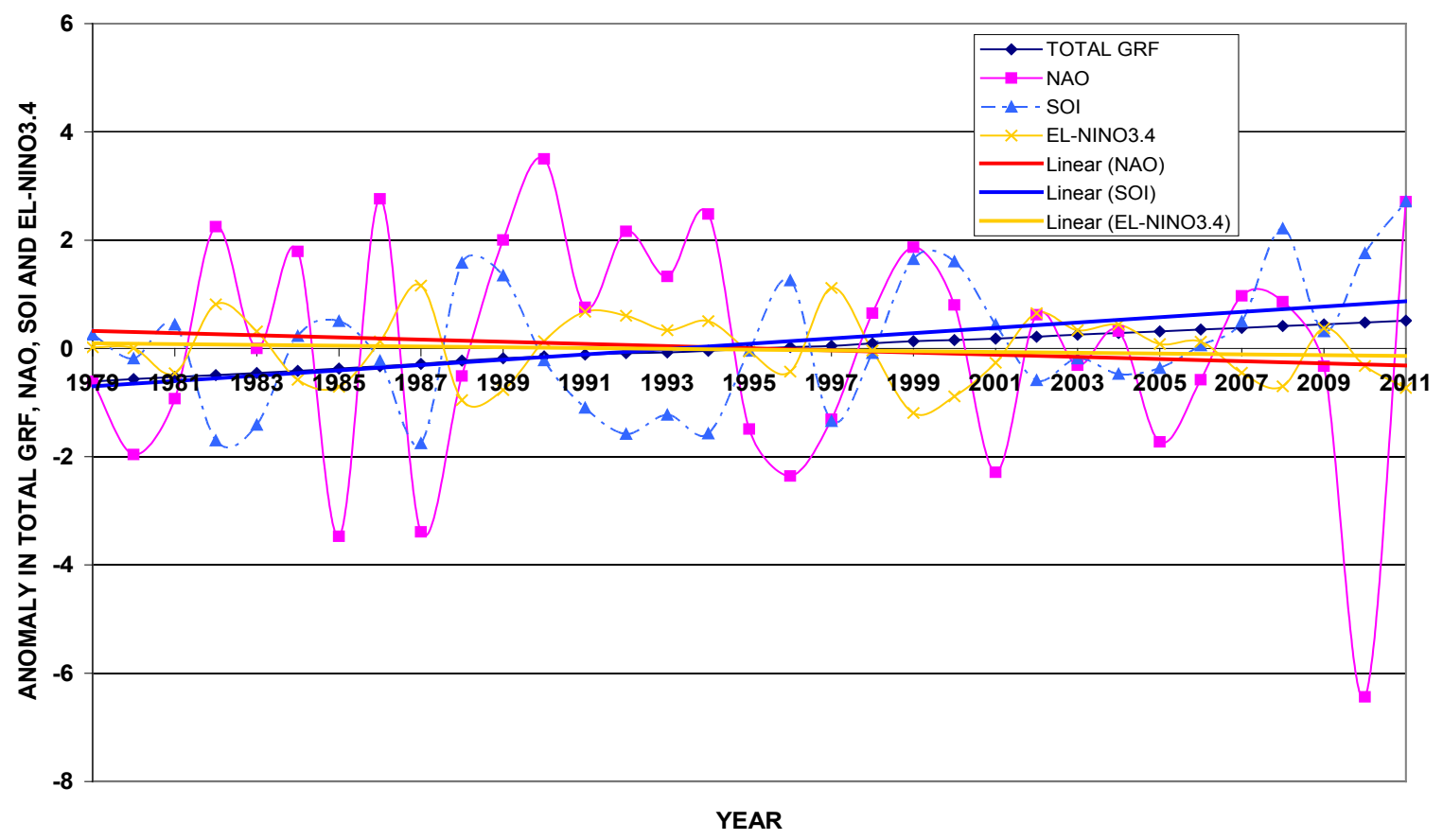

(g)

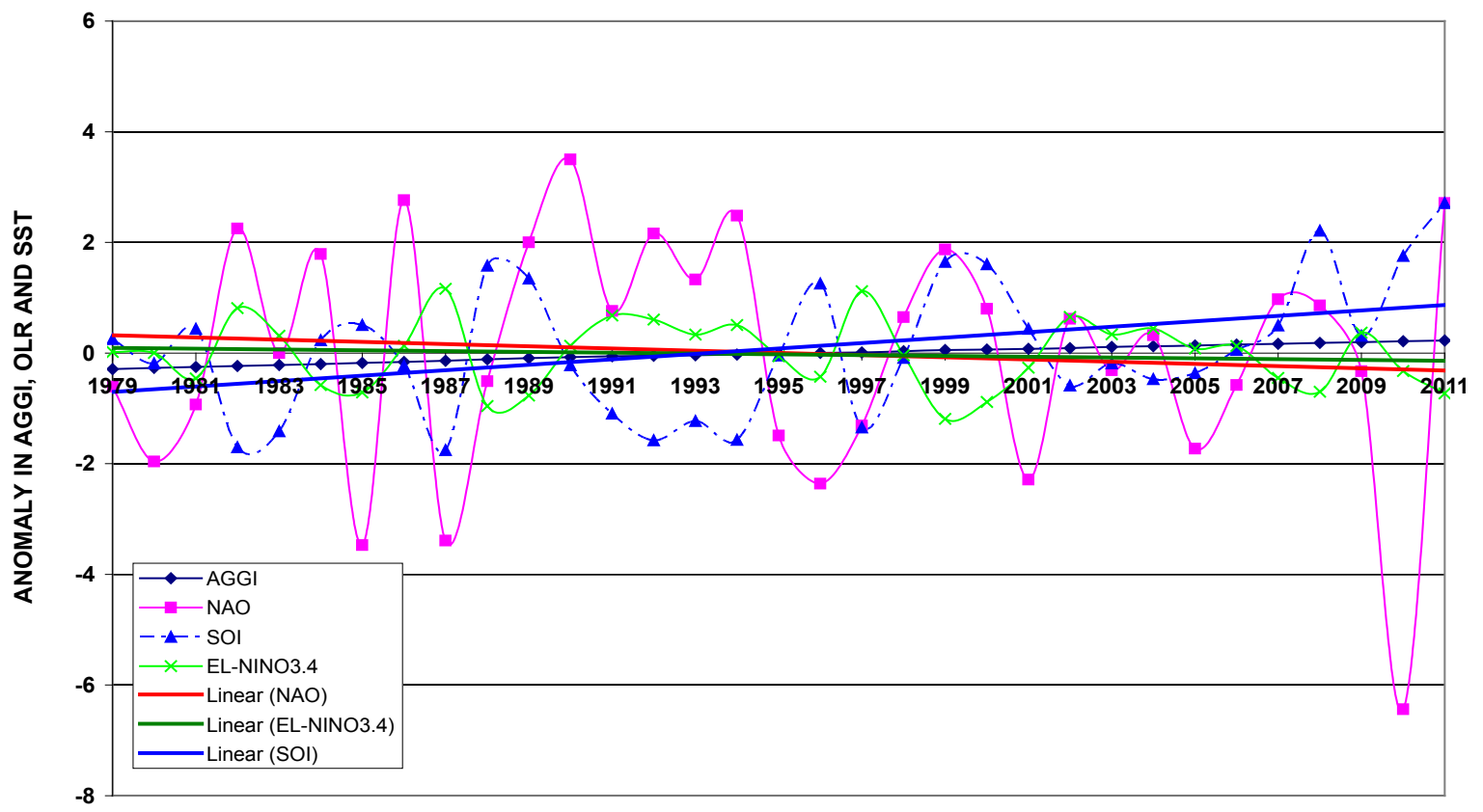

YEAR

(h)

Figure 11. (a) Time series of $\mathrm{CO}_{2}$, NAO, SOI and EL Nino 3.4 anomaly for the globe through the period (1979-2011); (b) Time series of $\mathrm{CH}_{4}$, NAO, SOI and EL Nino 3.4 anomaly for the globe through the period (1979-2011); (c) Time series of $\mathrm{N}_{2} \mathrm{O}$, NAO, SOI and EL Nino 3.4 anomaly for the globe through the period (1979-2011); d) Time series of CFC 12, NAO, SOI and EL Nino 3.4 anomaly for the globe through the period (1979-2011); (e) Time series of CFC 11, NAO, SOI and EL Nino 3.4 anomaly for the globe through the period (1979-2011); (f) Time series of 15-MINOR, NAO, SOI and EL Nino 3.4 anomaly for the globe through the period (1979-2011); (g) Time series of total GRF, NAO, SOI and EL Nino 3.4 anomaly for the globe through the period (1979-2011); (h) Time series of AGGI, NAO, SOI and EL Nino 3.4 anomaly for the globe through the period (1979-2011). 


\subsection{The Correlation Coefficient between the GRF and Weather and Climatic Elements of the Earth through the Period (1979-2011)}

Through this section, the annual mean values of weather meteorological elements (surface air temperature, $500 \mathrm{hPa}$ air temperature, sea level pressure, geopotential height at 500 level hPa, surface wind, precipitation rate, OLR, SST, NAO, SOI and El Nino 3.4 over the globe has been correlated with the GHG, S and global radiative forcing has been analyzed through the period of 1979-2011. Anomaly and linear correlation coefficient methods had been used through this analysis. The results revealed that:

1) For $\mathrm{CO}_{2}$, it is clear that there is an outstanding positive correlation coefficient $(0.918,0.840,0.832,0.895$ and 0.890 ) between $\mathrm{CO}_{2}$ and surface air temperature, $500 \mathrm{hPa}$ air temperature, geopotential height at level 500 $\mathrm{hPa}, \mathrm{OLR}$ and SST respectively over the globe through the study period. See Table 2.

2) For $\mathrm{CH}_{4}$, it is clear that there is an outstanding positive correlation coefficient (0.832) between $\mathrm{CH}_{4}$ and precipitation rate and significant correlation (0.707) with surface air temperature over the globe through the study period. See Table 2.

3) For $\mathrm{N}_{2} \mathrm{O}$, it is clear that there is an outstanding positive correlation coefficient, $(0.843,0.847$ and 0.803$)$ between $\mathrm{N}_{2} \mathrm{O}$ and surface air temperature, precipitation rate and SST respectively through the study period as observed in Table 2.

4) For CFC 12, it is clear that there is only an outstanding positive correlation coefficient (0.806) between CFC 12 and precipitation ate over the globe. As shown in Table 2.

5) For CFC 11, no clear significant correlation coefficient between CFC 11 and meteorological elements and climatic indices over the globe through the study period (1979-2011).

6) For15-MINOR, it is clear that there is an outstanding positive correlation coefficient, (0.843) between $15-$ MINOR and global precipitation rate. Significant correlation is $(0.786)$ with global surface air temperature. Significant correlation (0.758) with SST has been observed through the study period as shown in Table 2.

7) For total GRF, it is obvious that, there is an outstanding positive correlation coefficient, $(0.827$ and 0.857$)$ between total GRF and global surface air temperature and precipitation rate respectively over the globe through the period of study (1979-2011). In addition to that, a significant correlation (0.795) with SST observed as it is illustrated in Table 2.

8) For AGGI, it is clear that, there is an outstanding positive correlation coefficient, $(0.827$ and 0.857$)$ be-

Table 2. Correlation coefficient matrix between the anomaly of global radiative forcing and anomaly of global annual meteorological elements and climatic indices through the period (1979-2011).

\begin{tabular}{|c|c|c|c|c|c|c|c|c|}
\hline \multirow{3}{*}{$\begin{array}{c}\text { Meteorological } \\
\text { Elements and Climatic Indices } \\
\text { Surface air temperature }\end{array}$} & \multicolumn{8}{|c|}{ Global Radiative Forcing through the Period 1979-2011 (W/M-2) } \\
\hline & $\mathrm{CO}_{2}$ & $\mathrm{CH}_{4}$ & $\mathbf{N}_{2} \mathbf{O}$ & CFC 12 & CFC 11 & 15-MINOR & Total GRF & AGGI \\
\hline & 0.918024 & 0.707127 & 0.843433 & 0.609622 & 0.31776 & 0.786746 & 0.827388 & 0.82754 \\
\hline $500 \mathrm{hPa}$ temperature & 0.840601 & 0.501532 & 0.665005 & 0.389704 & 0.123157 & 0.598436 & 0.643048 & 0.643403 \\
\hline Surface pressure & -0.66817 & -0.54941 & -0.48916 & -0.56819 & -0.55258 & -0.53109 & -0.51149 & -0.51157 \\
\hline 500 hPa geopotential height & 0.832213 & 0.504543 & 0.689727 & 0.382592 & 0.076265 & 0.609663 & 0.660489 & 0.660712 \\
\hline Surface wind & 0.133966 & -0.1922 & -0.05411 & -0.24155 & -0.3964 & -0.13968 & -0.09421 & -0.09489 \\
\hline Precipitation & 0.366403 & 0.83247 & 0.847832 & 0.806665 & 0.571969 & 0.84339 & 0.857825 & 0.857528 \\
\hline Outcomes long wave radiation & 0.895361 & 0.58275 & 0.677631 & 0.49631 & 0.28587 & 0.630049 & 0.671062 & 0.671389 \\
\hline Sea surface temperature & 0.890022 & 0.688904 & 0.80383 & 0.607949 & 0.329496 & 0.758558 & 0.795115 & 0.79521 \\
\hline North Atlantic oscillation & 0.142676 & 0.000243 & -0.07773 & 0.032751 & 0.13715 & -0.05338 & -0.06904 & -0.06866 \\
\hline Southern oscillation index & -0.00406 & 0.299658 & 0.406407 & 0.203953 & 0.038910 & 0.364564 & 0.391314 & 0.390809 \\
\hline EI Nino 3.4 & 0.100101 & -0.07408 & -0.12147 & -0.01978 & 0.049022 & -0.09326 & -0.11633 & -0.11575 \\
\hline
\end{tabular}


tween AGGI and global surface air temperature and precipitation rate respectively over the globe through the period of study (1979-2011). Also a significant correlation (0.795) with SST is observed. Notably, it is approximately typically of total GRF correlation results. It is illustrated in Table 2.

9-There is no significant correlation observed between the global radiative forcing and the climatic indices NAO, SOI and El Nino through the period of study (1979-2011), as it is clear in Table 2.

\section{Discussion}

The global climate change will have a strong impact on development in coming decades. The greenhouse gas concentration has built up in the Earth's atmosphere since the beginning of the industrial era in the mid-1700s, primarily due to the burning of fossil fuels (coal, oil and natural gas) and the clearing of forests. Human activities have also increased the emissions of other greenhouse gases, such as methane and nitrous oxide. The absence of strong global action to reduce greenhouse gas emissions will hinder future development over the globe of the Earth. Scenarios of the climatic models have a great degree of uncertainties. The present work aims to uncover the impacts of GRF in climatic variability over the globe of the Earth using of calculating GRF and operational weather and climatic data. However, there are four fold studies in the present studies. First one is the variability of global annual geopotential height at level $500 \mathrm{hPa}$ through the period of (1948-2012). Analysis of the global annual geopotential height anomaly at level $500 \mathrm{hPa}$ observed that, it varies from year to a year with time and becomes continues above its normal value from year 2000 up to 2012. The trend of variation is a positive trend. An outstanding correlation coefficient between global annual geopotential height and global temperature composites mean reached to $(+1)$ in the tropics meanwhile the correlation decrease towards the north and south poles. It has a significant negative correlation of $(-0.9)$ with NAO over Iceland. Meanwhile, there is a positive correlation $(+0.7)$ over the north Atlantic region. In addition to that, it has significant correlations of $(+0.7)$ with SOI over the tropics. It has outstanding correlations over all the Atlantic Ocean through the study period (1948-2010). Also, there is a significant positive correlation reached at $(+0.7)$ with El Nino 3.4 over the tropics. Meanwhile, there are significant correlations reached at $(+0.7)$ over the central of the Atlantic Ocean. It is noticed that over the Atlantic Ocean the signs of correlation contradicting to the signs of correlations with SOI. Through second one, the relationship between the GRF and global annual weather elements variability has been studied. Through this section, the variability of weather meteorological elements (surface air temperature, 500 $\mathrm{hPa}$ air temperature, sea level pressure, geopotential height at $500 \mathrm{hPa}$ level, surface wind, precipitation rate, OLR and SST over the globe and GRF gases has been analyzed. For $\mathrm{CO}_{2}$, surface air temperature and $500 \mathrm{hPa}$ level of temperature anomaly, it is clear that, all of these three parameters have a sharp increase with time and all of it becomes above its normal value after year 2000 up to 2012. With the continual increase of $\mathrm{CO}_{2}$ the geopotential height increases too. Meanwhile, surface air pressure gradually decreases in contradicting to the variability of geopotential height. Precipitation rate increase to become more its normal values on year 1985 up to the year 2012 over the globe likely the variability of $\mathrm{CO}_{2}$ during the same period. Meanwhile the surface wind varies like a wave and not related to $\mathrm{CO}_{2}$ variation. Outgoing longwave radiation (OLR) and sea surface temperature (SST) varies and increases with time, typically with the $\mathrm{CO}_{2}$ variability for all the period (1950-2012). For $\mathrm{CH}_{4}$ it is clear that, $\mathrm{CH}_{4}$ increase sharply through the period of study (1979-2011) and becomes above its normal value since 1992 and do not return to its normal value until 2011. The increasing after Year 2000 matches with the increase of temperature. $\mathrm{CH}_{4}$ variability after year 2000 coincide with the variability of geopotential height at level $500 \mathrm{hPa}$ and contradicting with variation of sea level pressure in general. Also, it is noticed that, for the period of (1995-2011) the increase in precipitation rate matches with the increase in $\mathrm{CH}_{4}$. In fact the wind variability does not follow the $\mathrm{CH}_{4}$ variability. For OLR and SST it is observed that after 1997 they have amounted over its normal values and continues increase to the year 2011. For $\mathrm{N}_{2} \mathrm{O}$ and surface air temperature and $500 \mathrm{hPa}$ level of temperature anomaly, it is clear that, all of these three parameters have a sharp increase with time through the period (1979-2011) and all of it becomes above its normal value after year 1999 up to 2011. With the continued increase of $\mathrm{N}_{2} \mathrm{O}$ the geopotential height increases too. Global precipitation rate increase to become more its normal values on year 1995 up to year 2011 likely the variability of $\mathrm{N}_{2} \mathrm{O}$. Meanwhile the surface wind varies like a wave and not related to $\mathrm{N}_{2} \mathrm{O}$ variation through the period of study (1979-2011). Outgoing longwave radiation (OLR) and sea surface temperature (SST) varies and increases with time, typically with the $\mathrm{N}_{2} \mathrm{O}$ variability for all the period (1979-2011). The CFC 12 has become more its normal values since 1991. It decreases with time from the year 2004 up to 2011. Variability of CFC 12 with the geopotential height, 
surface air pressure, Precipitation rate, surface wind, OLR and SST are not clear through the study period. For CFC 11 variability, like as CFC 12 no connection appears with weather elements variably over the globe through the period of study. CFC 11 returned to its normal values from the year 2006. For 15-MINOR, and surface air temperature and $500 \mathrm{hPa}$ level of temperature anomaly, it is clear that, 15-MINOR became more than its normal values after 1993. All of these three parameters have a sharp increase with time through the period (2001-2011). With the continued increase of 15-MINOR, the geopotential height increase contradicted to surface air pressure almost time of the study period. Precipitation rate increase to became more its normal values on year 1995 up to the year 2011 over the globe likely the variability of 15-MINOR. Meanwhile the surface wind varies like a wave and not related to 15-MINOR variation through the period of study (1979-2011) as shown in Figure 8(c). Generally, OLR and SST vary and increase with time, typically with the 15-MINOR variability for all the period (1979-2011). It is noticed that the variability of total GRF and AGGI values is the same with the variability of the global annual weather elements through the period of study except with surface air pressure and wind. The total GRF and AGGI values has become above normal since 1995 with the same manner of the meteorological elements in general. Third one, the variability of GRF and climatic indices NAO, SOI, El- Nino 3.4 and SST has been studied. It is revealed that there is a positive trend of the NAO, El Nino 3.4 and total GRF, AGGI and for each of greenhouse gases in general. Meanwhile the connection between CFC 12 and CFC 11 and climatic indices variability are not clear. Last one, the correlation coefficient between the GRF and weather and climatic elements of the Earth through the period (1979-2011) has been studied. Through this section, the annual mean values of weather meteorological elements (surface air temperature, $500 \mathrm{hPa}$ air temperature, sea level pressure, geopotential height at $500 \mathrm{hPa}$ level, surface wind, precipitation rate, OLR, SST, NAO, SOI and El Nino 3.4 over the globe has been correlated with the GHGs and global radiative forcing has been analyzed through the period of (1979-2011). Anomaly and linear correlation coefficient methods had been used. It is noticed that:

1) For $\mathrm{CO}_{2}$, an outstanding positive correlation coefficient, $(0.918,0.840,0.832,0.895$ and 0.890$)$ between $\mathrm{CO}_{2}$ and surface air temperature, $500 \mathrm{hPa}$ air temperature, geopotential height at $500 \mathrm{hPa}$ level, OLR and SST respectively over the globe.

2) For $\mathrm{CH}_{4}$ an outstanding positive correlation coefficient (0.832) between $\mathrm{CH}_{4}$ and precipitation rate and significant correlation (0.707) with surface air temperature over the globe.

3) For $\mathrm{N}_{2} \mathrm{O}$, an outstanding positive correlation coefficient, $(0.843,0.847,0.803)$ between $\mathrm{N}_{2} \mathrm{O}$ and surface air temperature, precipitation rate and SST respectively.

4) For CFC 12, it is clear that there is only an outstanding positive correlation coefficient (0.806) between CFC 12 and precipitation ate over the globe.

5) For CFC 11, no clear significant correlation coefficient between CFC 11 and meteorological elements and climatic indices over the globe 0.

6) For 15-MINOR, there is an outstanding positive correlation coefficient, $(0.843)$ between 15-MINOR and global precipitation rate. It has a significant correlation $(0.786)$ with global surface air temperature. Significant correlation (0.758) with SST has been observed through the study period.

7) For total GRF, it is obvious that, there is an outstanding positive correlation coefficient, $(0.827$ and 0.857$)$ between total GRF and global surface air temperature and precipitation rate respectively over the globe. In addition to that, a significant correlation (0.795) with SST observed.

8) For AGGI, it is clear that, there is a significant positive correlation coefficient, $(0.827$ and 0.857$)$ between AGGI and global surface air temperature and precipitation rate respectively over the globe through the period of study (1979-2011). Also a significant correlation (0.795) with SST is observed. Notably, it is approximately typically of total GRF correlation results.

9) In general, there is no significant correlation observed between the global radiative forcing and the climatic indices NAO, SOI and El Nino through the period of study (1979-2011).

\section{Conclusion}

Finally, one can conclude that the GRF is impacting on the annual variability of weather and climatic elements on the globe. The present work conducts that the global annual climatic variability of weather elements and global warming is strongly related to the global radiative forcing and human activities. Emissions of GHG must be reduced to eliminate its impacts on the global abnormal extreme weather events to exist and to control the global 
change of climate. However, using renewable, clean energy sources as a source of power will break the global change of climate and control the weather.

\section{Acknowledgements}

It is a pleasure for the authors to thank the Earth System Research Laboratory, Physical Sciences Division, Climate Diagnostics Centre for supporting the data used throughout this study. Plots and images were provided by the NOAA-CIRES Climate Diagnostics Centre, Boulder, Colorado, USA from their Web site at www.esrl.noaa.gov/psd/. The NOAA annual greenhouse gas index (AGGI) data from NOAA Web site http://www.esrl.noaa.gov/gmd/aggi/. Also, thanks to the Climate Prediction Centre for supporting the NAO, SOI, El Nino 3.4 and SST data which obtained through the Web site www.cpc.ncep.noaa.gov/data/indices/.

\section{References}

[1] IPCC (Intergovernmental Panel on Climate Change) (2007) Climate Change: The Physical Science Basis. In: Solomon, S., Qin, D., Manning, M., Chen, Z., Marquis, M., Averyt, K.B., Tignor, M. and Miller, H.L., Eds., Contribution of Working Group I to the Fourth Assessment Report of the Intergovernmental Panel on Climate Change, Cambridge University Press, New York, 996.

[2] Oxford American Dictionary. Oxford University Press, New York, 1980.

[3] Michaels, P.J. and Stooksbury, D.E. (1992) Global Warming: A Reduced Threat? Bulletin of the American Meteorological Society, 73, 1563-1577.

[4] Fiodorov (2012) Global Warming. StudyMode.com.

[5] CAST (2004) Carbon Sequestration and Greenhouse Gas Fluxes in Agriculture: Challenges and Opportunities. Task Force Reports, R142, Council for Agricultural Science and Technology, October 2011.

[6] Dlugokencky, E.J., Masarie, K.A., Lang, P.M. and Tans, P.P. (1998) Continuing Decline in the Growth Rate of the Atmospheric Methane Burden. Nature, 393, 447-450. http://dx.doi.org/10.1038/30934

[7] Dlugokencky, E.J., Houweling, S., Bruhwiler, L., Masarie, K.A., Lang, P.M., Miller, J.B. and Tans, P.P. (2003) Atmospheric Methane Levels off: Temporary Pause or a New Steady-State? Geophysical Research Letters, 30, ASC 5-1 to ASC 5-4. http://dx.doi.org/10.1029/2003GL018126

[8] Hofmann, D.J., Butler, J.H., Dlugokencky, E.J., Elkins, J.W., Masarie, K., Montzka, S.A. and Tans, P. (2006) The Role of Carbon Dioxide in Climate Forcing from 1979 to 2004: Introduction of the Annual Greenhouse Gas Index. Tellus B, 58, 614-619. http://dx.doi.org/10.1111/j.1600-0889.2006.00201.x

[9] Dlugokencky, E.J., Bruhwiler, L., White, J.W.C., Emmons, L.K., Novelli, P.C., Montzka, S.A., Masarie, K.A., Lang, P.M., Crotwell, A.M., Miller, J.B. and Gatti, L.V. (2009) Observational Constraints on Recent Increases in the Atmospheric $\mathrm{CH}_{4}$ Burden. Geophysical Research Letters, 36, L18803. http://dx.doi.org/10.1029/2009GL039780

[10] Montzka, S.A., Dlugokencky, E.J. and Butler, J.H. (2011) Non- $\mathrm{CO}_{2}$ Greenhouse Gases and Climate Change. Nature, 476, 43-50. http://dx.doi.org/10.1038/nature10322

[11] Valipour, M., Mousavi, S.M., Valipour, R. and Rezaei, E. (2013) A New Approach for Environmental Crises and Its Solutions by Computer Modeling. http://www.civilica.com/Paper-ICECS01-ICECS01 005.html

[12] Valipour, M., Mousavi, S.M., Valipour, R. and Rezaei, E. (2013) Deal with Environmental Challenges in Civil and Energy Engineering Projects Using a New Technology. Journal of Civil and Environmental Engineering, 3, 127. http://dx.doi.org/10.4172/2165-784X.1000127

[13] Rhodes, S.L., Ely, D. and Dracup, J.A. (1984) Climate and the Colorado River: The Limits of Management. Bulletin of the American Meteorological Society, 65, 682-691. http://dx.doi.org/10.1175/1520-0477(1984)065<0682:CATCRT $>2.0$. CO;2

[14] Stott, P.A., Stone, D.A. and Allen, M.R. (2004) Human Contribution to the European Heat Wave of 2003. Nature, 432, 610-614. http://dx.doi.org/10.1038/nature03089

[15] Wang, G., Eltahir, E.A.B., Foley, J.A., Pollard, D. and Levis, S. (2004) Decadal Variability of Rainfall in the Sahel: Results from the Coupled GENESIS-IBIS Atmosphere-Biosphere Model. Climate Dynamics, 22, 625-637. http://dx.doi.org/10.1007/s00382-004-0411-3

[16] Wang, G.L. (2005) Agricultural Drought in a Future Climate: Results from 15 Global Climate Models Participating in the IPCC 4th Assessment. Climate Dynamics, 25, 739-753. http://dx.doi.org/10.1007/s00382-005-0057-9

[17] Hafez, Y.Y. (2008) The Role Played by Blocking over the Northern Hemisphere in Hurricane Katrina. The Journal of American Science, 4, 10-25.

[18] Sheffield, J. and Wood, E.F. (2008) Projected Changes in Drought Occurrence under Future Global Warming from 
Multi-Model, Multi-Scenario, IPCC AR4 Simulations. Climate Dynamics, 31, 79-105. http://dx.doi.org/10.1007/s00382-007-0340-Z

[19] Barriopedro, D., Fischer, E.M., Luterbacher, J., Trigo, R.M. and García-Herrera, R. (2011) The Hot Summer of 2010: Redrawing the Temperature Record Map of Europe. Science, 332, 220-224. http://dx.doi.org/10.1126/science.1201224

[20] Burke, E.J. (2011) Understanding the Sensitivity of Different Drought Metrics to the Drivers of Drought under Increased Atmospheric $\mathrm{CO}_{2}$. Journal of Hydrometeorology, 12, 1378-1394. http://dx.doi.org/10.1175/2011JHM1386.1

[21] Valipour, M., Mousavi, S.M., Valipour, R. and Rezaei, E. (2012) Air, Water, and Soil Pollution Study in Industrial Units Using Environmental Flow Diagram. Journal of Basic and Applied Scientific Research, 2, 12365-12372.

[22] Almazroui, M., Islam, M.N., Dambula, R. and Jones, P.D. (2013) Trends of Temperature Extremes in Saudi Arabia. International Journal of Climatology, 34, 808-826. http://dx.doi.org/10.1002/joc.3722

[23] Hafez, Y.Y. and Almazroui, M. (2013) The Role Played by Blocking Systems over Europe in Abnormal Weather over Kingdom of Saudi Arabia in Summer 2010. Advances in Meteorology, 2013, Article ID: 705406.

[24] Dai, A.G. (2013) Increasing Drought under Global Warming in Observations and Models. Nature Climate Change, 3, 171. http://dx.doi.org/10.1038/nclimate1811

[25] Brohan, P., Kennedy, J.J., Harris, I., Tett, S.F.B. and Jones, P.D. (2006) Uncertainty Estimates in Regional and Global Observed Temperature Changes: A New Data Set from 1850. Journal of Geophysical Research, 111, D12106. http://dx.doi.org/10.1029/2005JD006548

[26] Burke, E.J. and Brown, S.J. (2008) Evaluating Uncertainties in the Projection of Future Drought. Journal of Hydrometeorology, 9, 292-299. http://dx.doi.org/10.1175/2007JHM929.1

[27] Landsea, C.W. and Knaff, J.A. (2000) How Much Skill Was There in Forecasting the Very Strong 1997-98 El Niño? Bulletin of the American Meteorological Society, 81, 2107-2119. http://dx.doi.org/10.1175/1520-0477(2000)081<2107:HMSWTI>2.3.CO;2

[28] Halpert, M.S. and Ropelewski, C.F. (1992) Surface Temperature Patterns Associated with the Southern Oscillation. Journal of Climate, 5, 577-593. http://dx.doi.org/10.1175/1520-0442(1992)005<0577:STPAWT>2.0.CO;2

[29] Trenberth, K.E. (1984) Signal versus Noise in the Southern Oscillation. Monthly Weather Review, 112, 326-332. http://dx.doi.org/10.1175/1520-0493(1984)112<0326:SVNITS $>2.0 . C O ; 2$

[30] Ropelewski, C.F. and Jones, P.D. (1987) An Extension of the Tahiti-Darwin Southern Oscillation Index. Monthly Weather Review, 115, 2161-2165. http://dx.doi.org/10.1175/1520-0493(1987)115<2161:AEOTTS >2.0.CO;2

[31] Kellogg, W.W. (1991) Response to Skeptics of Global Warming. Bulletin of the American Meteorological Society, 72, 499-511. http://dx.doi.org/10.1175/1520-0477(1991)072<0499:RTSOGW>2.0.CO;2

[32] Trenberth, K.E. (1997) The Definition of El Nino. Bulletin of the American Meteorological Society, 78, $2771-2777$. http://dx.doi.org/10.1175/1520-0477(1997)078<2771:TDOENO>2.0.CO;2

[33] Trenberth, K.E. and Caron, J.M. (2000) The Southern Oscillation Revisited: Sea Level Pressures, Surface Temperatures, and Precipitation. Journal of Climate, 13, 4358-4365. http://dx.doi.org/10.1175/1520-0442(2000)013<4358:TSORSL $>2.0 . C O ; 2$

[34] Kumar, K.K., Rajagopalan, B. and Cane, M.A. (1999) On the Weakening Relationship between the Indian Monsoon and ENSO. Science, 284, 2156-2159. http://dx.doi.org/10.1126/science.284.5423.2156

[35] Dai, A.G. and Wigley, T.M.L. (2000) Global Patterns of ENSO-Induced Precipitation. Geophysical Research Letters, 27, 1283-1286. http://dx.doi.org/10.1029/1999GL011140

[36] Hurrell, J.W. (1995) Decadal Trends in the North Atlantic Oscillation: Regional Temperatures and Precipitation. Science, 269, 676-679. http://dx.doi.org/10.1126/science.269.5224.676

[37] Deser, C. (2000) On the Teleconnectivity of the "Arctic Oscillation". Geophysical Research Letters, 27, 779-782. http://dx.doi.org/10.1029/1999GL010945

[38] Ambaum, M.H.P., Hoskins, B.J. and Stephenson, D.B. (2001) Arctic Oscillation or North Atlantic Oscillation? Journal of Climate, 14, 3495-3507.

[39] Wallace, J.M. and Thompson, D.W.J. (2002) The Pacific Center of Action of the Northern Hemisphere Annular Mode: Real or Artifact? Journal of Climate, 15, 1987-1991. http://dx.doi.org/10.1175/1520-0442(2002)015<1987:TPCOAO $>2.0 . C O ; 2$

[40] Wettstein, J.J. and Mearns, L.O. (2002) The Influence of the North Atlantic-Arctic Oscillation on Mean, Variance, and Extremes of Temperature in the Northeastern United States and Canada. Journal of Climate, 15, 3586-3600. http://dx.doi.org/10.1175/1520-0442(2002)015<3586:TIOTNA $>2.0 . C O ; 2$

[41] Rodwell, M.J., Rowell, D.P. and Folland, C.K. (1999) Oceanic Forcing of the Wintertime North Atlantic Oscillation and European Climate. Nature, 398, 320-323. http://dx.doi.org/10.1038/18648 
[42] Mehta, V.M., Suarez, M., Manganello, J. and Delworth, T. (2000) Oceanic Influence on the North Atlantic Oscillation and Associated Northern Hemisphere Climate Variations: 1959-1993. Geophysical Research Letters, 27, 121-124. http://dx.doi.org/10.1029/1999GL002381

[43] Schneider, E.K., Bengtsson, L. and Hu, Z.Z. (2003) Forcing of Northern Hemisphere Climate Trends. Journal of the Atmospheric Sciences, 60, 1504-1521. http://dx.doi.org/10.1175/1520-0469(2003)060<1504:FONHCT>2.0.CO;2

[44] Kalnay, E., Kanamitsu, M., Kistler, R., Collins, W., Deaven, D., Gandin, L., et al. (1996) The NCEP/NCAR 40-Year Reanalysis Project. Bulletin of the American Meteorological Society, 77, 437-471. http://dx.doi.org/10.1175/1520-0477(1996)077<0437:TNYRP>2.0.CO;2

[45] IPCC TAR WG1 (2001) Climate Change 2001. In: Houghton, J.T., Ding, Y., Griggs, D.J., Noguer, M., van der Linden, P.J., Dai, X., Maskell, K. and Johnson, C.A., Eds., Climate Change 2001: The Scientific Basis, Contribution of Working Group I to the Third Assessment Report of the Intergovernmental Panel on Climate Change, Cambridge University Press, 1-94.

[46] Philips, J.L. (1996) How to Think about Statistics. 5th Edition, W.H. Freeman, New York, 191.

[47] Livezey, R.E. and Chen, W.Y. (1983) Statistical Field Significance and Its Determination by Monte Carlo Techniques. Monthly Weather Review, 111, 46-59. http://dx.doi.org/10.1175/1520-0493(1983)111<0046:SFSAID>2.0.CO;2

[48] Spiegel, M.R. (1961) Theory and Problems of Statistics. Schaum, New York, 359. 
Scientific Research Publishing (SCIRP) is one of the largest Open Access journal publishers. It is currently publishing more than 200 open access, online, peer-reviewed journals covering a wide range of academic disciplines. SCIRP serves the worldwide academic communities and contributes to the progress and application of science with its publication.

Other selected journals from SCIRP are listed as below. Submit your manuscript to us via either submit@scirp.org or Online Submission Portal.
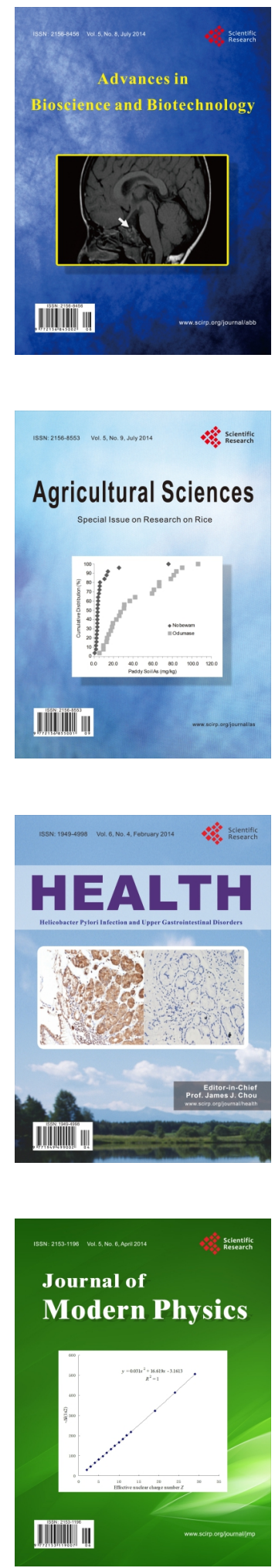
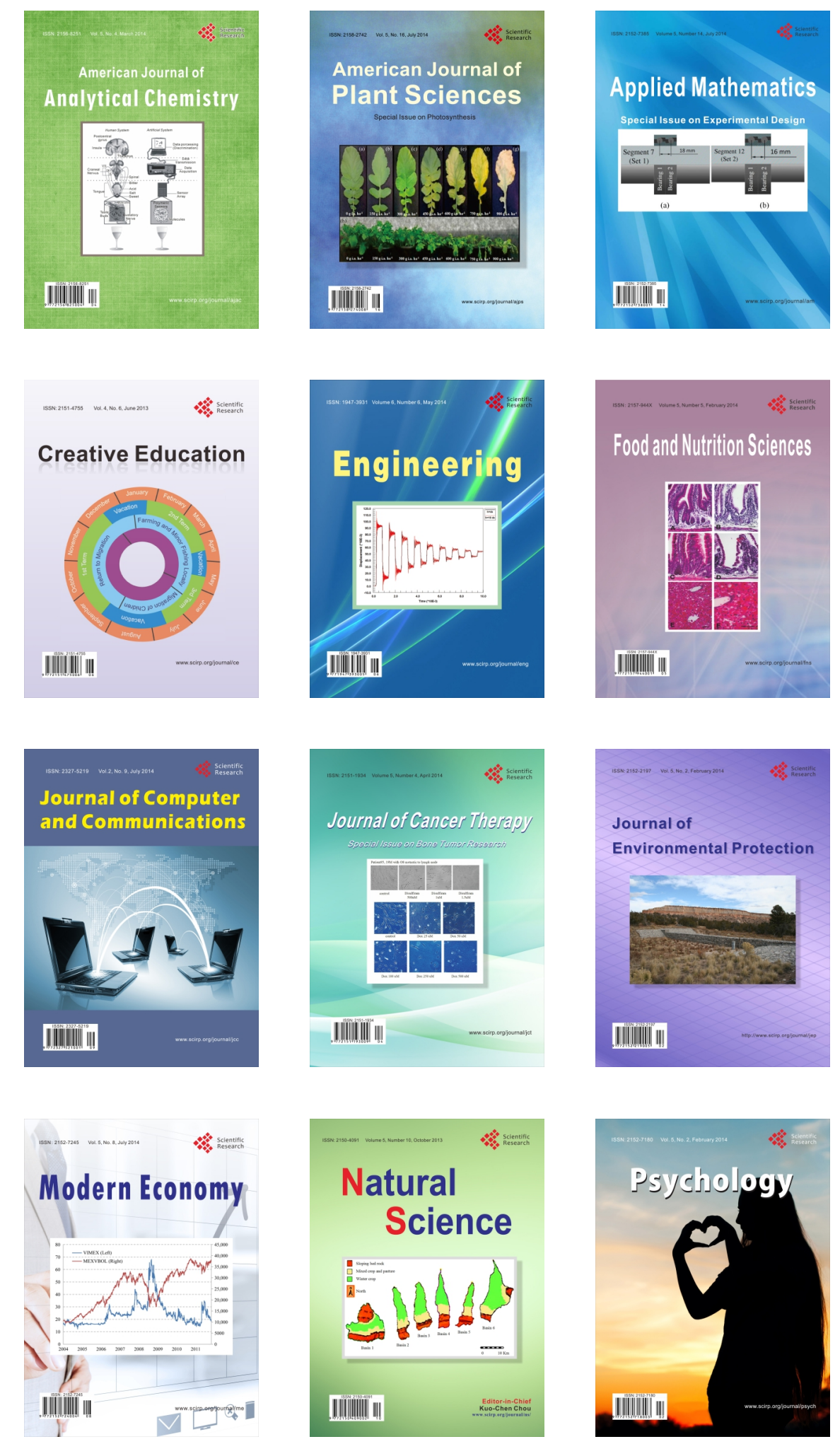